San Jose State University

SJSU ScholarWorks

Mineta Transportation Institute Publications

$1-2022$

\title{
Drivers' Response to Scenarios when Driving Connected and Automated Vehicles Compared to Vehicles with and without Driver Assist Technology
}

Srinivas S. Pulugurtha

University of North Carolina at Charlotte

Raghuveer Gouribhatla

University of North Carolina at Charlotte

Follow this and additional works at: https://scholarworks.sjsu.edu/mti_publications

Part of the Graphics and Human Computer Interfaces Commons, Navigation, Guidance, Control, and Dynamics Commons, and the Transportation Commons

\section{Recommended Citation}

Srinivas S. Pulugurtha and Raghuveer Gouribhatla. "Drivers' Response to Scenarios when Driving Connected and Automated Vehicles Compared to Vehicles with and without Driver Assist Technology" Mineta Transportation Institute Publications (2022). https://doi.org/10.31979/mti.2022.1944

This Report is brought to you for free and open access by SJSU ScholarWorks. It has been accepted for inclusion in Mineta Transportation Institute Publications by an authorized administrator of SJSU ScholarWorks. For more information, please contact scholarworks@sjsu.edu. 


\section{SJSU San Josis STRE}

\section{$M T I / /$ mase}

Drivers' Response to Scenarios when Driving Connected and Automated Vehicles Compared to Vehicles with and without Driver Assist Technology

Raghuveer Gouribhatla

Srinivas S. Pulugurtha

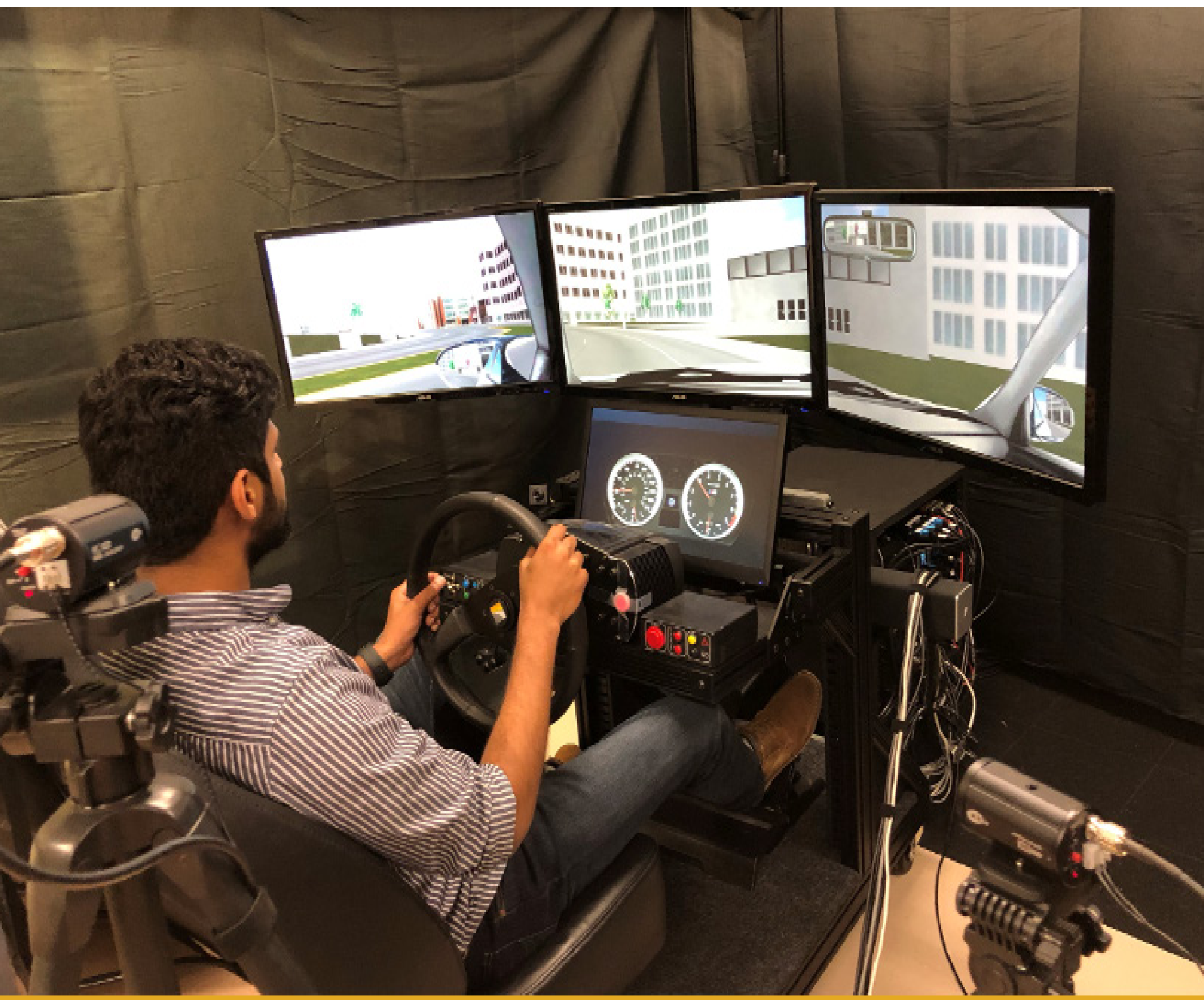




\section{Mineta Transportation Institute}

Founded in 1991, the Mineta Transportation Institute (MTI), an organized research and training unit in partnership with the Lucas College and Graduate School of Business at San José State University (SJSU), increases mobility for all by improving the safety, efficiency, accessibility, and convenience of our nation's transportation system. Through research, education, workforce development, and technology transfer, we help create a connected world. MTI leads the Mineta Consortium for Transportation Mobility (MCTM) funded by the U.S. Department of Transportation and the California State University Transportation Consortium (CSUTC) funded by the State of California through Senate Bill 1. MTI focuses on three primary responsibilities:

\section{Research}

MTI conducts multi-disciplinary research focused on surface transportation that contributes to effective decision making. Research areas include: active transportation; planning and policy; security and counterterrorism; sustainable transportation and land use; transit and passenger rail; transportation engineering; transportation finance; transportation technology; and workforce and labor. MTI research publications undergo expert peer review to ensure the quality of the research.

\section{Education and Workforce}

To ensure the efficient movement of people and products, we must prepare a new cohort of transportation professionals who are ready to lead a more diverse, inclusive, and equitable transportation industry. To help achieve this, MTI sponsors a suite of workforce development and education opportunities. The Institute supports educational programs offered by the Lucas Graduate School of Business: a
Master of Science in Transportation Management, plus graduate certificates that include High-Speed and Intercity Rail Management and Transportation Security Management. These flexible programs offer live online classes so that working transportation professionals can pursue an advanced degree regardless of their location.

\section{Information and Technology Transfer}

MTI utilizes a diverse array of dissemination methods and media to ensure research results reach those responsible for managing change. These methods include publication, seminars, workshops, websites, social media, webinars, and other technology transfer mechanisms. Additionally, MTI promotes the availability of completed research to professional organizations and works to integrate the research findings into the graduate education program. MTI's extensive collection of transportation-related publications is integrated into San José State University's world-class Martin Luther King, Jr. Library.

\section{Disclaimer}

The contents of this report reflect the views of the authors, who are responsible for the facts and accuracy of the information presented herein. This document is disseminated in the interest of information exchange. MTI's research is funded, partially or entirely, by grants from the California Department of Transportation, the California State University Office of the Chancellor, the U.S. Department of Homeland Security, and the U.S. Department of Transportation, who assume no liability for the contents or use thereof. This report does not constitute a standard specification, design standard, or regulation. 
Report 21-35

\section{Drivers' Response to Scenarios \\ when Driving Connected and}

\section{Automated Vehicles Compared to Vehicles with and without Driver Assistance Technology}

Raghuveer Gouribhatla

Srinivas S. Pulugurtha

January 2022 


\section{TECHNICAL REPORT \\ DOCUMENTATION PAGE}

\begin{tabular}{|c|c|c|c|}
\hline $\begin{array}{l}\text { 1. Report No. } \\
21-35\end{array}$ & $\begin{array}{l}\text { 2. Government } \\
\text { Accession No. }\end{array}$ & \multicolumn{2}{|c|}{ 3. Recipient's Catalog No. } \\
\hline \multirow{2}{*}{\multicolumn{2}{|c|}{$\begin{array}{l}\text { 4. Title and Subtitle } \\
\text { Drivers' Response to Scenarios When Driving Connected and } \\
\text { Automated Vehicles Compared to Vehicles with and without Driver } \\
\text { Assistance Technology }\end{array}$}} & \multicolumn{2}{|l|}{$\begin{array}{l}\text { 5. Report Date } \\
\text { January } 2022\end{array}$} \\
\hline & & \multicolumn{2}{|c|}{ 6. Performing Organization Code } \\
\hline \multicolumn{2}{|l|}{$\begin{array}{l}\text { 7. Authors } \\
\text { Raghuveer Gouribhatla - 0000-0003-2817-2157 } \\
\text { Srinivas S. Pulugurtha - 0000-0001-7392-7227 }\end{array}$} & \multicolumn{2}{|c|}{$\begin{array}{l}\text { 8. Performing Organization Report } \\
\text { CA-MTI-1944 }\end{array}$} \\
\hline \multirow{2}{*}{\multicolumn{2}{|c|}{$\begin{array}{l}\text { 9. Performing Organization Name and Address } \\
\text { Mineta Transportation Institute } \\
\text { College of Business } \\
\text { San José State University } \\
\text { San José, CA } 95192-0219\end{array}$}} & \multicolumn{2}{|c|}{ 10. Work Unit No. } \\
\hline & & \multicolumn{2}{|c|}{$\begin{array}{l}\text { 11. Contract or Grant No. } \\
\text { 69A3551747127 }\end{array}$} \\
\hline \multirow{3}{*}{\multicolumn{2}{|c|}{$\begin{array}{l}\text { 12. Sponsoring Agency Name and Address } \\
\text { U.S. Department of Transportation } \\
\text { Office of the Assistant Secretary for Research and Technology } \\
\text { University Transportation Centers Program } 1200 \text { New Jersey Avenue, } \\
\text { SE Washington, DC } 20590\end{array}$}} & \multirow{2}{*}{\multicolumn{2}{|c|}{ 13. Type of Report and Period Covered }} \\
\hline & & & \\
\hline & & \multicolumn{2}{|c|}{ 14. Sponsoring Agency Code } \\
\hline \multicolumn{4}{|l|}{ 15. Supplemental Notes } \\
\hline \multicolumn{4}{|c|}{$\begin{array}{l}\text { 16. Abstract } \\
\text { Traffic related crashes cause more than } 38,000 \text { fatalities every year in the United States. They are the leading cause of } \\
\text { death among drivers up to } 54 \text { years in age and incur } \$ 871 \text { million in losses each year. Driver errors contribute to about } \\
94 \% \text { of these crashes. In response, automotive companies have been developing vehicles with advanced driver assistance } \\
\text { systems (ADAS) that aid in various driving tasks. These features are aimed at enhancing safety by either warning } \\
\text { drivers of a potential hazard or picking up certain driving maneuvers like maintaining the lane. These features are } \\
\text { already part of vehicles with Driver Assistance Technology, and they are vital for successful deployment of connected } \\
\text { and automated vehicles in the near future. However, drivers' responses to driving vehicles with advanced features have } \\
\text { been meagerly explored. This research evaluates driver participants' response to scenarios when driving connected and } \\
\text { automated vehicles compared to vehicles with and without Driver Assistance Technology. The research developed } \\
\text { rural, urban, and freeway driving scenarios in a driver simulator and tested on participants sixteen years to sixty-five } \\
\text { years old. The research team explored two types of advanced features by categorizing them into warnings and } \\
\text { automated features. The results show that the advanced features affected driving behavior by making driver participants } \\
\text { less aggressive and harmonizing the driving environment. This research also discovered that the type of driving scenario } \\
\text { influences the effect of advanced features on driver behavior. Additionally, aggressive driving behavior was observed } \\
\text { most in male participants and during nighttime conditions. Rainy conditions and female participants were associated } \\
\text { with less aggressive driving behavior. The findings from this research help to assess driver behavior when driving } \\
\text { vehicles with advanced features. They can be inputted into microsimulation software to model the effect of vehicles } \\
\text { with advanced features on the performance of transportation systems, advancing technology that could eventually save } \\
\text { millions of dollars and thousands of lives. }\end{array}$} \\
\hline $\begin{array}{l}\text { 17. Key Words } \\
\text { Simulator, advanced driver assistance system, } \\
\text { warning, automated, connected, driver behavior }\end{array}$ & \multicolumn{3}{|c|}{$\begin{array}{l}\text { 18. Distribution Statement } \\
\text { No restrictions. This document is available to the public } \\
\text { through The National Technical Information Service, } \\
\text { Springfield, VA } 22161 .\end{array}$} \\
\hline $\begin{array}{l}\text { 19. Security Classif. (of this report) } \\
\text { Unclassified }\end{array}$ & $\begin{array}{l}\text { 20. Security Classif. } \\
\text { (of this page) } \\
\text { Unclassified }\end{array}$ & $\begin{array}{l}\text { 21. No. of Pages } \\
97\end{array}$ & 22. Price \\
\hline
\end{tabular}

Form DOT F 1700.7 (8-72) 
Copyright (C) 2022

\section{by Mineta Transportation Institute}

All rights reserved.

DOI: $10.31979 / \mathrm{mti} .2022 .1944$

Mineta Transportation Institute

College of Business

San José State University

San José, CA 95192-0219

Tel: (408) 924-7560

Fax: (408) 924-7565

Email: mineta-institute@sjsu.edu

transweb.sjsu.edu/research/1944 


\section{ACKNOWLEDGMENTS}

The authors express their sincere thanks and gratitude to the University of Iowa for the help and support with the National Advanced Driving Simulator (NADS) $\operatorname{miniSim}^{\mathrm{TM}}$ and the driver simulator software tool used in this study.

The authors recognize the initial efforts by Harrison Rohrer of Charlotte Engineering Early College with developing the driving scenarios. They also thank all the study participants. 


\section{CONTENTS}

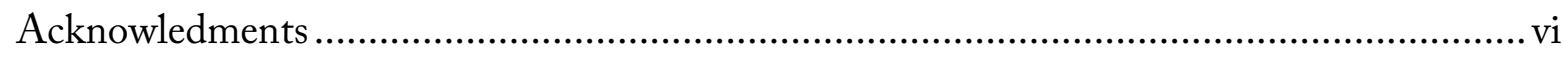

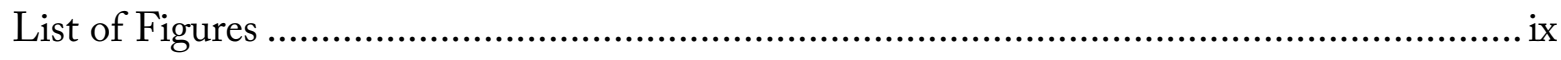

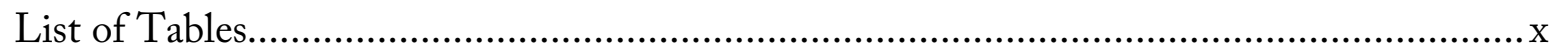

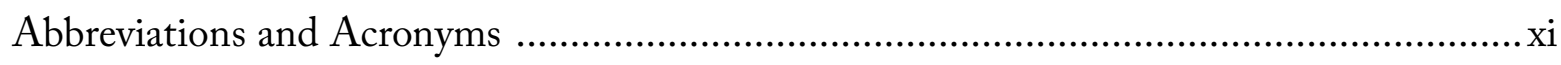

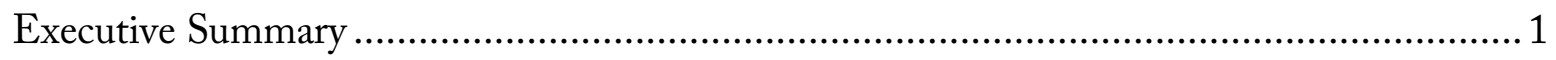

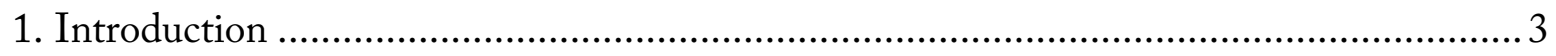

1.1 Need for Research and Problem Statement...................................................... 6

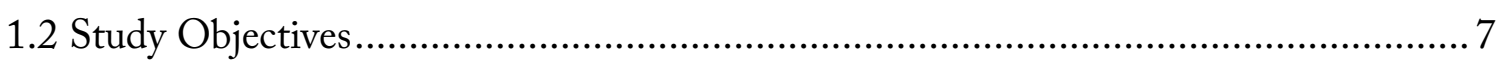

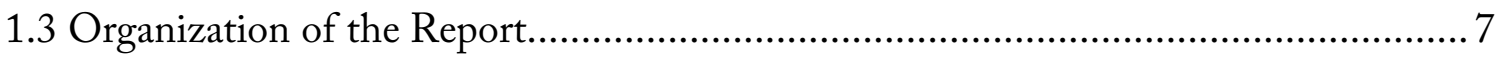

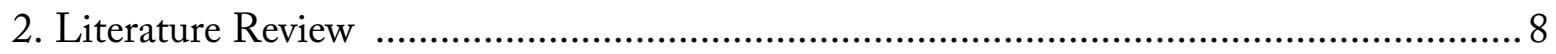

2.1 Survey and Mathematical Methods to Assess Driver Behavior ............................... 8

2.2 Field Test Methods to Assess Driver Behavior ...................................................... 8

2.3 Microsimulation Methods to Assess Driver Behavior ............................................. 10

2.4 Driver Simulator Methods to Assess Driver Behavior ................................................ 10

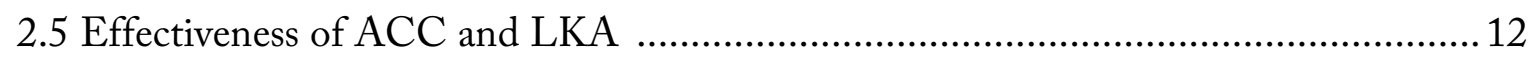

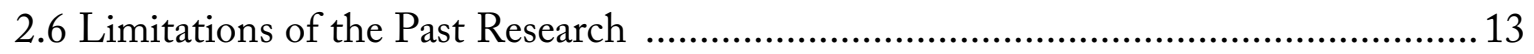

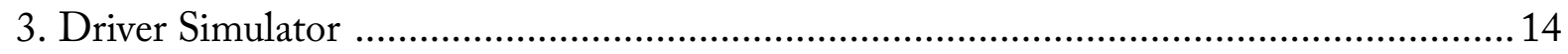

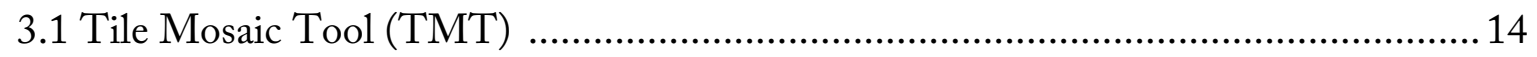

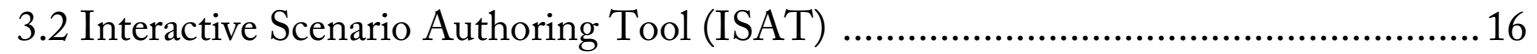

3.2.1 Traffic Condition ............................................................................. 17

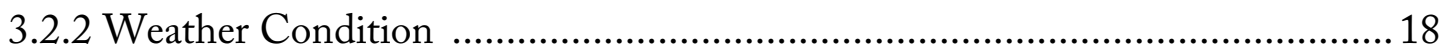

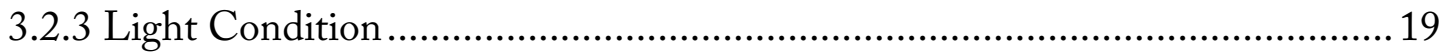

3.2.4 Scenario Fabrication........................................................................ 20

3.2.5 Data Verification/ Extraction ............................................................22

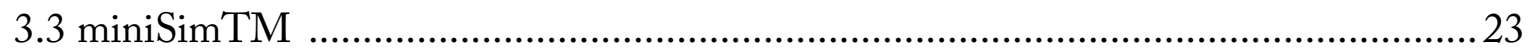

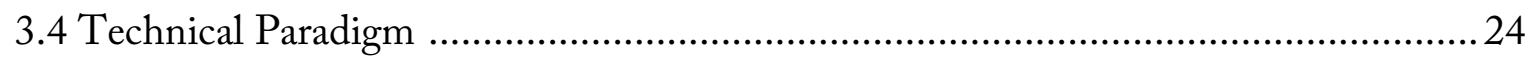

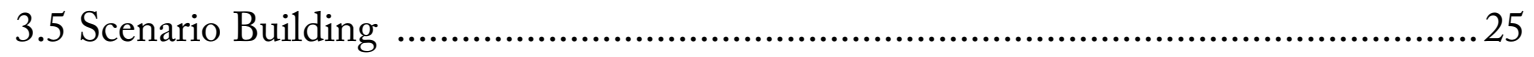

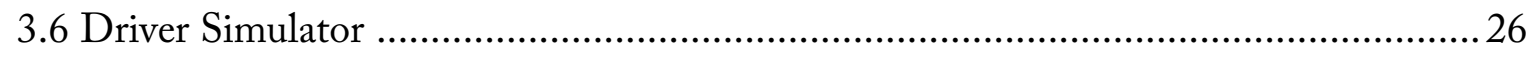

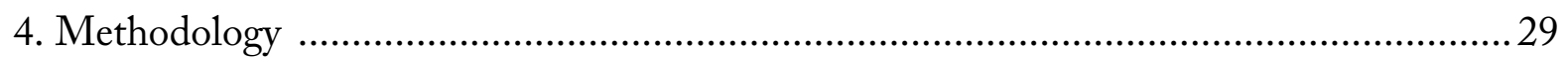

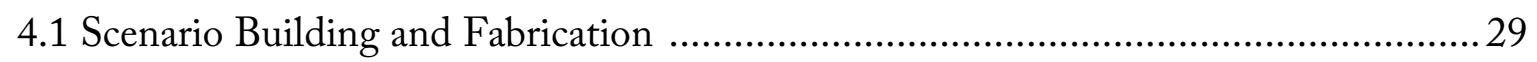

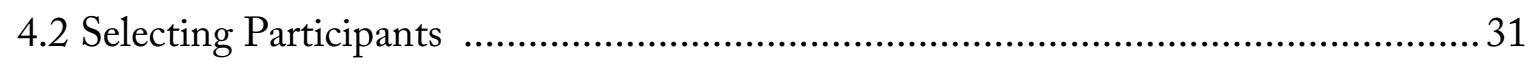

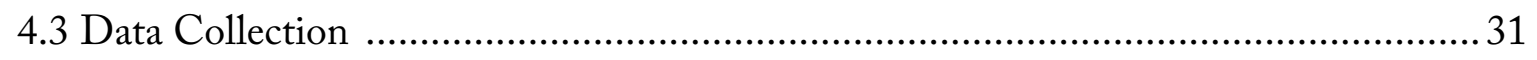

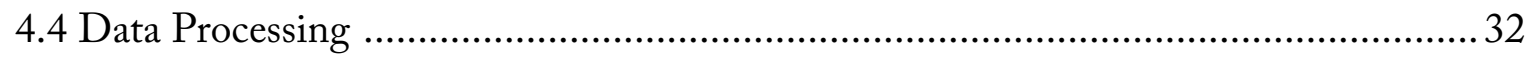




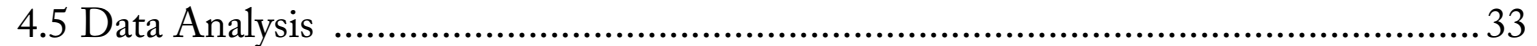

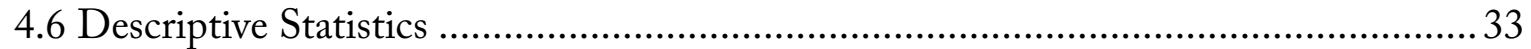

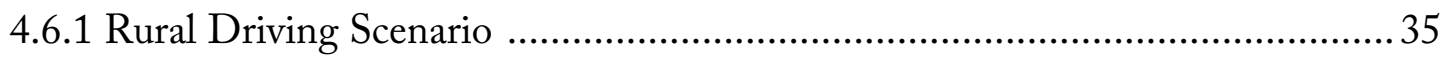

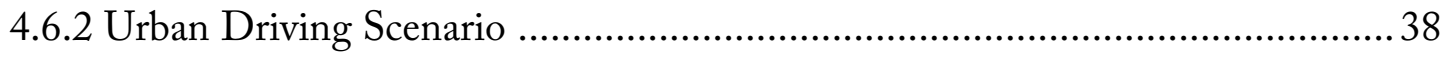

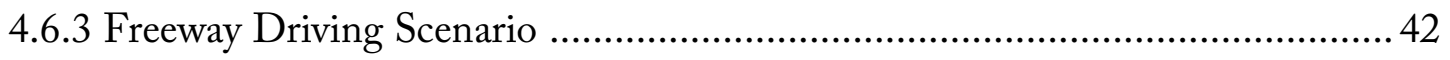

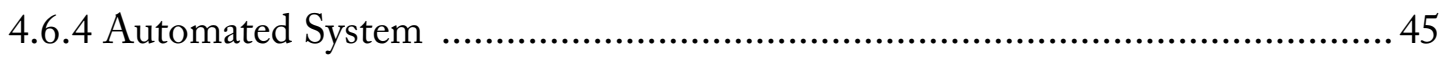

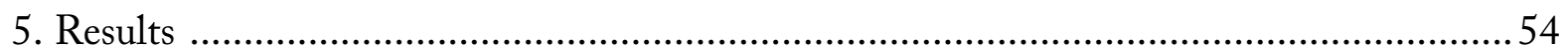

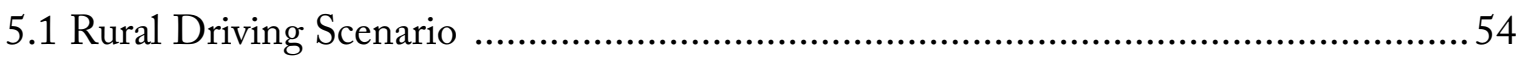

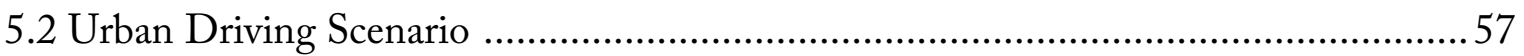

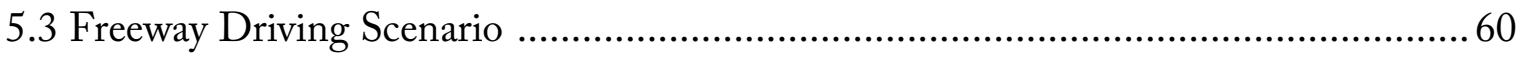

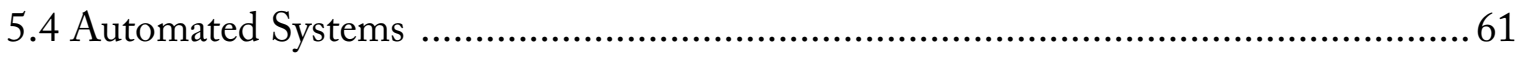

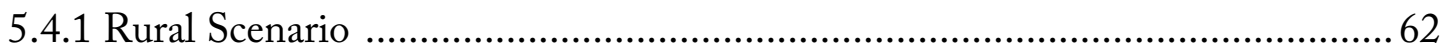

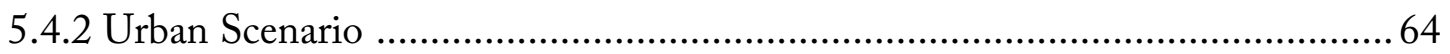

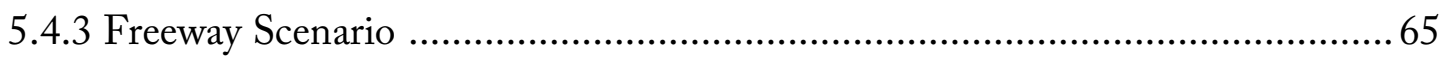

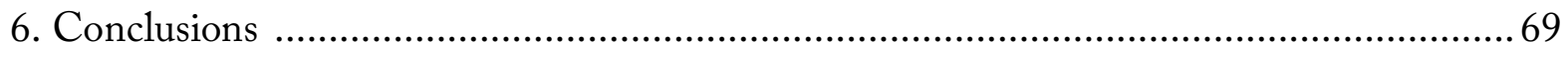

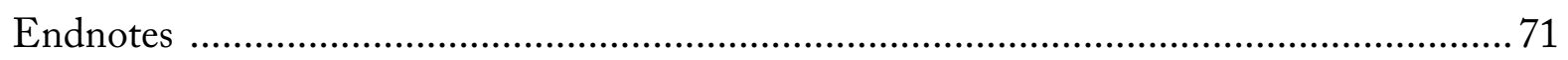

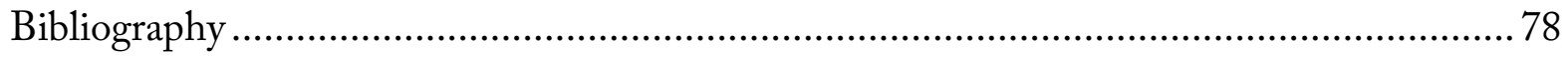

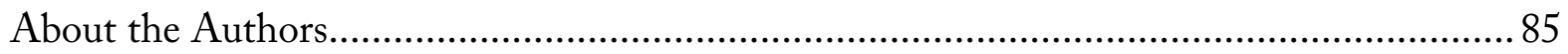




\section{LIST OF FIGURES}

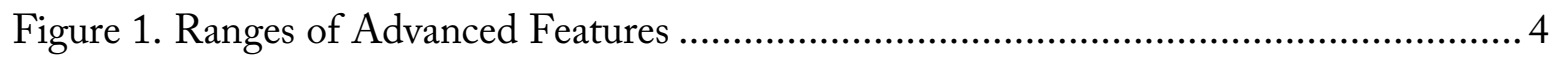

Figure 2. Functional Flowchart of Driving Simulation Development.................................... 14

Figure 3. Screenshot of a Sample Road Network in the TMT ........................................... 15

Figure 4. Screenshot of a Road Network in ISAT ……................................................. 17

Figure 5. Traffic Light Manager for Four-legged Intersection ............................................. 19

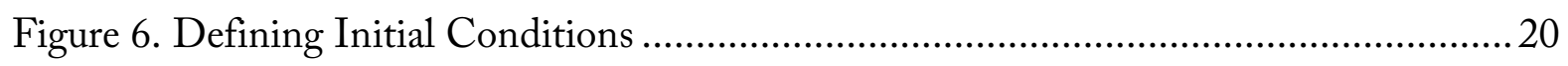

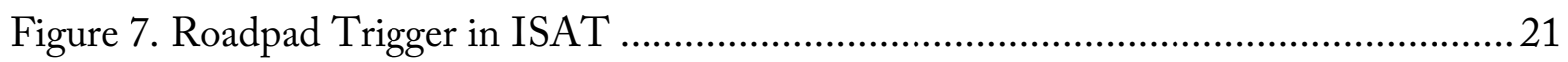

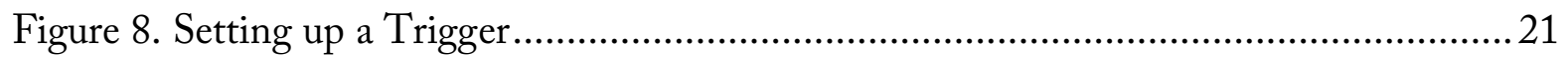

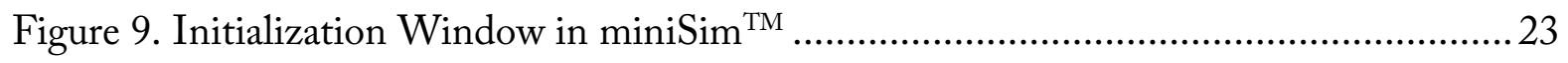

Figure 10. Technical Interaction Schematic of the Driver Simulator....................................2 24

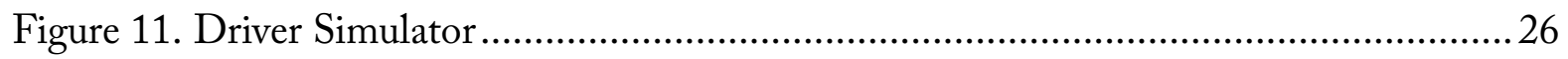

Figure 12. Driving Wheel and Panel Buttons ................................................................ 26

Figure 13. Buttons to Control ACC and LKA During Simulation....................................28

Figure 14. Simulating a Scenario in Driver Simulator........................................................28

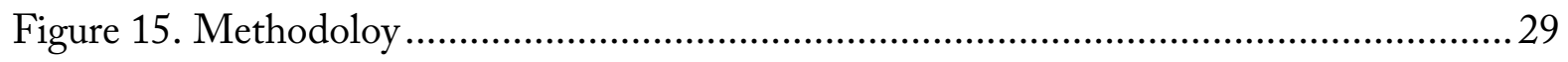




\section{LIST OF TABLES}

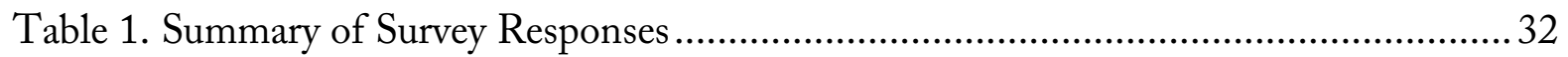

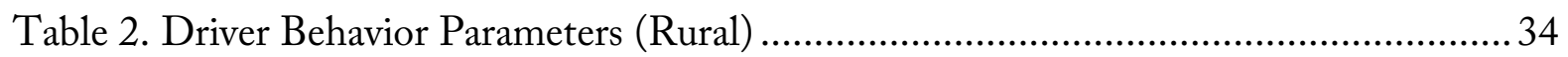

Table 3. Driver Behavior Parameters (Urban) .................................................................. 34

Table 4. Driver Behavior Parameters (Freeway) ………..................................................... 34

Table 5. Provision of Vehicles with or without Advanced Features to Participants .............. 35

Table 6. Driver Behavior Parameters - ADAS (Rural) .......................................................... 36

Table 7. Driver Behavior Parameters - Age, Gender, Lighting Condition, and

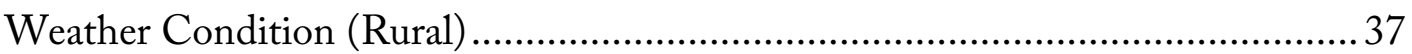

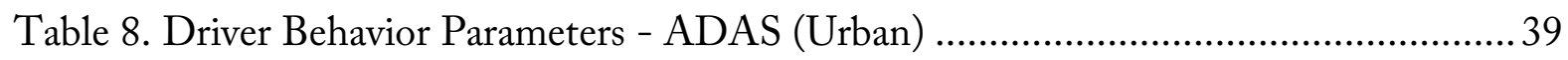

Table 9. Driver Behavior Parameters - Age, Gender, Lighting Condition, and

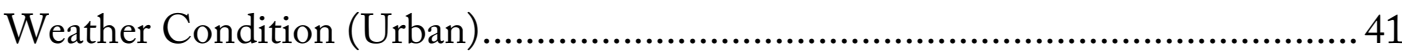

Table 10. Driver Behavior Parameters - ADAS (Freeway) .................................................. 43

Table 11. Driver Behavior Parameters - Age, Gender, Lighting Condition, and Weather Condition (Freeway) ............................................................................ 44

Table 12. Driver Behavior Parameters - No ADAS, Warning and Automated

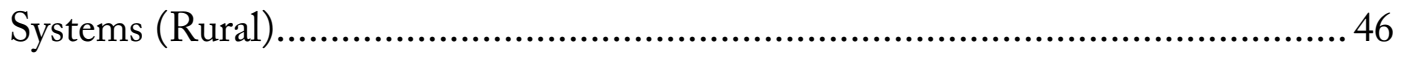

Table 13. Driver Behavior Parameters - LKA and LDW (Rural) ……............................... 47

Table 14. Driver Behavior Parameters - ACC, BSW and OSW (Rural)............................. 48

Table 15. Driver Behavior Parameters - No ADAS, Warning and Automated

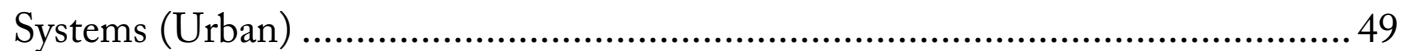

Table 16. Driver Behavior Parameters - LKA and LDW (Urban) .....................................50

Table 17. Driver Behavior Parameters - ACC, BSW and OSW (Urban) ............................5 50

Table 18. Driver Behavior Parameters - No ADAS, Warning and Automated

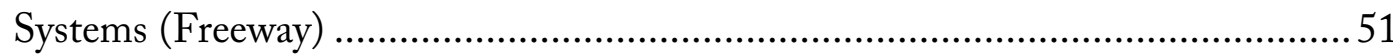

Table 19. Driver Behavior Parameters - LKA and LDW (Freeway) ................................52

Table 20. Driver Behavior Parameters - ACC, BSW and OSW (Freeway) ..........................53

Table 21. ANOVA Results - ADAS, Lighting, and Weather Conditions (Rural) ..............55

Table 22. ANOVA Results - ADAS, Lighting, and Weather Conditions (Urban) ............. 58

Table 23. ANOVA Results - ADAS, Lighting, and Weather Conditions (Freeway) ..........60 60

Table 24. ANOVA Results - Automated, Warning, and No ADAS (Rural).......................62

Table 25. ANOVA Results - Automated, Warning, and No ADAS (Urban) .......................64

Table 26. ANOVA Results - Automated, Warning, and No ADAS (Freeway) ...................66 


\section{Abbreviations and Acronyms}

ACC

ADAS

AEB

BSW

CACC

FCW

ISAT

LDW

LKA

TET

TIT

TMT

VSL
Adaptive Cruise Control

Advanced Driver Assistance System

Automatic Emergency Braking

Blind Spot Warning

Cooperative Adaptive Cruise Control

Front Collision Warning

Interactive Scenario Authoring Tool

Lane Departure Warning

Lane Keep Assist

Time Exposed Time to Collision

Time Integrated Time to Collision

Tile Mosaic Tool

Variable Speed Limit 


\section{Executive Summary}

Driver errors are the leading cause of traffic crashes, contributing to about $94 \%$ of crashes. Automotive companies strive to enhance their vehicles to eliminate driver errors and reduce the number of crashes. Various advanced features are designed to assist with-or in some cases, take over-certain driving maneuvers. These features include lane departure warning (LDW), blind spot warning (BSW), over speed warning (OSW), lane keep assist (LKA), forward collision warning (FCW), adaptive cruise control (ACC), and automated emergency braking (AEB). Each of these advanced features is focused on a particular task, reducing the driving load on the driver and enhancing safety. They make up critical components of Driver Assistance Technology and are vital for the success of connected and automated vehicles in the future.

The advanced driver assistance systems (ADAS) are focused on reducing crashes. Despite the increase in vehicles with advanced features in the market, the total number of crashes increased from 6.45 million in 2017 to $~ 6.76$ million in 2019, as reported by the National Highway Traffic Safety Administration (NHTSA). Additionally, the acceptance levels of ADAS among drivers is questionable. Many surveys have determined that drivers are unaware of the applications and limitations of the ADAS features. Further, drivers admitted to blindly trusting such features, worsening the problem. Also, drivers' responses to scenarios when driving vehicles with advanced features has been poorly explored. Thus, there is a need to evaluate drivers' response to scenarios when driving connected and automated vehicles compared to vehicles with and without Driver Assistance Technology.

The National Advanced Driving Simulator (NADS) miniSim ${ }^{\mathrm{TM}}$ was used to capture driver behavior in this study. Rural, urban, and freeway scenarios were developed to test on the drivers (participants aged sixteen to sixty-five) in various weather and lighting conditions. Other variables including socioeconomic and demographic characteristics were also captured through a questionnaire provided to the participants.

The study is categorized into four stages. The first stage involved developing appropriate driving scenarios. In order to improve the applicability of the results, rural, urban, and freeway driving conditions were simulated as these are the typical scenarios encountered by drivers. The second stage involved the careful selection of participants such that the sample population accurately reflects the general population. Participants aged sixteen to sixty-five were selected for the study. Each participant was tested across all three driving scenarios while a vehicle with or without advanced features was provided to them at random. The advanced features can be categorized as follows: (1) warning features, including LDW, BSW, and OSW features and (2) automated features, including LKA and ACC features.

The third stage involved data processing and analysis to derive meaningful results. The analysis of variance (ANOVA) test was performed to evaluate the effectiveness of the advanced features. Driver behavior parameters such as hard braking, hard cornering, lane departure events, speeding events, average headway, and brake pedal force were assessed. The fourth stage involved identifying and using changes in driver behavior to ascertain behavioral differences among drivers with and without advanced features. 
LDW was observed to reduce lane departure events in all driving scenarios (rural, urban, and freeway). OSW was observed to reduce the average and maximum speeds making driving less aggressive in rural and urban scenarios only, indicating they were not as effective in freeway scenario. Similarly, BSW was also observed to affect the brake pedal force and influence aggressive driving. Providing two advanced features at a time also affected brake pedal force indicating they were effective in influencing aggressive driving. Further, none of the warning features were observed to influence the participant following behavior as the average headway difference with and without Driver Assistance Technology was not found to be statistically significant.

While the ADAS is effective in meeting their intended objectives, they seem to inadvertently affect other driving behaviors. The type of driving scenario (rural, urban, or freeway) also seemed to influence the way an advanced feature affects driver behavior. Braking behavior is predominantly affected by the presence of an advanced feature in most cases, which also influenced vehicle handling events like lane-following, turning, and car-following in some cases. Other factors such as lighting and weather conditions, and participants' age and gender also affected driving behavior. More lane departures and longer headways were observed at nighttime. Similarly, longer headways were observed in rainy weather condition but lane-changing, braking, and turning maneuvers were observed to be less aggressive. Participants over twenty-five and male participants were observed to exhibit relatively higher levels of aggressive driving behaviors.

Driving behavior improved further when vehicles with automated systems (ACC and LKA) were provided individually or in combination. Automated systems improved braking, vehicle handling, and lane-following behaviors in all three scenarios. Less aggressive speeding behavior was observed in the freeway scenario. However, more aggressive car-following behavior was observed with automated systems. The variation in driving behavior among participants when provided with automated systems dropped drastically. The effects of automated systems were influenced by the type of driving scenario. The intervention of ADAS with driving tasks led to safer driving conditions. The driving safety improved with the level of assistance provided to the drivers. 


\section{Introduction}

Traffic deaths are a major issue in the United States today and they are the leading cause of deaths among people up to fifty-four years in age. ${ }^{1}$ More than 38,000 people are killed in road crashes annually in the United States, which equals a rate of 12.4 deaths per 100,000 people. ${ }^{1}$ An estimated $\$ 380$ million is lost in direct medical bills, while total economic impacts of the crashes-direct or indirect-amount to roughly $\$ 871$ million. ${ }^{1}$ Further, new vehicles are added to the roads with each passing year, with more than 17.6 million passenger cars and trucks sold in 2016 alone and a total recorded 3.21 trillion vehicle miles traveled in 2018., ${ }^{2,3}$ This increases traffic exposure and contributes to a higher risk of crashes.

It is estimated that $94 \%$ of crashes occur due to driver errors. ${ }^{4}$ The nature of driver errors varies widely and has been broadly classified into four types: recognition errors, decision errors, performance errors, and non-performance errors. ${ }^{5}$ Recognition errors account for about $41 \%$ of crashes, making them the most common error type. ${ }^{5}$ These could be errors such as incorrectly estimating the distance or speed of the vehicle. Decision errors cause $34 \%$ of crashes and include speeding, following too closely, or making illegal actions. ${ }^{5}$ Performance errors account for $10 \%$ of crashes and encompass issues such as losing control of the vehicle. ${ }^{5}$ Non-performance issues-such as health issues-led to $7 \%$ of crashes. ${ }^{5}$

Although it is not possible to address non-performance issues which are largely random and unpredictable, $85 \%$ of errors can be handled effectively using advanced features. These features enhance or automate certain driving tasks and aim to achieve safety. Figure 1 shows a schematic of different types of advanced features. 
Figure 1. Ranges of Advanced Features

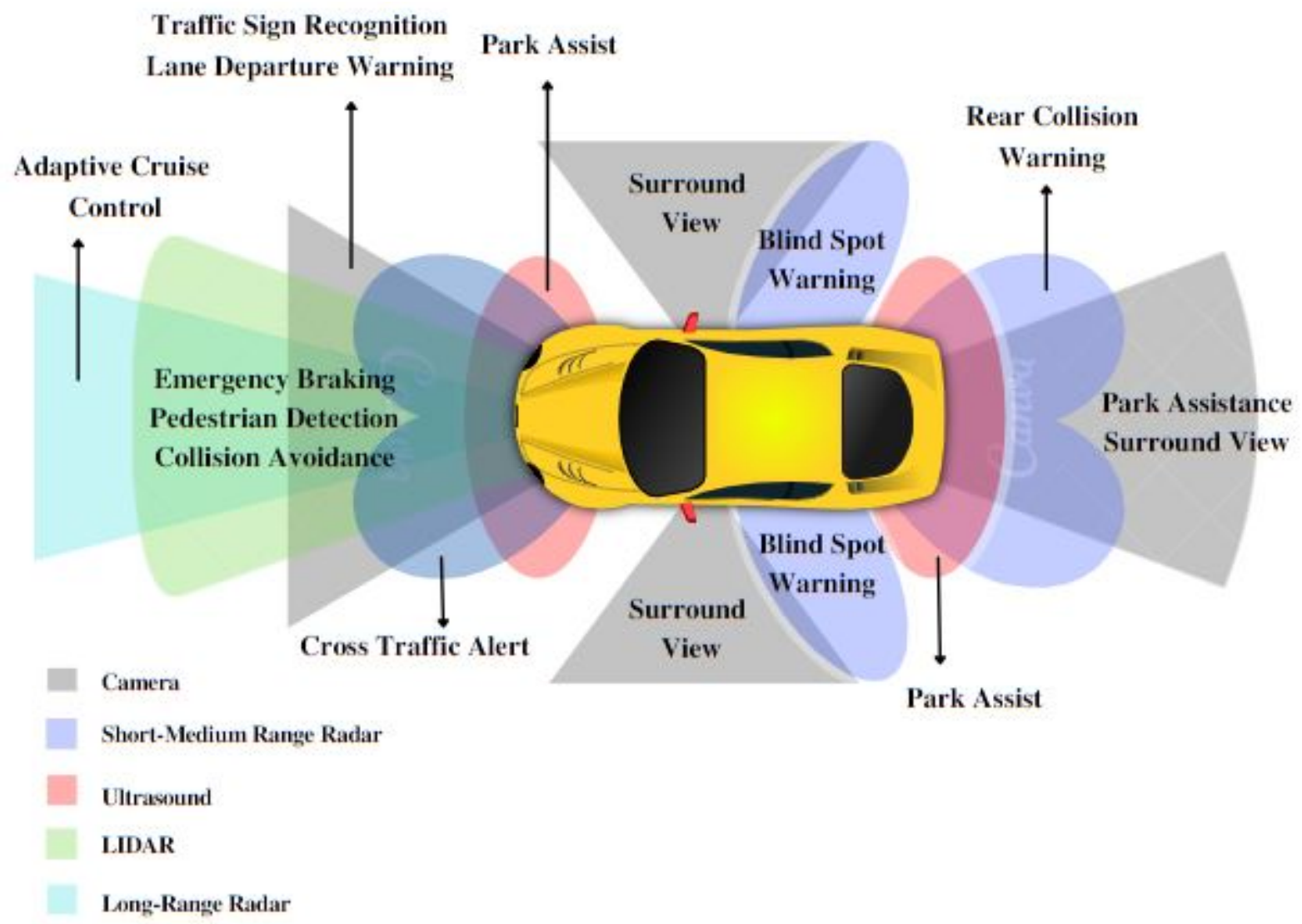

All the external advanced features use sensors with varying detection ranges. The smallest range of detection is for parking assist systems that are used at low speeds in parking lots that do not require long stopping distances. Adaptive cruise control (ACC) has the longest detection range, as it is mostly engaged at higher speeds and on freeways. The cone of detection is narrow as the vehicle acts in response to its leading vehicle. Blind spot warning (BSW) also has a smaller detection range as it responds to vehicles in adjacent lanes. Advanced driver assistance systems (ADAS) such as emergency braking and collision avoidance are powered by medium range sensors to best suit their purposes. Overall, advanced features require different types of cameras or sensors for each purpose. ACC uses long-range radar systems while emergency braking and collision avoidance systems use light detection and ranging (LiDAR). The warning or alert systems use sensors that have smaller detection ranges while partially automated systems use sensors with longer detection ranges. These systems also deliver progressive levels of assistance based on users' needs. The levels are classified as follows. ${ }^{6}$

Adaptive systems: these are systems that trigger actions based on inputs from another vehicle entering the vicinity (examples: ACC, adaptive head lights, and adaptive light control).

Automated systems: these are systems that can perform certain actions without the intervention of the driver (examples: automated parking, automated braking, and collision avoidance system).

Monitoring systems: these systems essentially monitor the conditions in the vicinity of vehicle and determine if a corrective action needs to be conducted (examples: parking assist, speed monitoring, pedestrian monitoring, and proximity monitoring). 
Warning systems: these systems actively monitor the conditions in the vicinity of a vehicle and warn the drivers of any potential safety hazards. These are, for example: lane departure warning (LDW), BSW, over speed warning (OSW), and forward collision warning (FCW).

The advanced features address the first three types of driver-related errors that contribute to the majority of crashes. There are ongoing and extensive efforts to improve traffic safety, especially in the automotive market where new driver assist technologies are evolving. Despite these efforts, a $14 \%$ increase in road related deaths were recorded from 2014 to $2016 .{ }^{7}$ There have also been many debates over ADAS making drivers more reluctant and distracted, resulting in unwanted side effects. ${ }^{7}$ Past studies revealed that $70 \%$ of drivers preferred ADAS for their vehicles. ${ }^{8}$ However, the question of whether they understand these technologies still remains.

A survey by the American Automobile Association (AAA) revealed that $21 \%$ of vehicle owners using BSW features did not understand the limitations of the system while Fleet Manager expected the number to be about $80 \% .^{8,9}$ On the other hand, 33\% of the vehicle owners did not understand that the sensors engaging the Emergency Braking System (EBS) could be blocked. ${ }^{8}$ Also, $40 \%$ of drivers misunderstood the application of FCW and Automatic Emergency Braking (AEB) systems believing that the FCW system would automatically apply brakes. ${ }^{9}$ While the limitations of drivers' understanding of ADAS is evident, what magnifies the issue of driver safety is their reliance on such systems. It was reported that $29 \%$ of the respondents to a survey felt comfortable engaging in other activities when provided with ACC, 30\% did not do shoulder checks when provided with BSW, and 25\% did not look back over their shoulder when provided with rear cross traffic alert. ${ }^{8}$

ACC and active lane keeping/lane keeping assist (LKA) were tested under multiple driving conditions by the Insurance Institute for Highway Safety (IIHS) in a series of track tests. ${ }^{10}$ ACC is an automated system that maintains a designated speed and following distance from the leading vehicle. This system can adjust its speed based on the leading vehicle and can also make a complete stop if required. LKA is another automated system that keeps the vehicle in its respective lane using steering control. These systems do have some limitations, however. The tests by IIHS revealed ACC reacted aggressively in some scenarios while failing to react to already stopped vehicles in some other scenarios. ${ }^{10}$ Similarly, LKA was also observed to steer over the shoulder in some cases where the lanes weren't detected. ${ }^{10}$

In addition to this, a survey revealed that $74 \%$ of the respondents were very satisfied with LKA while $85 \%$ of the respondents were very satisfied with ACC. ${ }^{11}$ While $65 \%$ of the respondents trusted LKA to work every time, ACC was trusted by $72 \%$ of the respondents. ${ }^{12}$ Most tests on ADAS like ACC and LKA are performed under safer conditions compared to real-world traffic conditions and with better-trained drivers. ${ }^{12}$ Also, it is possible that such systems make drivers more reluctant and less prompt when driving. ${ }^{12}$ Further, a few consumers also complained of LKA not working properly at nighttime and in rainy weather condition. ${ }^{12}$

The percentage of users relying on ADAS, the limitations that apply to various advanced features, and the lack of knowledge of the applications of ADAS among drivers can lead to unsafe driving conditions. While ADAS makes driving tasks easier on one hand, they may inadvertently make driving more difficult. The ADAS takes up certain driving tasks making a driver's job easier to some extent, but the driver needs to be alert at all times to take over automated driving functions as soon as any of these systems fail to react or disengage. This brings forth the argument whether 
ADAS lead to other unforeseen effects on drivers. This can be assessed by evaluating the behavior of drivers using vehicles with advanced features and drawing comparisons with drivers using vehicles without ADAS to better understand the driving patterns and safety implications.

While it is difficult to precisely capture driver behavior in the real world, there have been few research studies where drivers were provided with a test vehicle to capture and analyze driving behavior or by conducting surveys. ${ }^{13,14}$ Though these research studies captured some aspects of drivers' understanding, they are not entirely accurate as they are limited to selected scenarios, and may involve a long and cumbersome process. Privacy may also be a trade-off. This brings the application of a driver simulator into the play.

The driver simulator is a platform that can be used to capture driver behavior and ensure the safety and privacy of the drivers (participants). Driver simulators also enable researchers to capture a wide range of customizable driving characteristics in a shorter span of time. As such, using a driving simulator may bridge knowledge gaps which are relatively challenging to navigate in the field. The focus of this study is to evaluate driver participants' response to scenarios when driving vehicles with and without advanced features like LDW, BSW, OSW, ACC, and LKA.

Drivers' responses or behaviors could vary according to the advanced feature, driving scenario, and participant characteristics, as well as lighting and weather conditions. Therefore, rural, urban and freeway scenarios were developed in a driver simulator and tested on drivers (participants) aged sixteen to sixty-five years who were randomly assigned vehicles with or without advanced features. This study aims to capture general driving behavior in all types of settings, discussed later in detail.

\subsection{Need for Research and Problem Statement}

Human errors are a major contributor to road crashes. Automotive companies and researchers have made ongoing efforts to reduce human intervention in driving and improve safety, with the ultimate goal of complete automation in the future. Federal institutions like the National Highway Traffic Safety Administration (NHTSA) and the Federal Highway Administration (FHWA) have also been monitoring the performance of various emerging advanced features and evaluating their acceptance and ease of use via testing procedures. ${ }^{15}$ Further, the NHTSA publishes articles and provides information on ADAS, explaining their working mechanisms, advantages, and limitations to educate drivers. ${ }^{16}$

There have been considerable research efforts to investigate the effectiveness of ADAS. The data collected for these evaluations mainly stems from reported incidents. Despite the proven records of these systems, a low level of acceptance seems to exist among drivers. Many drivers are confused with the application of ADAS which could lead to drastic outcomes, which is alarming.

The ADAS cannot be assessed for specific driving conditions in the real world, and their effects can only be anticipated or collected post-event. Employing a driver simulator helps design specific driving scenarios that can test the limits of such systems and develop a deeper sense of their

applicability. A wide range of testing conditions can be simulated which otherwise may be difficult to analyze.

Although there have been significant efforts to evaluate the effectiveness of ADAS, a model with a broad sense of applicability is rare. Past studies on the effects of ADAS on drivers are limited to 
very specific conditions or to a defined set of parameters. However, the driving behavior, use of ADAS, and effectiveness could vary based on the road functional class (freeway compared to nonfreeway roads) and area type (urban compared to rural). There is a need to evaluate the effect of ADAS on driving behavior under various driving conditions. The findings from such a study would guide policymakers and automotive companies to formulate well-defined testing criteria. Therefore, this study focuses on developing driver behavior models for different driving scenarios such as urban, rural, and freeways.

Younger drivers are more comfortable using advanced technologies while older drivers may not be equally comfortable or even familiar with advanced technologies. Thus, the socioeconomic aspects and driving history also have a bearing on driving behavior and the use of ADAS. Considering demographic and socioeconomic variables, driving history, and drivers' prior understanding of ADAS could allow researchers to better understand their role, generate defined parameters, and design more optimal ADAS for the drivers.

The purpose of this study is to evaluate the effects of ADAS on driver behavior. The advanced features are tested in different driving conditions that include urban, rural and freeway scenarios, and capture daytime and nighttime variances, as well as weather conditions such as rain or snow. Furthermore, along with socioeconomic and demographic factors, additional variables include participants' driving history, alcohol consumption, and sleep patterns on the day before the study. This enables the comparison of the effects of ADAS across multiple facets and also identifies any gaps which are highly applicable to the multi-faceted situations that arise in real-world.

\subsection{Study Objectives}

The objectives of this study are:

- to collect data and assess driver participants' response to scenarios when driving connected and automated vehicles compared to vehicles with and without Driver Assistance Technology;

- to identify the effects of advanced features on driver behavior for different driving conditions, demographic, and socioeconomic characteristics; and

- to model the effects of advanced features on driver behavior with individual systems and combinations of two or more systems.

\subsection{Organization of the Report}

The reminder of the report is organized as follows. Chapter 2 presents an extensive review of the various methods adopted to evaluate ADAS. The chapter discusses survey methods, field test methods, microsimulation methods, and driver simulator methods and identifies prevailing gaps. Chapter 3 synthesizes the driver simulator system. The various tools involved in developing the simulation conditions and participant selection criteria are also discussed in detail. Chapter 4 discusses the methodology adopted along with data collection and processing efforts. Chapter 5 presents results from the research, while conclusions and scope for further work are discussed in Chapter 6. 


\section{Literature Review}

Investigating past research efforts on ADAS is vital to understand their effects on driver behavior and safety. Also, this exercise helps to identify any knowledge gaps and methodologies adopted by past researchers which serve as a foundation to establish a more concrete framework. This chapter presents an overview of the past studies categorized based on the relevant research areas.

\subsection{Survey and Mathematical Methods to Assess Driver Behavior}

Abdul et al. (2007) investigated driver behavior based on the pressure applied on brake and gas pedals. ${ }^{17}$ They employed a cerebellum model articulation controller (CMAC) to model driver behavior. They observed the application of CMAC to be reasonable for predicting various driver behavior characteristics and understand the effects of a drivers' emotion and subconscious mind. Wang et al. (2014) evaluated driver behavior based on the acceleration and brake force parameters and steering wheel angle using mathematical models. ${ }^{18}$ They used these parameters to incorporate into ADAS and observed that driver behavior varies for different driving actions and generalizing driver behavior based on only a few actions is not ideal. Similarly, Kamaruddin and Wahab (2010) tried predicting driver behavior based on speech configuration. ${ }^{19}$ They found that emotions conveyed in speech patterns - especially when sleepy — can be used to profile driver behavior. Kuge et al. (2000) evaluated driver behavior using a hidden Markov model (HMM). ${ }^{20}$ They demonstrated the efficient application of HMM for both the application and modeling of driver behavior, particularly for lane-changing behavior. Sathyanarayana et al. (2008) also developed an HMM framework to identify driver behaviors and distractions using mathematical models. ${ }^{21}$

Tran et al. (2012) used vision-based foot gestures and HMM to analyze and predict braking behaviors of drivers. ${ }^{22}$ They used visual methods to capture driver behavior data and employed HMM to predict the pedal pressing gestures and achieved a 94\% accuracy with this method. Similarly, Yannis et al. (2010) investigated the acceptance of ADAS among older driver via surveys from 23 European countries. ${ }^{23}$ The authors developed ordered logit models, and the results showed relatively better acceptance of ADAS among older drivers and females. Morignot et al. (2014) evaluated the effectiveness of and acceptance of ADAS via a surveying method. ${ }^{24}$ They presented results to help develop ADAS in the future.

\subsection{Field Test Methods to Assess Driver Behavior}

Alkim et al. (2007) investigated the effects of LDW and ACC in congested mixed traffic conditions on driver behavior using a field vehicle in Netherlands. ${ }^{25}$ They observed an $8 \%$ improvement in traffic safety and a $3 \%$ reduction in fuel consumption. Additionally, the estimated reduction in emissions was about $10 \%$.

McCall et al. (2007) focused on developing human-centric ADAS—such as predictive braking and $\mathrm{ACC}$ - and evaluated its effects on driver behavior using a test vehicle in real-world driving conditions. ${ }^{26}$ Cognition-based adjustments were made to the vehicle to capture driver behavior and the framework showed promising results. Ziefle et al. (2008) evaluated the effects of visual and auditory ADAS on older drivers. ${ }^{27}$ They observed better driving performance in the absence of any 
ADAS, while auditory systems contributed the highest to distraction. Their findings indicate that older drivers preferred auditory systems over visual systems.

Inata et al. (2008) modeled driver behavior using micro-electric sensors mounted on vehicles which were driven in real-world traffic environments. ${ }^{28}$ The sensing equipment recorded the pedal operation of the vehicle, which was used for analyses. The researchers developed a theoretical model to estimate driver behavior and then compared it to urban driving data to distinguish hurried driving from relaxed driving. Angkititrakul et al. (2009) used mathematical models (Gaussian mixture model) and algorithms (piecewise auto-regressive exogenous) to understand and incorporate driver behavior into car-following models. ${ }^{29}$ The data was obtained from real-world driving conditions. They captured braking and acceleration parameters in response to the distance from the leading vehicle. The framework was then used to evaluate and model driver behavior.

Kondyli and Elefteriadou (2009) investigated driver behavior using data obtained from driver responses to various questions that addressed their thinking while merging onto a highway. ${ }^{30}$ They tried to correlate the driver's behavioral thinking to driver characteristics. Pauwelussen and Feenstra (2010) investigated the effects of ACC and LDW on driver behavior in real-world driving conditions. ${ }^{31}$ They observed that the ACC system led to larger headways between vehicles while manual override of the system resulted in shorter headways.

Farah and Koutsopoulos (2014) explored the effect of infrastructure to vehicle (I2V) assistance systems on drivers using test vehicles. ${ }^{32}$ They observed reduced ranges of acceleration and deceleration while their car-following was more synchronized. Olaverri-Monreal et al. (2014) examined the effect of the location and angle of in-vehicle displays on driver safety. ${ }^{33}$ They observed the driver gaze when looking at driver information systems in the vehicle that are currently existing in the market and inferred that they meet the NHTSA guidelines for the gazing away from road values. Driver preferences for the in-vehicle display and location converged with the market, while mobile applications and social media were found to be unnecessary.

Son et al. (2015) employed a road-testing method to evaluate the acceptance of FCW and LDW based on the age and gender of the driver. ${ }^{34}$ While females and younger drivers showed lowest acceptance for ADAS, males and late middle-aged drivers showed higher likelihood of acceptance. Miyajima et al. (2016) developed machine learning models to analyze data collected from realworld driving conditions over 15 years. ${ }^{35}$ They observed various driver behaviors including lanechanging, car-following, and pedal operation. They developed statistical models to predict risky driving and frustrated driving behaviors. Sieber et al. (2016) investigated driver behaviors in collision avoidance using a field test study ${ }^{36}$ They observed driver behavior and perception with different times of collision and observed that the speed of the obstacle had the greatest effect on driver behavior.

Cades et al. (2017) investigated the effects of LDW on driver behavior while the participants performed a secondary task. ${ }^{37}$ They observed no significant effect of LDW on reducing workload on driver cognition while performing secondary tasks. Lyu et al. (2019) investigated the effect of ADAS on driver behavior using field operational tests in China on a test route. ${ }^{38}$ The effects of FCW and LDW were primarily assessed in their study. They observed increased braking time and decreased relative speed when provided with ADAS. Also, higher acceptance of FCW was observed over LDW. The acceptance was higher on freeways compared to urban roads. 


\subsection{Microsimulation Methods to Assess Driver Behavior}

Kikuchi et al. (2003) used microsimulation to explore the effects of ACC in platooning based on the different positions of the vehicle. ${ }^{39}$ They observed reduced reaction times to achieve stability in the platoon. Both ACC-equipped and non-ACC vehicles were found to display enhanced safety. Derbel et al. (2012) investigated the effect of mixed traffic-made up of vehicles equipped with ACC - in a crash scenario. ${ }^{40}$ Enhanced safety and also reduced crash risk were observed when vehicles equipped with ACC were involved in a crash.

Jeong et al. (2014) investigated the effect of an inter-vehicle safety warning information system (ISWS), which communicates hazardous maneuvers of vehicles that could lead to a crash. ${ }^{41}$ Probe vehicles captured drivers' behavior and were fed into a VISSIM simulation, while the Surrogate Safety Assessment Model (SSAM) was used to measure safety. Rear-end conflicts were observed to reduce with penetration rates, while congestion increased. The standard deviation of speed decreased by $40 \%$.

Researching the effectiveness of multiple integrated systems, Li et al. (2016) evaluated the effect of integrating I2V with ACC and variable speed limit (VSL) in different combinations on traffic safety. ${ }^{42}$ The time exposed time to collision (TET) which indicates the total time spent by a vehicle in safety-critical situation and time integrated time to collision (TIT) which is time remaining for a collision to occur if two vehicles continue to maintain the same speed were used as surrogate safety measures in their study. Integrating technologies led to better results when compared to individual effects. Employing a similar methodology, Li et al. (2017a) evaluated the effects of ACC on safety of freeways. ${ }^{43}$ Enhanced safety was observed with the increase in penetration rates, while the combination of ACC and VSL were observed to produce the best results. Li et al. (2017b) also investigated the effect of cooperative adaptive cruise control (CACC) on rear-end crash risk on freeways. ${ }^{44} \mathrm{~A}$ significant reduction in crash risk was observed with CACC while the TET and TIT reduced by over $90 \%$.

Cicchino (2017) analyzed the effectiveness of FCW, AEB - separately and in combination-in reducing rear-end crashes. ${ }^{45} \mathrm{FCW}$ and $\mathrm{AEB}$ reduced rear-end crashes by $27 \%$ and $43 \%$ respectively and by $50 \%$ when combined. The likeliness of vehicles experiencing rear-end crashes reduced in the case of vehicles with individual systems but increased when the vehicles were equipped with both systems. Yue et al. (2018) examined the integration of connected vehicles with different ADAS. ${ }^{46}$ About a 70\% reduction in crashes was achieved by the integration, while FCW was found to reduce rear-end crash risk by $35 \%$ in foggy conditions.

\subsection{Driver Simulator Methods to Assess Driver Behavior}

Kaptein et al. (1996) found that driver simulator-based study results are valid, and that validity increases with the resolution of the simulation and the presence of a moving base. ${ }^{47}$ Strayer and Johnston (2001) investigated the effect of conversing on cellular phones on driving using a driver simulator. ${ }^{48}$ They observed longer reaction times to traffic lights, irrespective of hand-held or hands-free devices. Similarly, another driver simulator-based study by Strayer et al. (2003) observed that using hands-free devices for conversation increased reaction times when stopping at intersections due to reduced visual attention. ${ }^{49}$ 
Choudhary and Velaga (2017) investigated the effects of talking and texting on driving behavior in a suddenly arising situation (pedestrian crossing) using driver simulator. ${ }^{50}$ Mean speeds were observed to reduce if the drivers were on phone, while the probability of a crash increased by three to four times. Strayer and Drews (2004) observed that the effect of cell phone conversations was higher on young drivers compared to older drivers. ${ }^{51}$ In another study, Strayer et al. (2006) observed that the drivers were involved in comparatively higher number of crashes when talking on cell phones due to decreased reaction times to braking, while intoxicated driving led to smaller headways from leading vehicles. ${ }^{52}$ Overall, the effect of using a phone and intoxication were observed to have similar effects when driving conditions and time to task were the same in their study. Further, text messaging was also observed to constrain driver attention to braking lights, significantly leading to crashes (Drews et al., 2009)..$^{53}$

Lundgren and Tapani (2006) investigated the safety effects of ADAS using a driver simulator. ${ }^{54}$ They observed that the functionalities of ADAS and changes in driver behavior for ADASequipped vehicles could affect safety. Driver-vehicle behavior was observed to substantially affect safety. van Driel et al. (2007) evaluated the effectiveness and acceptance of congestion assistant using a driver simulator. ${ }^{55}$ They observed improved driver safety behaviors when approaching a traffic jam. Lee and Abdel-Aty (2008) captured driver responses to warning messages and VSL using a driver simulator. ${ }^{56}$ They observed that variation in driving speeds reduced, leading to better traffic flow and reduced congestion.

Hoogendoorn and Minderhoud (2002) investigated the effects of intelligent cruise control and intelligent speed adaptation on driver behavior. ${ }^{57}$ They observed improved capacities and reduced reliability at bottlenecks when cruise control was engaged, while intelligent speed adaption did not improve capacity and reliability. Martin and Elefteriadou (2010) researched the effect of ADAS on driver behavior using a driving simulator. ${ }^{58}$ They observed changes in driver behavior when using vehicles equipped with ACC and lane-changing on arterials/freeways. Calvi and Blasis (2011) evaluated driver behavior when using acceleration lanes. ${ }^{59}$ They observed that merging behavior was dictated by the traffic volume on main roads and not the length of the acceleration lane. Son et al. (2011) assessed the effect of voice recognition system on driver distraction, especially for older drivers. ${ }^{60}$ The distraction effects were evaluated for both urban and highway sections, and it was observed that both age and environmental conditions affected driving behavior when the driver had to perform two tasks.

Maag et al. (2012) investigated the effects of ADAS on drivers using single and multi-driver simulators. ${ }^{61}$ They evaluated the effects of merging systems and advanced warning systems and supported the use of multi-driver simulators to understand and capture driver behavior. Saleh et al. (2013) examined the compatibility of driver and ADAS with LKA using driver simulator. ${ }^{62}$ They observed improved lane keeping when the system was engaged, despite varied driver behavior. Aziz et al. (2013) investigated the understanding and effects of LDW on driver behavior using a driver simulator. ${ }^{63}$ They found that the dynamic nature of the driving environment could limit the driving cognitive model leading to cautious driving scenarios that could result in a tragedy, irrespective of any secondary tasks performed by the drivers.

Rommerkirchen et al. (2014) investigated human-machine interactions to understand the effect of ADAS on drivers using a driver simulator. ${ }^{64}$ They observed that game-time (interaction) reduced in complex driving situations. In a similar study, Biondi et al. (2014) investigated the effect of a beeping ADAS on driver behavior using a driver simulator..$^{65}$ They observed that the beeping 
sounds disrupted the vehicle trajectory as the drivers deviated from the lane. They observed such sounds to be distracting for the driver in contrast to their original functionality.

Using a low fidelity simulator, Spivey and Pulugurtha (2016) evaluated the visibility of twowheelers encountered by left-turning motorists at urban intersections in nighttime conditions, compared to other hazards. ${ }^{66}$ The observed response times to a two-wheeler were not different from the response times to a passenger car with two headlights. However, the response times were significantly shorter than the times to recognize no hazard or a two-wheeler with no headlight. Differences were observed when response times were compared for daytime and nighttime conditions.

Gaspar et al. (2016) evaluated the impacts of FCW and LDW on driver behavior using a driver simulator. ${ }^{67}$ They compared the effects on both distracted and undistracted drivers and observed that the driver behaviors fell into categories based on distraction. Significant variation in driver lane-changing behavior was also observed in their research. Mas et al. (2011) investigated the effect of lateral control assistance systems on driver behavior in avoiding obstacles using driver simulator. ${ }^{68}$ They observed an equal effect from both assisted and non-assisted drivers in avoiding obstacles. However, the lateral control assistance system contributed to faster reaction times. Witt et al. (2018) investigated the effect of drivers' characteristics and personality on their driving behavior using virtual and driving simulations. ${ }^{69}$ They attempted to develop a driver cognitive model to help design ADAS. Phone use was found to significantly affect driving for both younger and older drivers, with younger drivers having a higher crash risk compared to experienced drivers. ${ }^{70}$

\subsection{Effectiveness of ACC and LKA}

ACC maintains a designated speed and distance for a vehicle with respect to its leading vehicle, while the LKA ensures that the vehicle stays in its respective lane. Consumer Reports (2017b) considers ACC to be more of a luxury feature than a safety feature due to its functionality. ${ }^{71}$ Combining ACC with other ADAS may mask the minimal effectiveness of the system. Further, ACC functionality seems to vary across automotive make. ${ }^{72} \mathrm{ACC}$ has been observed to be jerky with acceleration and braking maneuvers, and its response to already stopped vehicles was identified as a limitation. Additionally, it was observed that drivers with ACC were driving at higher speeds compared to drivers without ACC. ${ }^{73}$

Similarly, there are anticipated advantages and limitations of the LKA feature. The LKA and LDW were expected to mitigate over half a million crashes in 2016 alone. ${ }^{74}$ The LKA performs a lane keeping test every five to fifteen seconds and provides a stipulated steering torque to maintain the vehicle in its lane, allowing the driver to take over if required. ${ }^{75}$ It is expected to have significant effects on safety especially on run-off and head-on crashes. ${ }^{76,77}$ It is estimated that a $100 \%$ effective lane departure prevention system could reduce single vehicle run off crashes by $65 \% .{ }^{78}$

The ACC and LKA features in combination control both the longitudinal and lateral movements of a vehicle and provide a basis for a more advanced automated driving version. The reliability of drivers on these systems also plays a vital role in their effectiveness, as it dictates the attention they are paying while driving. Many studies have highlighted the direct impacts of these features but a deeper understanding of their effects on driving behavior needs to be investigated. This will help 
establish parameters that can be used as inputs to evaluate the effects of vehicles with advanced features in a traffic stream using microsimulation software.

\subsection{Limitations of the Past Research}

Extensive research has been done on the effect of various tasks that could influence driver behavior. Various methodologies have been adopted to investigate the effects of advanced features in a vehicle on driver behavior. Methodologies employing surveys and mathematical models generally aimed to research the adaptability of the methods in modeling driver behavior, although some focused at studying the acceptance levels of different ADAS. Some of these studies were also focused on predicting driver behavior, which yielded reasonable results. However, these methods often rely on self-reporting and the participants could be biased when answering the questions, especially when they are being scrutinized by another person.

Field test methods were explored to capture driver behavior and drivers' acceptance of advanced features in some cases. Some researchers looked at the acceptance rates of different advanced features based on age and gender, while a few others focused on the effect of advanced features on driving behavior. Similarly, driver simulator studies have been conducted to examine the effect of advanced features in certain conditions. Most of the driver simulator studies did not take demographic characteristics into consideration, nor did they compare participants from two demographic groups (young and old).

Previous studies have also been hypotheses driven, leading to concentrated research with reduced applicability. Another limitation of past studies is the investigation of only one or two ADAS at once. This study focuses on capturing driver behavior in various driving situations and also includes different types of advanced features to reach meaningful conclusions. The findings can be used to develop driver models that can be applied in many cases. Driver simulators provide a perfect platform to model various driving conditions and ensure precision. The results can then be used to develop an accurate model of driving behavior. 


\section{Driver Simulator}

The National Advanced Driver Simulator (NADS) miniSim ${ }^{\mathrm{TM}}$ was used for this study. Developing the desired conditions in the driver simulator involves multiple processes. Figure 2 depicts a flowchart summarizing the processes of developing simulated driving scenarios.

Figure 2. Functional Flowchart of Driving Simulation Development

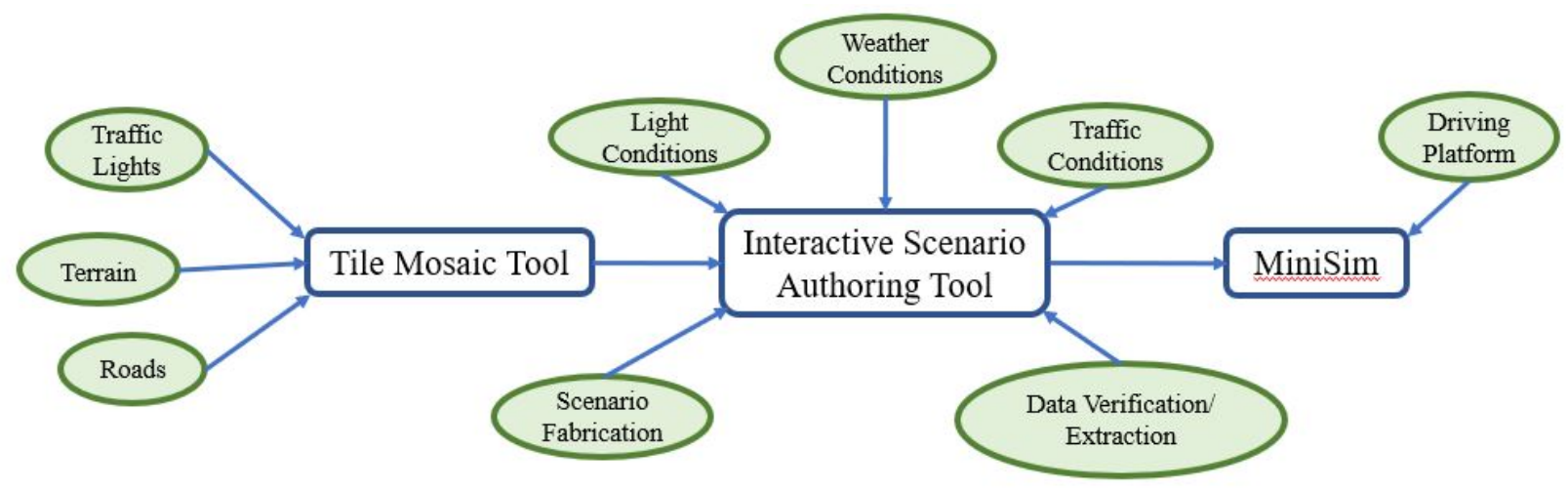

As displayed in Figure 2, three tools are required to develop the final driving simulation scenarios. The initial step involved developing a road network, which is handled in the Tile Mosaic Tool (TMT). The initial road network along with terrain conditions was built in the TMT. After developing the road network, it was imported into the Interactive Scenario Authoring Tool (ISAT). This tool allows users to define various driving conditions including weather conditions (rain, snow, fog, or clear weather), lighting conditions (day or night), traffic lights, or for a specific type of vehicle with a desired level of traffic. The output file from ISAT is then imported into miniSim $^{\mathrm{TM}}$ which then simulates the scenario to test driving behavior. The development process to attain the final simulation product based on guidance documents from the University of Iowa, $2016^{79}$ is discussed next in detail.

\subsection{Tile Mosaic Tool (TMT)}

The TMT allows users to generate world or database files. The world files are constructed using tile models, where each tile model contains information about the roads, the terrain, and feature objects. Placing tile models adjacent to each other in a desired pattern forms a road network. There are multiple categories including city, commercial, fillers, freeway, industrial, mountain, railroad, residential, rural, urban, special, and suburb. The tiles are named for the type of road they depict. For example, freeway tiles contain roads that replicate freeway conditions, whereas residential tiles represent local roads that are typically found in residential areas. Commercial tiles have terrains with commercial blocks with trading and shopping locations. Filler tiles can be used to fill in gaps between other tiles, varying from small road sections to intersections. Special tiles are similar to filler tiles and create locations such as interchanges. 
The TMT offers several types of roads that can be observed in the real-world, while also providing special tiles that create conditions such as snowy or wet roads. The tiles also display road markings, terrain conditions, and vegetation, and more complex tiles display both traffic signs and control devices such as signals and stop/yield signs. Figure 3 shows a screenshot of a road network created with a set of tiles.

Figure 3. Screenshot of a Sample Road Network in the TMT

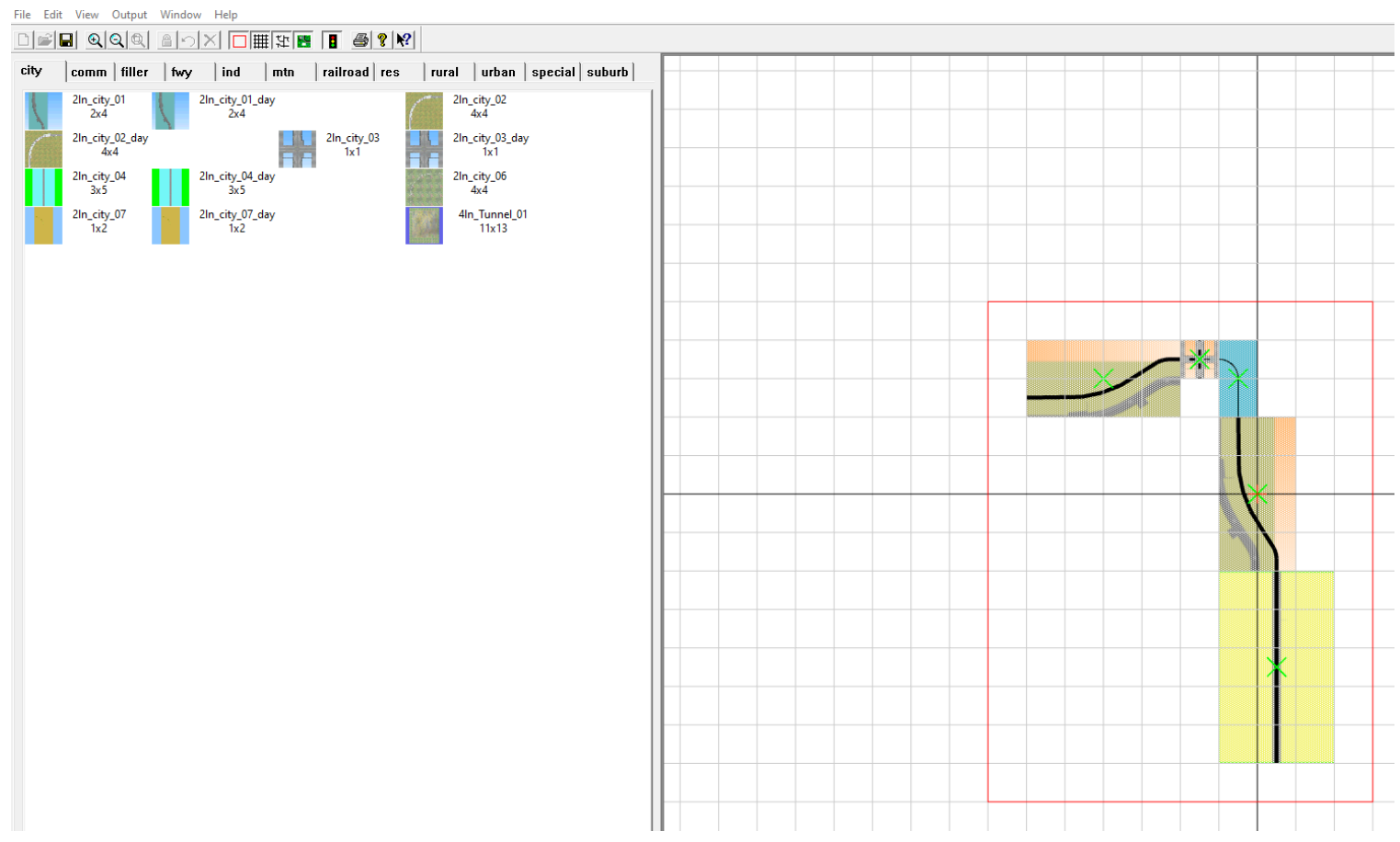

As depicted in Figure 3, the tiles need to be attached so that roads align and there are no gaps when they are visualized in the driver simulator. The road section in the blue tile is thinner than the adjacent tiles, indicating a two-lane curved road connected to four-lane roads at each end. This may lead to small inconsistencies in visualization and proper care needs to be taken. The boundary of the tiles is displayed with red lines using the red square symbol in the menu bar.

The grid in the background helps place tiles easily when developing a network file and can be activated using the grid symbol. However, it is important that the tiles are created while developing the world files within the TMT so that they can be adjusted in ISAT before the simulation. The green cross seen in the tiles indicates that they have been created in TMT and can be activated using the traffic light symbol. For example, changing a Stop sign to a Yield sign or assigning signal timings.

TMT is initially set up as a grid on which the tiles are placed. There are a few important points to be remembered while developing world files in the TMT. Firstly, not all tiles can be placed adjacent to each other. For example, one cannot place a two-lane rural road tile adjacent to a fourlane urban road tile. A dialog box with the list of compatible tiles with their categories, rotation, and size is displayed when the right mouse button is pressed after selecting the adjacent tile, which 
is then added from the list. A non-compatible tile may also be added forcefully by pressing the Shift key. Some issues, such as a gap showing empty space or a failed visualization may occur in such cases.

There are certain tiles that have unique controls, such as tiles that contain traffic signs, traffic lights, or road signs that need to be changed in ISAT or while visualizing. For example, all the roads are given the same road name in the default condition that can be changed while visualizing. Similarly, speed limit signs can be altered to change speed limits. To edit the tiles, the unique controls need to be enabled in the TMT by clicking the right mouse button and selecting the appropriate option. After the completion of a desired world file, a set of commands need to be run in the "command prompt" window that generates a set of visual and logical files to capture information from the TMT. It is important to generate both visual and logical files in the same session to maintain consistency of information and avoid any mismatches. The TMT tool generates a file in the ".mos" format, or the mosaic file. This mosaic file is then imported into ISAT for further development.

\subsection{Interactive Scenario Authoring Tool (ISAT)}

The ISAT puts together all the information designed by users and generates a scenario file (.scn) that can be imported into miniSim ${ }^{\mathrm{TM}}$ for simulated driving. Additionally, the ISAT is also capable of extracting data from the final output files. Developing a scenario file involves multiple processes, which starts with defining the traffic conditions. Figure 4 shows a screenshot of the same road network imported into the ISAT. The task bar to the left shows a list of different elements that can be added into the scenario using icons available in the menu bar at the top of the screenshot.

The icons highlighted using the gray circle deal with the navigation through the map or network, including zooming in or out, viewing the entire network, finding any element, or using the undo or redo options. The icons highlighted by black circle show the different modes offered by the ISAT that allow users to play, record, and analyze driving conditions. The red circle highlights icons that are used to add dynamic and static objects such as vehicles, traffic signs, and virtual objects to the simulation. The blue circle shows icons that represent different types of weather conditions such as rain, snow, lightning, and fog. The green circle represents triggers that are used to simulate driving, while the orange circle shows the traffic and traffic light manager that controls traffic in the simulation, as desired by the user. The boxes by the side of the road network add certain actions into the scenario. 
Figure 4. Screenshot of a Road Network in ISAT

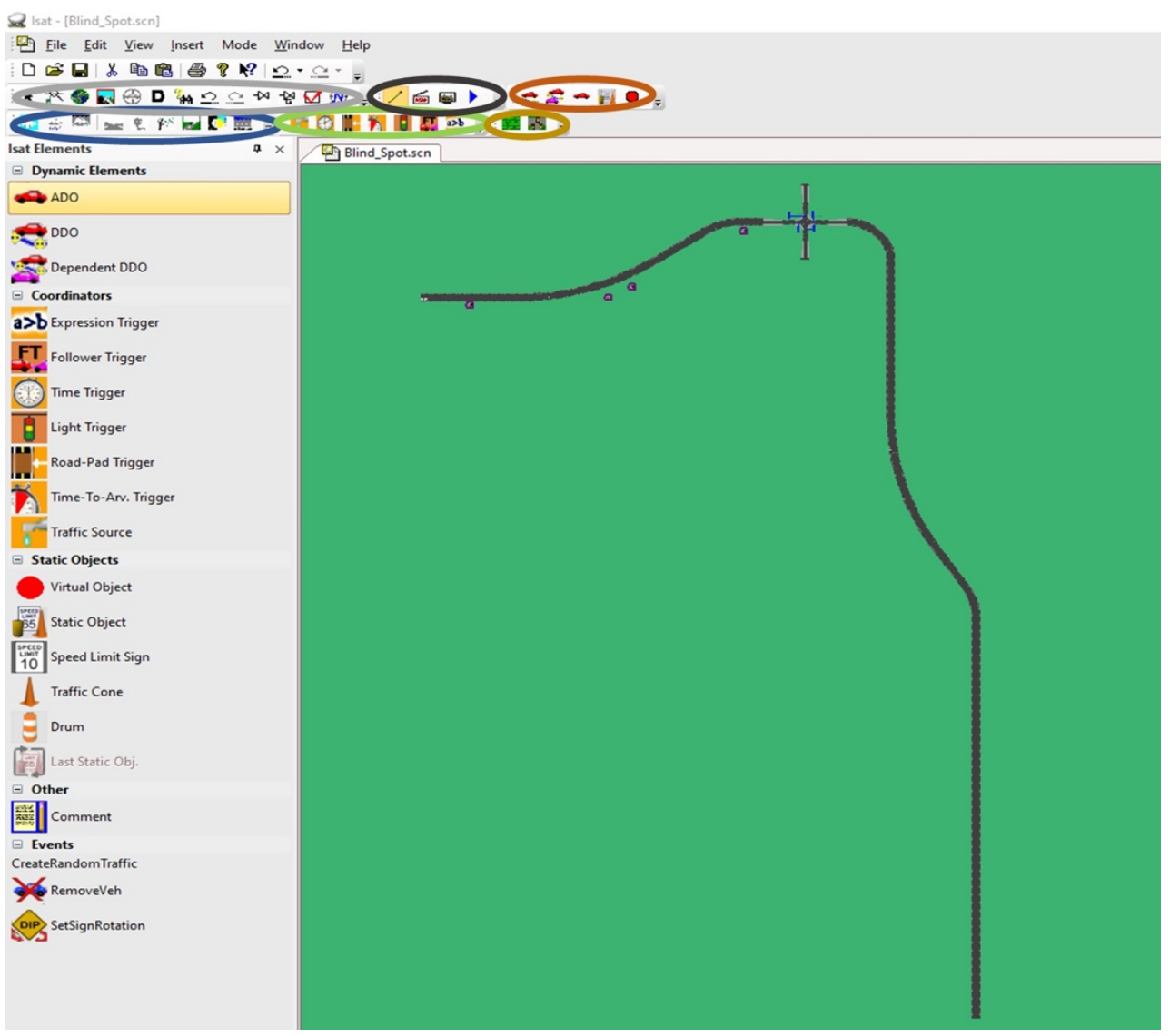

\subsubsection{Traffic Condition}

The ISAT allows users to select pedestrians or any type of vehicle ranging from bicycles to trains. Additionally, multiple features such as color, speed, tire condition, brake condition, etc. can also be specified. ISAT also allows users to also select the type of drivers in the vehicles, which are in turn deemed to be dynamic objects in the ISAT.

There are two types of dynamic objects that can be added into a scenario. The first type is the Deterministic Dynamic Object (DDO) whose actions are pre-determined by the user. These objects simply follow a path that is pre-defined and the speed of the DDO can be set at each node of the path. These objects do not follow traffic rules and cannot avoid collisions and as such, can be called intuition-less objects. The second type of dynamic object is the Autonomous Dynamic Object (ADO). These objects resemble human drivers and follow traffic rules. However, they can be instructed to perform certain actions that defy the traffic rules.

Adding each vehicle individually in the scenario is a tedious and time-consuming process. The ISAT offers a "traffic source" option that allows users to add multiple vehicles at regular intervals throughout the simulation from a designated point in the network. Multiple vehicles can be added to each traffic source in a loop. For example, if five vehicles are added to a traffic source, it generates the same five vehicles once it has generated all of them. 
Pedestrians can be added into the scenario as DDOs, defining their path to cross a road. There are multiple ways to generate an object in a simulation. By default, the simulation generates objects at the start, but this may not work under some conditions. For example, if the user wants to simulate a pedestrian crossing the road at a mid-block section when the driver is at the location, the default case may generate the pedestrian as soon as the simulation starts, and the pedestrian may have already crossed the road by the time the driver reaches the specific point. To overcome such challenges, the simulation can also delay the generation of the object. There is an "activation delay" option available when adding objects to the scenario which allows the object to be generated after a specified period of time. This is a good approach; however, the driving time may differ from one driver to another driver, thus each driver may be at a different point in the simulation at the given time and as such the previously mentioned simulation may work only in some of the cases. The third way of generating an object in a simulation is to define the "creation radius" of the object which works with reference to the location of the external driver in the simulation. This ensures that a desired scenario is executed in reference to the location of the driver.

The lifetime option allows users to determine how long an object remains in the simulation. For example, a car may be temporarily inserted behind another vehicle to create a lane-changing scenario. Static objects can also be added into the scenario to convey additional information like the speed of the road, traffic cones, warning signs, etc. While the TMT already provides sign information (speed, curve, etc.), more can be added using static objects if the user feels they are not abundant enough. However, it is important to remember that these only provide visual information and do not play a role in defining the simulation's behavior. For example, if an ADO is set to follow the speed limit, it follows the speed limit set on the default signs imported from the TMT.

The next step in defining traffic conditions is to allocate the traffic signal split times. Figure 5 shows a screenshot of the "traffic light manager" which shows a list of all the traffic signals available in the network. The user can configure the desired number and duration of states using the "add state" option. It is important to remember that when a light is green, only its complementing light or all the other lights are red. Figure 5 depicts a traffic signal head-which controls traffic movements - on the right side. This helps users to determine the cycle of the traffic signal. The other signal heads turn red when one is green or yellow.

While this scenario only contains one traffic signal, this window shows all the available signals which can be assigned cycles as necessary, turned off, or triggered when a driver is nearby, at a distance determined by users.

\subsubsection{Weather Conditions}

The ISAT allows the user to select weather conditions from rain, snow, fog, and lightning. Further, the ISAT lets users simulate weather conditions at specific stretches or for the whole network route. Upon selecting the weather option, the user can draw a polygon to define the area. Varying levels of intensity (for example, light $\mathrm{v}$. severe rainfall) are also configurable options. 
Figure 5. Traffic Light Manager for Four-legged Intersection

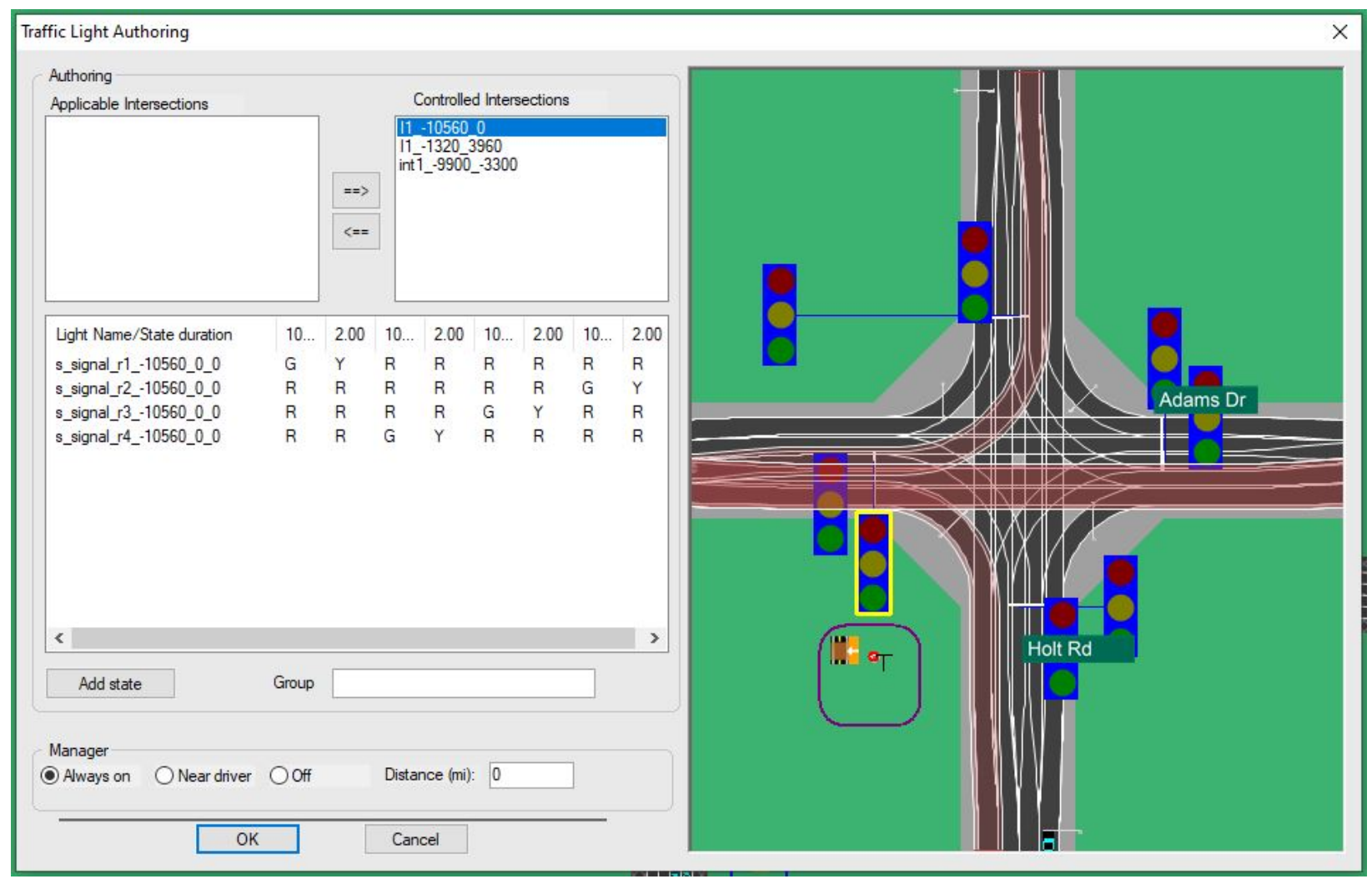

\subsubsection{Light Conditions}

The "initial conditions" tab allows users to configure light conditions according to time of day. This is where other vehicle conditions of the external driver can be specified as well. Light conditions cannot change during a simulation and remains constant throughout. The properties tab allows users to configure headlight options for all the vehicles in the scenario.

Figure 6 shows the "initial conditions" tab that allows users to configure the light and vehicle conditions. The first option is to select the type of vehicle and users can choose between cab and trailer options for certain types of vehicles.

Users can also configure tire and brake conditions, with four and three options respectively. The headlights of the vehicle can also be turned on in the "initial conditions" tab and configured as well. The vehicle can also be assigned a failure type that allows users to observe behavior of participants in failed conditions. The simulation can also be prompted to stop on the detection of a collision. Light conditions and the date of the simulation can also be changed. 
Figure 6. Defining Initial Conditions

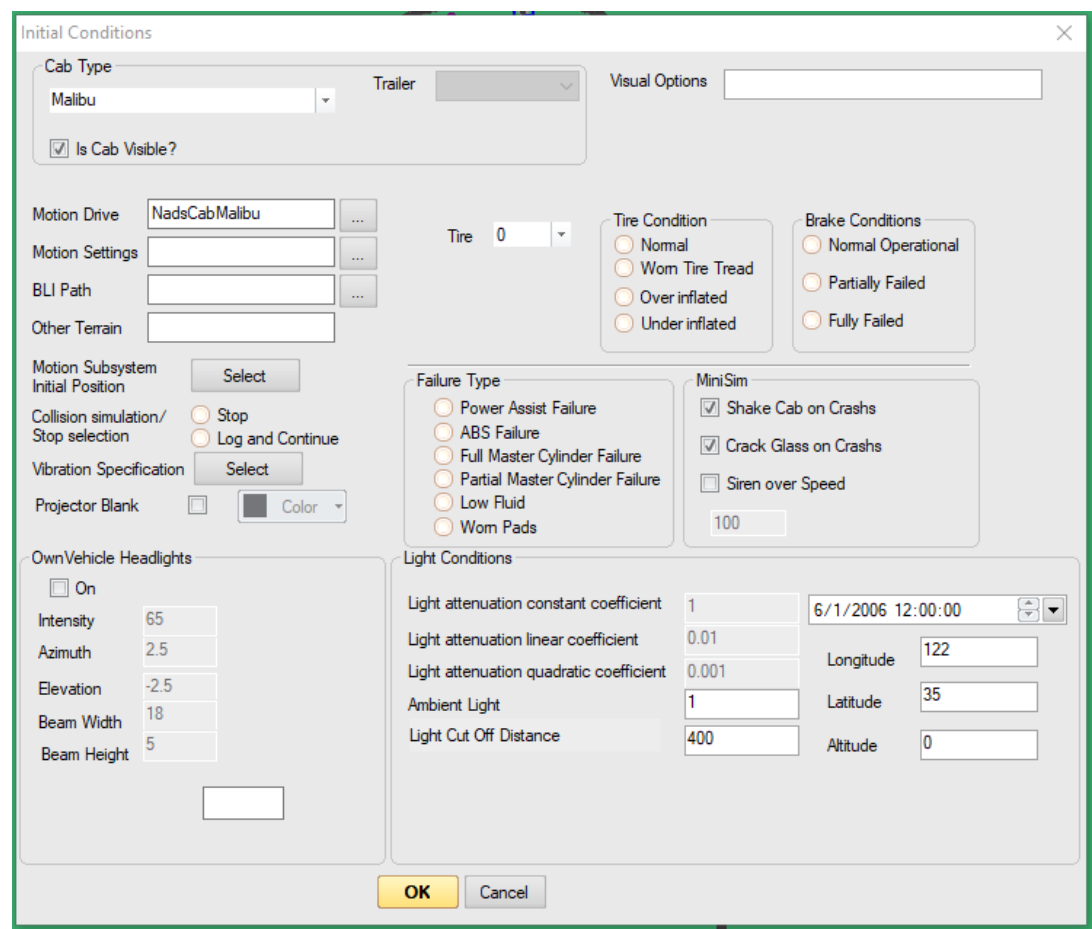

\subsubsection{Scenario Fabrication}

After all the required elements have been added, the simulation conditions can be fabricated as desired using triggers. While all the previous sections simply add elements to the simulation that would just normally follow the pre-defined rules, this is where they can be instructed to perform certain actions that would help create testable driving conditions for the participants. There are different types of triggers that perform various functions. A few terms that help define the actions associated with triggers are: firing which refers to performing any action defined by a trigger; target set is any set of elements that would be affected by the trigger's action; and instigator set is the set elements whose actions fire a trigger.

The ISAT offers six different types of triggers that can be used to define the actions for various elements in a simulation. They are the global time trigger, roadpad trigger, time to arrival trigger, follow trigger, traffic light trigger, and expression trigger. Figure 7 shows an image of a roadpad trigger. 
Figure 7. Roadpad Trigger in ISAT

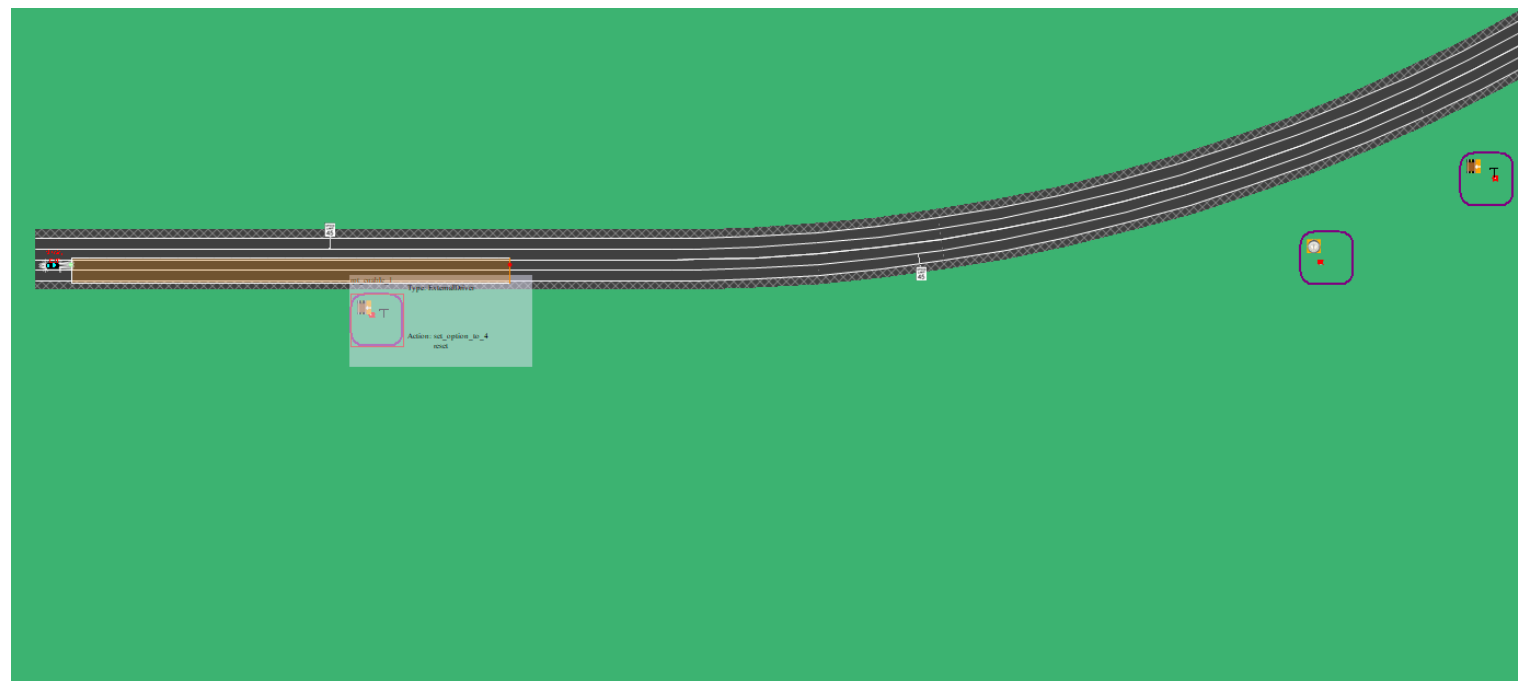

In Figure 7, depicts the roadpad which fires when the vehicle is on the pad. The roadpad needs to be placed on the driver side to trigger the action while the external driver is placed on the road before the roadpad. Other triggers can also be observed to the right of the image. Additionally, there are a few more settings that can be explored related to each type of trigger.

Figure 8 shows the steps involved in setting up a trigger, which in this case is the roadpad trigger. There are four tabs in a trigger window. They are predicate, general, action, and comment. The instigator set can be assigned in the predicate tab which could be a designated ADO, the external driver, or any other desired element in the scenario.

Figure 8. Setting up a Trigger
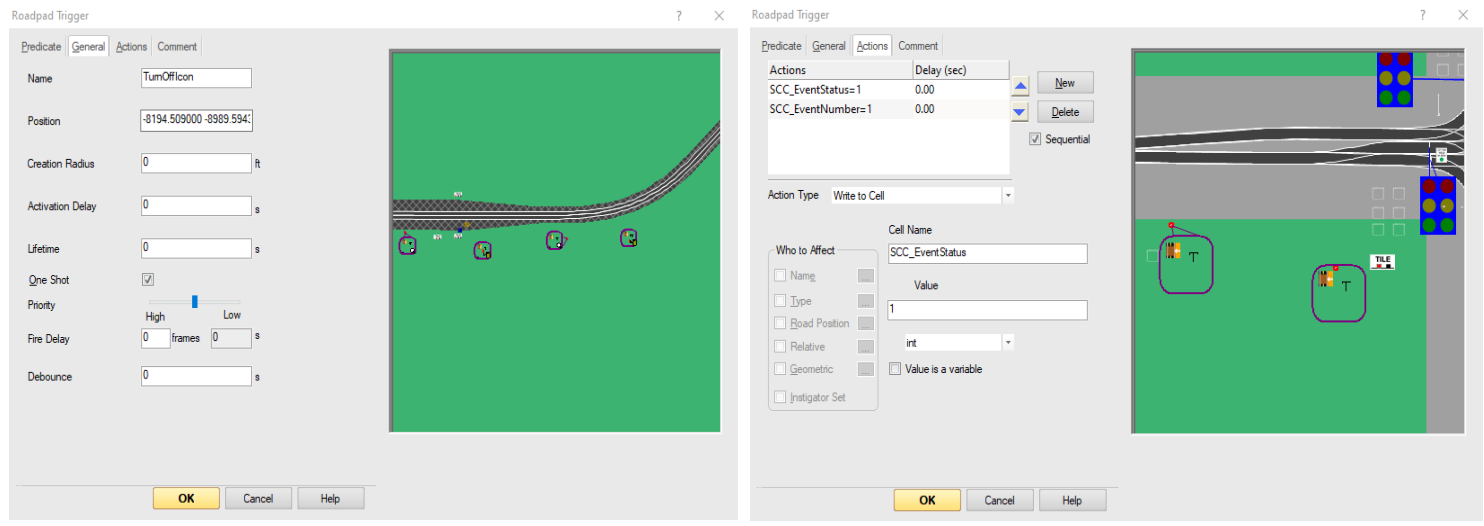

Figure 8 depicts the general tab on the left-hand side. The one-shot option deletes a trigger from the simulation after an action has been fired once. The fire-delay option can be used to delay the actions that are fired by a trigger until after all the necessary conditions are met. The default value used by the ISAT is "0", which immediately fires the actions. A trigger can be prompted to perform an action multiple times during a simulation using the debounce option. The default value is usually set to " 0 " and can be changed as required, which dictates the time gap between each action. The effects of activation delay and creation radius options were discussed previously and the action 
tab defines the action that need to be fired by the trigger, which prompts the system to capture the event information in post-simulation reports. The comment tab allows users to make notes for future simulations or other users. When there are multiple triggers in a scenario, they can be assigned priorities, allowing one trigger to fire after another.

The global time trigger follows the time of the simulation and fires when the simulation reaches a specific time. This trigger does not require any other settings by the instigator and solely follows the clock. The roadpad trigger designates actions to objects at certain points in the road. Actions can be specific to certain objects-for example, if the user requires a vehicle to drive in the opposite lane, they can name and add an ADO to the trigger so only that vehicle performs the specified action. The time to arrival trigger is very similar to a roadpad trigger but in addition to a pad, the time taken by the instigator set to reach a designated point is less than or equal to a defined value. These triggers are typically used to create near collision scenarios. The follow trigger allows the user to define the firing conditions when a vehicle follows another vehicle for a specified period and distance. In this case, the instigator set could be either the leading or the following car. The trigger also allows users to define tolerance levels in the specified values, and also enables the vehicles to follow the same or different lanes.

For example, this function can be used to generate a BSW condition in the simulation. The traffic light trigger performs actions that area fired based on signal changes. In this case, the traffic lights in the scenario make up the instigator set. Users can select the traffic light and define the color (green, red, or yellow) to trigger an action. In addition to all the aforementioned triggers, small expressions can also be written in the scenario using the expression trigger where the system can be prompted to read if a value is equal to, more, or less than a defined value for a variable. This trigger can be fired at the beginning of the simulation or by a creation radius. For example, an expression trigger may be used to alert a driver if they cross a speed limit.

\subsubsection{Data Verification/ Extraction}

The ISAT allows for the verification of created scenarios and the extraction of data from the simulation. The ISAT provides four different modes that target different levels of scenario development. The authoring mode enables users to add new elements to the scenario or edit the existing elements. The rehearsal mode generates a walkthrough of the conditions in a scenario. The rehearsal mode runs the scenario on the ISAT platform using an autonomous driver model and any element can be followed. Since the driver is an autonomous model (similar to an ADO), it is more precise than a human participant in the simulation.

The driving behaviors and dynamics are stored as frames that encompass a defined time-period of the run and a collection of such frames is called a buffer. The ISAT also allows users to record the rehearsal to be stored for reference in the future. The ISAT also plays the simulations that were driven by human drivers in $\operatorname{miniSim}^{\mathrm{TM}}$ to observe and extract data from the files. The simulations are then stored as data acquisition (DAQ) files that can be imported into the ISAT using the playback mode. Additionally, the movie option records parts of simulations that capture desired time frames. The ISAT also displays certain variables of the external driver during the playback to observe how their behaviors were changing at any point of interest. As previously mentioned, the behaviors are stored as frames which can be searched for information or conditions. For example, the frames could be extracted if speed limits exceed a certain value. The ISAT offers multiple 
variables that can be extracted from the simulation DAQ file using the playback mode. It can also be exported in various formats.

\section{$3.3 \operatorname{miniSim}^{\mathrm{TM}}$}

Along with participant simulations, $\operatorname{miniSim}^{\mathrm{TM}}$ offers several options that can be handy for users. Every simulation automatically generates DAQ files with time and date stamps. In addition to this, a text file is generated that can capture eleven different variables. The authoring needs to be done in the ISAT to prompt the capture of the variables. However, only up to twenty events can be captured by this method. The driving report can be viewed immediately on the screen at the end of a simulation by selecting the option in $\operatorname{miniSim}^{\mathrm{TM}}$.

MiniSim $^{\mathrm{TM}}$ also enables users to specify multiple levels of selection paradigms by defining the priority levels. Additionally, miniSim ${ }^{\mathrm{TM}}$ slows users to select different types of vehicles at the start of the simulation, such as a passenger car, pickup truck, or a luxury car. The default vehicle type assigned to a simulation is a passenger car. Figure 9 shows a screenshot of the window in $\operatorname{miniSim}^{\mathrm{TM}}$.

Figure 9. Initialization Window in $\operatorname{miniSim}^{\mathrm{TM}}$

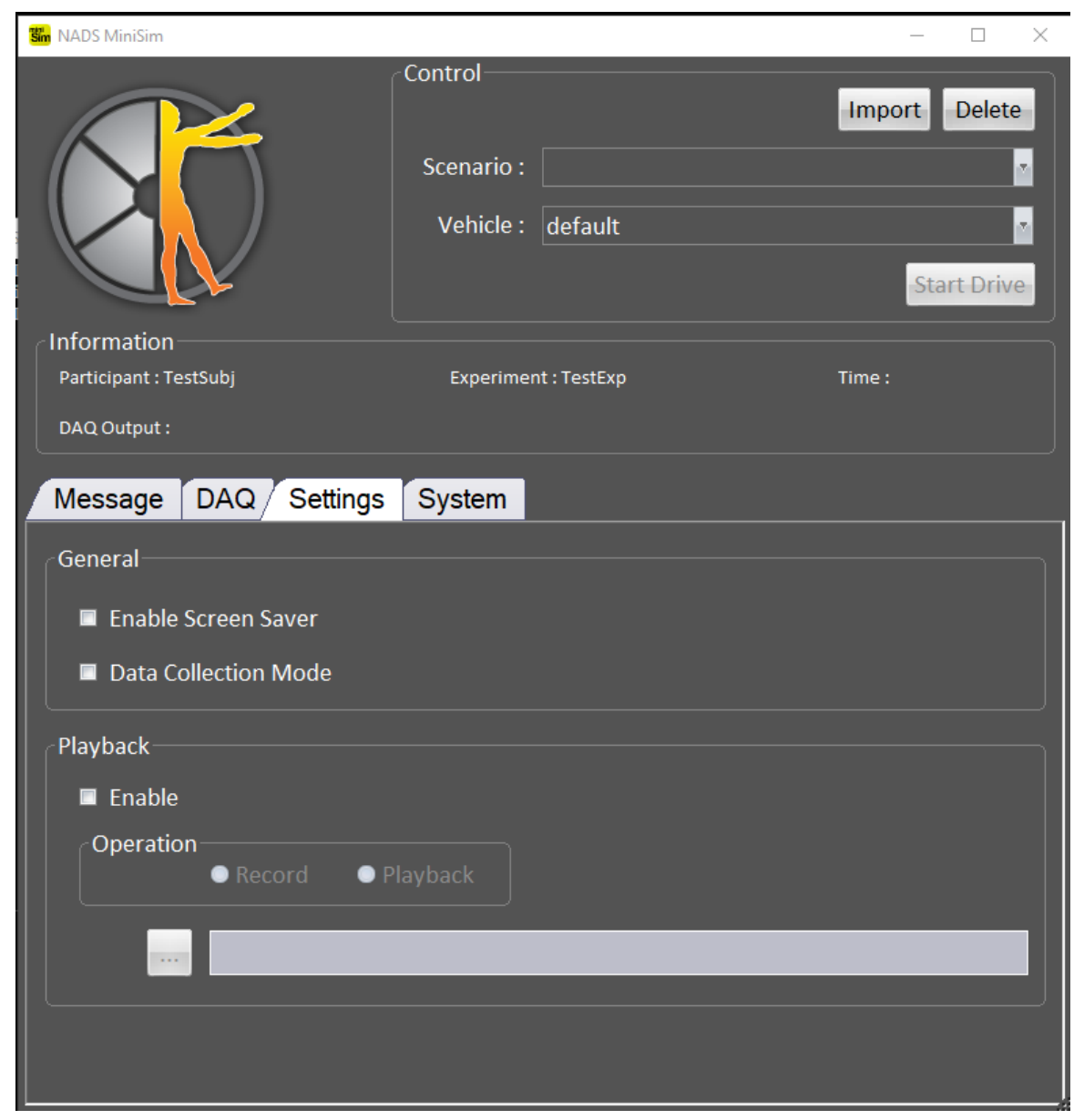

The scenario and the type of vehicle can be selected from the available drop-down menus. The DAQ tab allows users to specify the name of the participant and scenario type. A unique folder is 
created for each participant which is especially helpful when each participant tests multiple scenarios. The DAQ output is generated at the end of a simulation. The screensaver mode simply activates a screensaver when the simulator is not in use. The data collection mode lets users collect data while the playback option lets them record the simulation. The message tab displays the success or failure messages of a simulation. The DAQ tab names the files and segregates them appropriately. The settings tab enables users to select options related to simulation while the system tab indicates that the associated systems are online and communicating.

\subsection{Technical Paradigm}

While the different stages handled by each tool were discussed in the previous section, a set of files carries the information forward, putting together information from these platforms towards a final focal point. This section discusses the technicalities and needs for the three tools to work together. Figure 10 shows a schematic of the transfer of files that handle the data.

Figure 10. Technical Interaction Schematic of the Driver Simulator

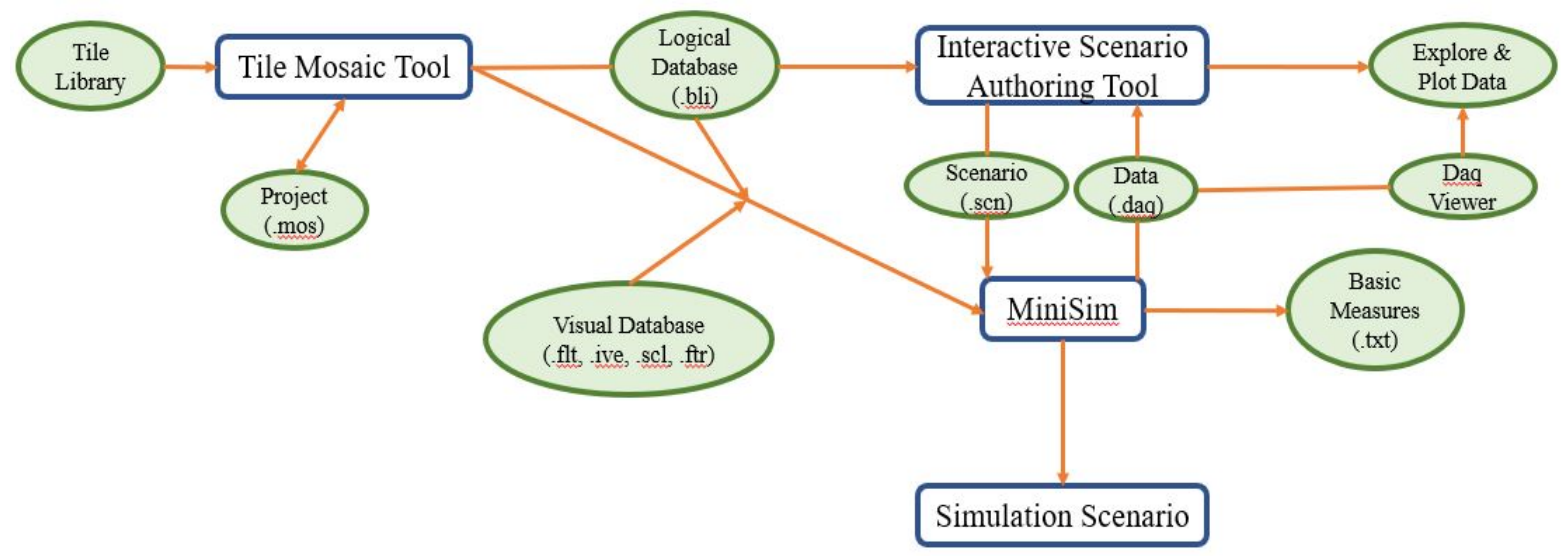

The tile library contains information of different types of tiles offered in the TMT. After putting the tiles together in the TMT, the output generated from the TMT is a project file in the ".mos" format and acts as an information holding file. The information is passed both ways from the TMT to the project files, as depicted in Figure 10. After developing a complete project file, several other files also need to be generated from the TMT to access the data in the ISAT and miniSim $^{\mathrm{TM}}$. One such file created in this process is a logical road information (LRI) file that stores information about the types of roads and the type of authoring that can be allowed for the tiles to be edited in the ISAT. This file is further converted into a binary LRI file called the BLI that stores the same information in a binary format. It optimizes the memory used to store information to be later accessed by the ISAT or miniSim ${ }^{\mathrm{TM}}$.

Other files that are created in the process include a "scenario control list" (SCL) file that summarizes the elements used in the TMT. The open flight or FLT files are necessary to convert the $2 \mathrm{D}$ tiles into $3 \mathrm{D}$ for visualization in miniSim $^{\mathrm{TM}}$. The other file required in this process is the "tile reference" (FTR) file that stores information on tile combinations required to configure a terrain along with the coordinate information, the rotation angle of a tile, and the category of the 
tile. Additionally, the system creates a three-dimensional model binary file (with "IVE" as the file extension) that optimizes the storage of the necessary information for $\operatorname{miniSim}^{\mathrm{TM}}$ to access later. As per Figure 10, the ISAT uses the logical database to carry the operations further as it only handles $2 \mathrm{D}$ portions of the process, while miniSim ${ }^{\mathrm{TM}}$ uses a combination of both logical and visual databases to configure simulation settings.

Additionally, there are many other files that are generated by default when TMT outputs are created. It is important to create both the logical and visual databases at the same time while building scenarios to maintain the consistency of information and avoid mismatches. Although the TMT allows users to copy built tiles from one file to another, copying large files may cause disruptions that needs to be carefully monitored to avoid losing work.

The ISAT uses the BLI file from the TMT to further add additional elements in the functional section. While the BLI files hold the logic of information from the TMT, additional layers are added to the same file to keep the comparative information constant. The ISAT then generates a scenario file that contains the additional information added while pointing to the base file adopted from the TMT. This allows for miniSim ${ }^{\mathrm{TM}}$ to cross reference with the other visual files that are developed in the TMT. This scenario (SCN) file is delivered to miniSim ${ }^{\mathrm{TM}}$ as shown in the flowchart. The miniSim ${ }^{\mathrm{TM}}$ then generates DAQ files that are sent back to the ISAT for analysis. The features and purpose of these files were discussed in the previous section. A DAQ viewer can also be used to explore the data individually as shown in Figure 3.

\subsection{Scenario Building}

This section presents the types of scenarios that were developed for analysis. Three types of setups were developed (urban, rural, and freeway) in the driver simulator, based on common real-world conditions. This ensures results can be attributed to general driving behavior rather than limiting their applicability to only one type of setup. Since this study aims to test the effect of different types of advanced features on driver behavior, various conditions were also simulated. They are discussed next.

- The base condition is the simulation without special conditions. It is a standard driving scenario in urban, rural, and freeway conditions without any advanced features and in daylight with clear weather.

- Varying weather (rain, snow, and fog) was another condition added to one of the base conditions.

- Varying lighting conditions (day or night) were also used in combination with the rainy weather condition. It involved changing the time of day in the initial conditions of a scenario.

- LDW, BSW, and OSW were provided individually and in combination to some participants in different driving scenarios.

- $\quad \mathrm{ACC}$ and LKA were provided to some participants in different driving scenarios. 


\subsection{Driver Simulator}

The driver simulator simulates the driving scenarios which are used to capture driving behavior under different conditions. It resembles the interior of a vehicle to give an accurate driving feel to the participants. Figure 11 shows the driving simulator setup.

Figure 11. Driver Simulator

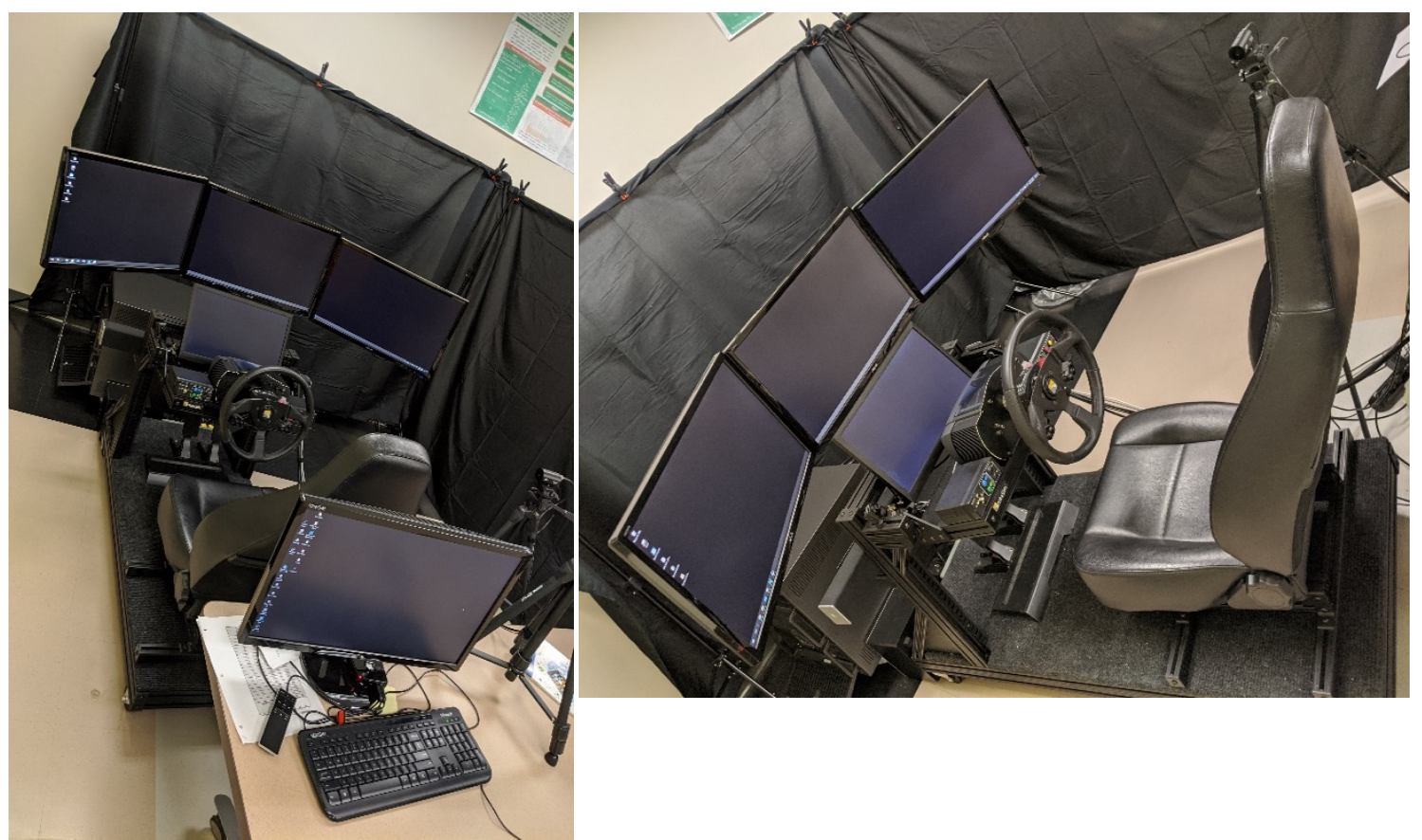

The setup of the driver simulator consists of five screens, seating, and a panel with a driving wheel, brake, and accelerator, as well as buttons that handle certain functions in the simulation. While the tab in Figure 11 is handled on the screen placed on the table in the left picture, the four screens seen in the right picture simulate the scenarios. The three adjacent screens are placed to emulate real-world driving. The screen placed below the three screens displays the vehicle panel and contains the speedometer, fuel gauge, etc. The driving wheel and panel buttons are placed in front of the bottom screen. Figure 12 shows the panel buttons and steering wheel.

Figure 12. Driving Wheel and Panel Buttons
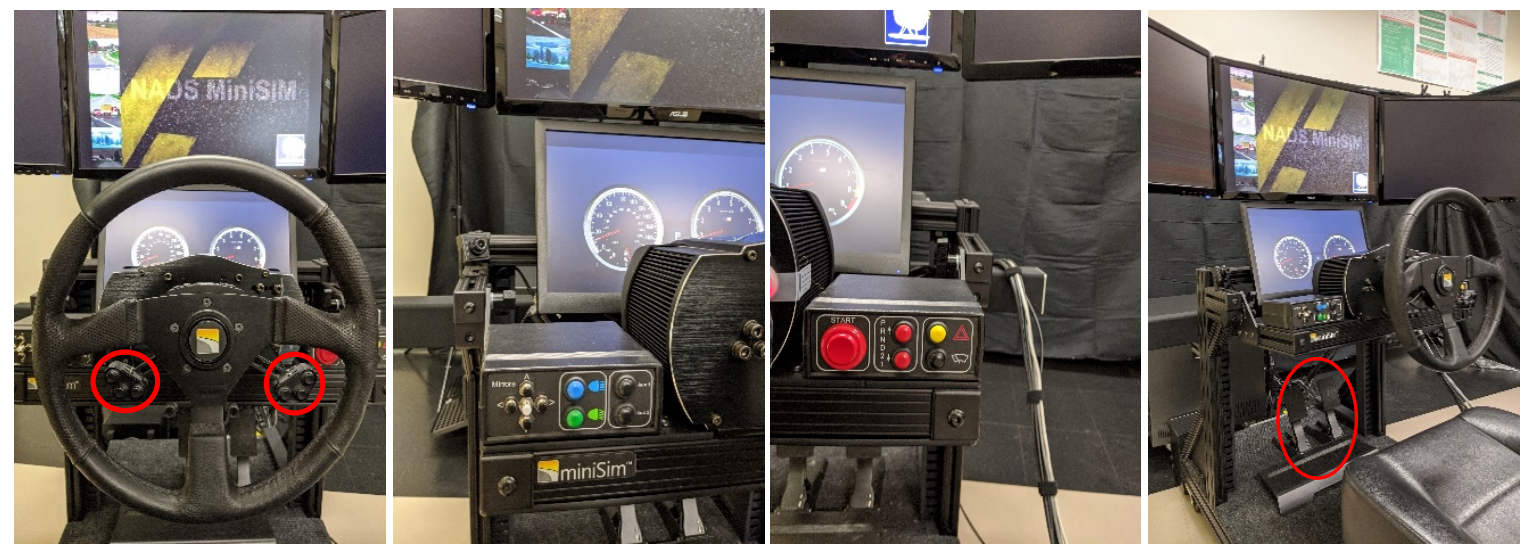
As can be observed from Figure 12, there are multiple panel buttons that handle actions in the simulation. The first picture from the left shows the orientation of the steering wheel within the setup. The two buttons highlighted by red circles in the first picture have three buttons on each side of the wheel. The first button on the top on each side can used for turning signals, the second can be used for making half shoulder checks that pan until the first side window, and the third button can be used for a complete shoulder check/view rotation until the rear passenger window. These can be used in case of lane-changing for shoulder checks.

The second picture shows the left panel which contains the mirror adjustment panel. The white button in the center toggles the mirror selection to left and right, and mirrors can be adjusted using the four surrounding black buttons. The green button is used to turn on the headlights while the blue button turns on the high beam. The two black buttons handle the aux input for two input points.

The third picture shows the right panel buttons of the simulator. The big red button turns on the vehicle in the simulation and a vibration is generated when the vehicle is turned on, like in the real-world. The two small red buttons beside the power buttons allow the participant to switch between parking, reverse, neutral, and driving gears. The yellow button is used for parking lights and the black button is used for wipers. The related symbols are also shown beside each button to provide general information for participants.

The fourth picture shows the brake and accelerator that are set up at the bottom of the screens highlighted by a red circle. They operate the movement of the vehicle in the simulation.

Figure 13 shows the setup of buttons to activate and control ACC and LKA during the simulation. The functions of the buttons as discussed from Figure 12 were revised in order to achieve the functions as shown in Figure 13. Activating one of these systems enables control of the vehicle at a level 1 automation stage, while activating the systems simultaneously simulates the vehicle at level 2 automation stage.

As can be observed from Figure 14, the simulation is set in daylight conditions where the vehicle is stopped at an intersection. The traffic lights are red while other vehicles are crossing the intersection from right side of the driver. The bottom screen can also be seen displaying the panel of the vehicle. The fifth screen in the left picture can be seen recording the time, featuring information on the type of scenario and vehicle as well. 
Figure 13. Buttons to Control ACC and LKA During Simulation

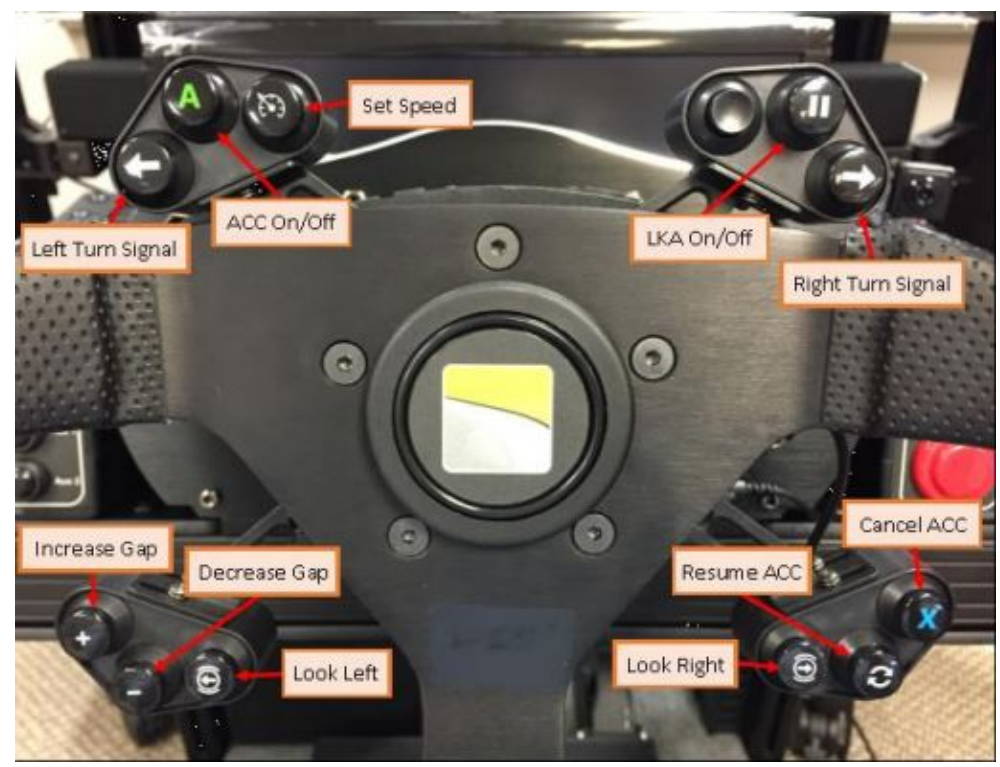

Source: (The University of Iowa, 2016) ${ }^{79}$

Figure 14. Simulating a Scenario in Driver Simulator
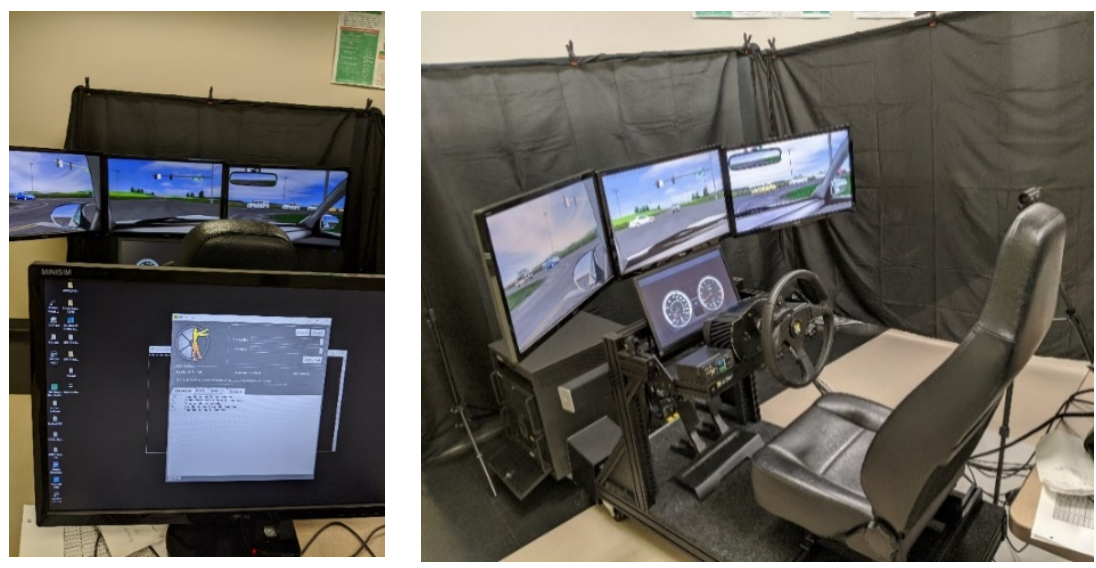


\section{Methodology}

This chapter provides an overview of the methodology adopted for this study. A flowchart of the methodology is presented in Figure 15. The first stage involved developing appropriate driving scenarios. In order to improve the applicability of the results, rural, urban, and freeway scenarios were simulated as these are the typical settings encountered by a driver. The second stage involved the careful selection of driver participants so that the sample population accurately represents the general population. The participants in the age group of sixteen to sixty-five years were selected for the study. Each participant was provided with all three driving scenarios while a vehicle with or without ADAS was allocated to them at random.

The third stage involved data processing and analysis to derive meaningful results. The analysis of variance (ANOVA) test was performed to evaluate the effectiveness of advanced features. Parameters of driver behavior like hard braking, hard cornering, lane departures, speeding events, average headway, and brake pedal force were assessed. The fourth stage involved the identification and application of changes in driver behavior to identify the behavioral differences among vehicles with and without advanced features.

Figure 15. Methodology

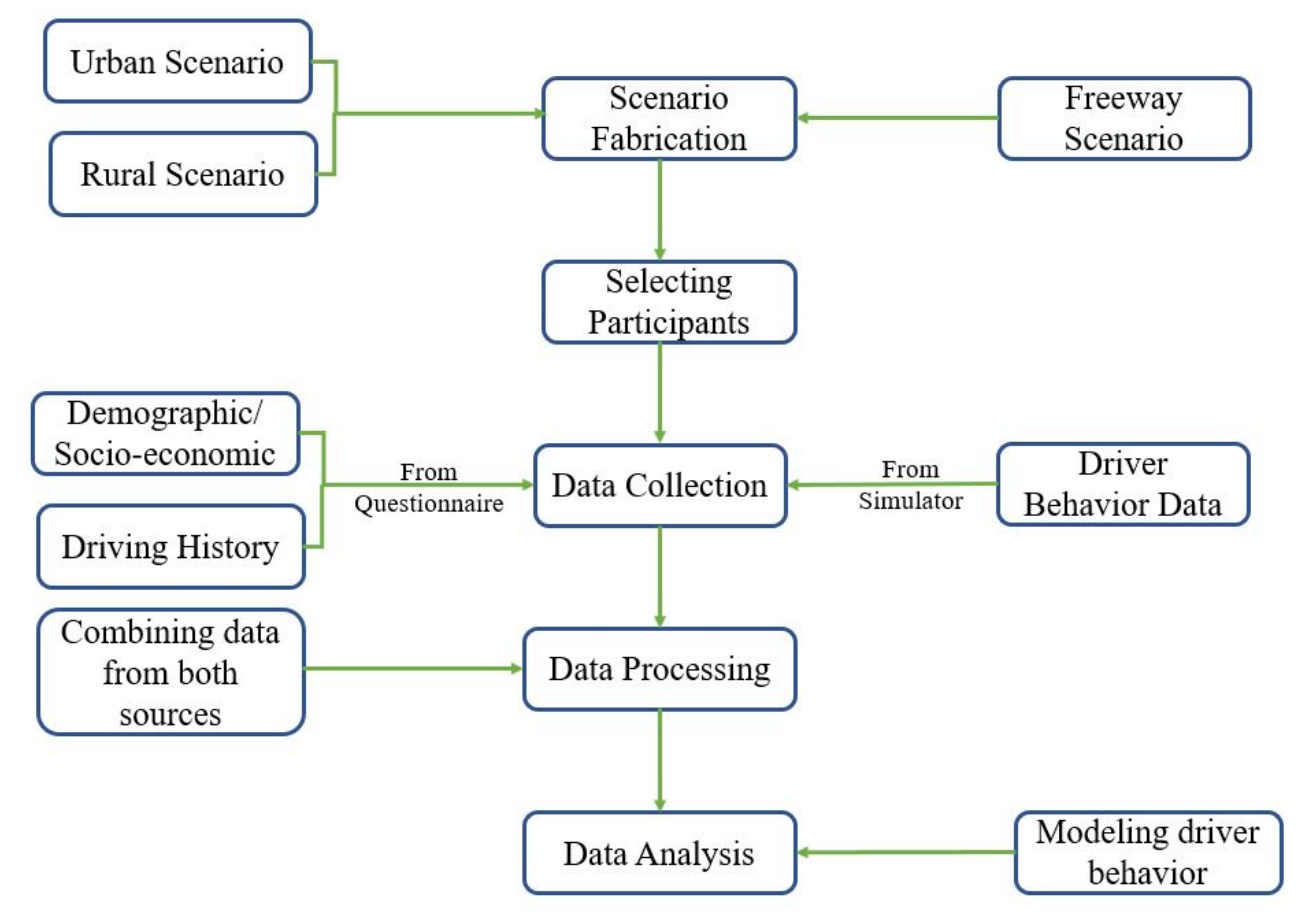

\subsection{Scenario Building and Fabrication}

As stated previously, three types of driving scenarios were developed-the rural scenario, urban scenario, and freeway scenario. These scenarios were developed with the intention of mimicking real-world conditions for the results to be applicable to general driving behavior rather than one type of scenario. Since the focus of this study is to test the effect of different types of ADAS on driver behavior, various ADAS conditions were simulated as follows. 
- The rural scenario was set up with two-lane undivided roads (one lane in each direction) later extending into four-lane undivided roads (two lanes in each direction). The scenario consists of only one traffic signal and one intersection with an all-way stop. The remaining route mostly represents county roads. The vehicles in this scenario consist of passenger cars, pickup trucks, and trucks. The speed limits were set at $55 \mathrm{mph}$. The simulation also consists of a gravel road for a small portion, which was intended to capture driver behavior (changes in speed or braking). This scenario was developed to last for seven to eight minutes.

- The urban scenario was set up for drivers to interact with the elements that are typical of urban conditions, such as traffic signals, passenger cars, trucks, school buses, motorcycles, and pedestrians. The speed limits were set at $45 \mathrm{mph}$ or $50 \mathrm{mph}$. The scenario is developed to last seven to eight minutes and consisted of four-lane roads.

- The freeway scenario was developed to last for six to seven minutes and consists of two interchanges that allow drivers to transition from one freeway to another freeway. The freeways were designed to be four-lane divided roads. The speed limits were set at $65 \mathrm{mph}$ for the first and $70 \mathrm{mph}$ for the second freeway. The vehicles in this scenario mostly comprise trucks and passenger cars. The simulation was set up to force interactions between the drivers and trucks while merging onto highways.

- The scenarios used clear weather and daytime conditions-typically referred to as base conditions - until they were specifically set to display other weather or light conditions.

- The simulator provides the option to add varying weather and light conditions to simulations, such as rain, snow, and fog. Further, varying lighting conditions (dawn, dusk, and night) can also be used during the simulation.

- The primary focus of the study is to evaluate the effect of advanced features on the driver behavior. Therefore, the simulations are generated with LDW, BSW, and OSW as the warning systems. They are used individually and in combination and are then compared to simulations without advanced features. The simulator allows users to assign advanced features to scenarios rather than vehicles which can be enabled via expressions that can be added prior to a simulation. The participants are provided with a vehicle with or without advanced features at random.

- The LDW displays a warning on the screen when the vehicle departs from its lane. BSW displays a warning light on the mirror when another vehicle is detected in a blind spot. OSW displays a text alerting the driver of over-speeding. The speed limit can be set using expressions.

- Additionally, LKA and ACC were provided as a part of the automated systems to the participants which can be activated during a simulation using the appropriate buttons on the wheelbase. Once the LKA is activated, it maintains the vehicle in the travel lane during the simulation. Likewise, ACC maintains a designated headway from the leading vehicle during the simulation.

- The navigation instructions are provided to the participants in text on the driving screen, which represents a heads-up display (HUD). 


\subsection{Selecting Participants}

Permission was obtained from the Institution Review Board (IRB) to conduct this study. Drivers between sixteen and sixty-five years of age with a valid driver's license were determined as the target participant population. The selection of participants was scrutinized carefully such that the sample is an accurate representation of the general population. The selection criteria included many factors, including demographic and socioeconomic characteristics. While the selection cannot be pre-controlled, identifying gaps in the data (demographic and socioeconomic) at every stage of the data collection process and selecting participants to accommodate for the missing data points is necessary. This was done throughout the data collection.

Once a participant was finalized for the study, they were given a small survey that captured demographic information. No personal information was collected in the survey to maintain anonymity. Participants were also informed that their participation was completely voluntary and they could choose to drop out of the study at any point. Similarly, if desired, they were permitted to skip questions in the survey.

Three types of driving conditions were provided for the participants-rural, urban, and freeway. The vehicle type was assigned based on the type of vehicle the participant drives for their regular commutes. This was captured from the responses to the survey questions before the start of simulated driving. The consent forms were provided to the parent/guardian for participants below the age of eighteen.

The survey provided to the participants captured information including their education, income, gender, ethnicity, and driving experience. Along with such information, other information like their driving history (previous crash involvement/ citations), vehicle ownership, and if they have already driven a vehicle with any kind of advanced features was gathered. This type of information was used to account for the driving behaviors based on their previous experience to different conditions.

Other information like alcohol consumption or lack of sleep on the previous day, that could affect the driving behavior were also collected in the survey. The participants were also given consent forms for them to understand their rights before participating in the survey.

\subsection{Data Collection}

This study collected data from two sources that were combined to form a single database. The socioeconomic and demographic data was collected from the survey questionnaire that the participants answered during the simulator study, as depicted in Figure 15. The questionnaire also collected participants' driving history, as well as variables such as age, gender, ethnicity, type of vehicle owned, education, household income, any record of prior crashes or citations, alcohol consumption in last twenty-four hours, hours of sleep, medication, marital status, and any advanced safety features in their personal vehicles. This data was used to determine the type of vehicle and ADAS to be assigned randomly to participants. Data on participants' driving behavior was collected by the driver simulator and extracted using the ISAT via the DAQ file viewer. 


\subsection{Data Collection}

Ensuring that the right data extracted from the ISAT is assigned to the right participant is very vital for the research. Considering the diversity of various variables from the questionnaire, any mismatch of data could lead to faulty results. Each participant was assigned the same ID on the questionnaire and DAQ files that are generated from their driving profiles. Each DAQ file was changed and assigned the corresponding participant ID immediately after driving each scenario to avoid any confusion later. The DAQ files allow users to extract a wide range of variables that capture driving behaviors such as hard braking, hard cornering, lane departures, accelerating, minimum speeds, average speed, maximum speeds, speeding events, and average headway. This data was combined with the survey responses for further analysis. This enables an in-depth analysis of driver behavior considering the extent of information collected.

Table 1 summarizes the distribution of samples collected for this study. The participant selection was made with an intent to fill any gaps to ensure a representative. This is to ensure the applicability of the research results to typical rural and urban areas.

Table 1. Summary of Survey Responses

\begin{tabular}{|c|c|c|c|}
\hline Variable & Category & Frequency & Percentage \\
\hline \multirow[t]{4}{*}{ Age } & $16-25$ years & 20 & 46.5 \\
\hline & $25-45$ years & 15 & 34.9 \\
\hline & $46-55$ years & 5 & 11.6 \\
\hline & $56-65$ years & 3 & 7 \\
\hline \multirow[t]{2}{*}{ Gender } & Male & 27 & 62.7 \\
\hline & Female & 16 & 37.3 \\
\hline \multirow[t]{4}{*}{ Ethnicity } & Caucasian & 20 & 46.5 \\
\hline & African-American & 10 & 23.25 \\
\hline & Hispanic & 3 & 7 \\
\hline & Asian & 10 & 23.25 \\
\hline \multirow[t]{5}{*}{ Education } & High School & 11 & 25.6 \\
\hline & Associate & 4 & 9.3 \\
\hline & Bachelor's & 14 & 32.6 \\
\hline & Master's & $\begin{array}{l}\text { 13!Unexpected } \\
\text { End of Formula }\end{array}$ & 30.2 \\
\hline & Doctorate & 1 & 2.3 \\
\hline \multirow[t]{6}{*}{ Income } & Less than $25 \mathrm{k}$ & 8 & 22.2 \\
\hline & $25 \mathrm{k}-49 \mathrm{k}$ & 5 & 13.9 \\
\hline & $50 \mathrm{k}-75 \mathrm{k}$ & 2 & 5.6 \\
\hline & $75 \mathrm{k}-99 \mathrm{k}$ & 4 & 11.1 \\
\hline & $100 \mathrm{k}-150 \mathrm{k}$ & 6 & 16.7 \\
\hline & $150 \mathrm{k}$ or more & 11 & 30.5 \\
\hline
\end{tabular}




\subsection{Data Analysis}

The variables that can be used to evaluate the effectiveness of the advanced features were selected. For example, average speed and maximum speed were used to analyze OSW. Similarly, lane departures were used to analyze LDW.

The primary aim of the research is to capture differences in driving behavior when driving a vehicle with advanced features compared to driver behavior when driving a vehicle without advanced features. Given the number of groups to compare and relevant variables, an ANOVA test was applied. ANOVA compares the mean values of multiple groups and determines if they are statistically different. ${ }^{80}$ An example hypothesis for ANOVA test is as follows.

Null hypothesis: The number of times participants exceed the speed limit with OSW is the same as the number of times participants exceed speed limit without OSW.

Alternate hypothesis: The number of times participants exceed speed limit with OSW is less than the number of times participants exceed speed limit without OSW.

An ANOVA test determines if we reject or fail to reject this hypothesis. The expected outcome is a rejection of the hypothesis, due to the difference in driving behavior with advanced features. Once the results from ANOVA are established, evaluating the magnitude of the difference helps capture the nature of effects of advanced features.

\subsection{Descriptive Statistics}

Tables 2, 3, and 4 depict descriptive statistics for various driving behaviors in rural, urban, and freeway scenarios, summarizing the following variables: number of hard braking events; number of hard cornering events; number of lane departure events; average speed; average headway; maximum speed; and brake pedal force. Hard braking represents the total number of times a participant applied sudden brakes during a simulation. Similarly, hard cornering is the total number of times a participant made sudden turns in the simulation. The number of times the participant deviated from their lane is represented by lane departures. These variables indicate aggressive or unsafe driving behaviors.

The average speed is the speed maintained by a participant throughout a simulation and is measured in miles per hour. Similarly, the maximum speed is the maximum speed reached during a simulation by a participant in miles per hour. The average headway is measured in feet and is the distance maintained by a participant from the leading vehicle. The brake force is the average force applied on the brake by a participant during a simulation measured in pounds. 
Table 2. Driver Behavior Parameters (Rural)

\begin{tabular}{|l|l|l|l|l|}
\hline Driver Behavior & Minimum & Mean & Maximum & Std. Dev. \\
\hline Hard Braking & 0.00 & 1.36 & 4.00 & 1.05 \\
\hline Hard Cornering & 0.00 & 3.10 & 12.00 & 2.76 \\
\hline Lane Departures & 0.00 & 7.38 & 30.00 & 6.91 \\
\hline Avg. Speed $(\mathrm{mph})$ & 14.60 & 41.13 & 62.10 & 9.23 \\
\hline Avg. Headway $(\mathrm{ft})$ & 49.50 & 386.57 & 853.70 & 229.12 \\
\hline Maximum Speed $(\mathrm{mph})$ & 42.80 & 61.69 & 107.50 & 15.41 \\
\hline Brake Force (lbs) & 0.33 & 21.29 & 60.00 & 13.87 \\
\hline
\end{tabular}

Note: Braking, cornering and lane departures are numbers without units. They are the number of times the corresponding action was performed per participant per simulation.

Table 3. Driver Behavior Parameters (Urban)

\begin{tabular}{|l|l|l|l|l|}
\hline Driver Behavior & Minimum & Mean & Maximum & $\begin{array}{l}\text { Std. } \\
\text { Dev. }\end{array}$ \\
\hline Hard Braking & 0.00 & 1.54 & 4.00 & 1.20 \\
\hline Hard Cornering & 0.00 & 1.62 & 5.00 & 1.26 \\
\hline Lane Departures & 0.00 & 4.84 & 21.00 & 5.14 \\
\hline Avg. Speed $(\mathrm{mph})$ & 30.50 & 42.20 & 55.30 & 6.03 \\
\hline Avg. Headway $(\mathrm{ft})$ & 157.70 & 750.63 & 1660.20 & 425.01 \\
\hline Maximum Speed $(\mathrm{mph})$ & 49.40 & 61.77 & 102.20 & 8.99 \\
\hline Brake Force (lbs) & 3.90 & 21.45 & 61.20 & 16.91 \\
\hline
\end{tabular}

Note: Braking, cornering and lane departures are numbers without units. They are the number of times the corresponding action was performed per participant per simulation.

Table 4. Driver Behavior Parameters (Freeway)

\begin{tabular}{|l|l|l|l|l|}
\hline Driver Behavior & Minimum & Mean & Maximum & Std. Dev. \\
\hline Hard Braking & 0.00 & 0.36 & 2.00 & 0.56 \\
\hline Hard Cornering & 0.00 & 3.34 & 10.00 & 1.87 \\
\hline Lane Departures & 0.00 & 15.18 & 39.00 & 9.68 \\
\hline Avg. Speed (mph) & 40.40 & 56.54 & 67.80 & 5.40 \\
\hline Avg. Headway (ft) & 77.30 & 342.71 & 823.70 & 206.95 \\
\hline Maximum Speed (mph) & 64.50 & 77.40 & 95.50 & 7.49 \\
\hline Brake Force (lbs) & 0.70 & 9.08 & 41.00 & 9.74 \\
\hline
\end{tabular}

Note: Braking, cornering and lane departures are numbers without units. They are the number of times the corresponding action was performed per participant per simulation.

Table 5 displays the types of advanced features (LDW, BSW, OSW, LKA, and ACC) that were provided to the participants, organized by each scenario type. The advanced features were provided individually as well as in combinations to the participants. 
Table 5. Provision of Vehicles with or without Advanced Features to Participants

\begin{tabular}{|l|l|l|l|}
\hline ADAS & Rural & Urban & Freeway \\
\hline LDW & 6 & 7 & 7 \\
\hline BSW & 7 & 7 & 7 \\
\hline OSW & 7 & 6 & 5 \\
\hline LDW \& BSW & 2 & 2 & 5 \\
\hline LDW \& OSW & 7 & 8 & 4 \\
\hline BSW \& OSW & 5 & 4 & 4 \\
\hline All & 2 & 3 & 5 \\
\hline ACC & 4 & 4 & 4 \\
\hline LKA & 4 & 4 & 4 \\
\hline ACC \& LKA & 8 & 8 & 8 \\
\hline None & 7 & 6 & 6 \\
\hline
\end{tabular}

\subsubsection{Rural Driving Scenario}

Table 6 shows the descriptive statistics comparing the participant groups where one group was provided with one of the warning systems (LDW, BSW, and OSW) and the other group was not. The mean values for hard braking, hard cornering, and lane departures for the group without LDW are higher, as indicated in Table 6. Additionally, the average headway for the participant group without LDW was lower than for the participant group with LDW. This indicates aggressive driving behaviors from participants without LDW while participants with LDW demonstrated safer driving behaviors. Average speed, maximum speed, and brake force have similar values between the two participant groups.

The average headway and brake pedal force values are distinct between the participant groups while the other parameters are similar. The participants with BSW seem to maintain shorter headways, while the other behavior parameters such as hard braking, lane departures, and average speed have lower values compared to participants driving a vehicle without BSW. It can be observed that hard braking, average speed, average headway, and maximum speed have higher mean values for the participant group without OSW compared to the participant group driving a vehicle with OSW. On the other hand, hard cornering events, lane departure events, and brake pedal force have higher mean values for the participant group driving a vehicle with OSW.

Young people are classified as people aged ten to twenty-five years by the World Health Organization. ${ }^{81}$ The participant groups were segregated accordingly to evaluate their driving behavior. Table 7 shows descriptive statistics of the parameters comparing young (fifteen to twenty-five years) and adult participants (above twenty-five years), male and female participants, daytime and nighttime conditions, and clear and rainy weather conditions in the rural scenario. The mean of hard braking events is higher for adult participants compared to young participants. The mean values of average speed and maximum speed are also higher for adult participants whereas the mean values of other driving behavior parameters are similar in the rural scenario.

The mean values of the average headway and brake force are slightly higher for female participants compared to male participants. The other driver behavior parameters are similar in the rural 
scenario. The mean values of hard cornering, lane departures, and average headway are higher for the participants group that drove in nighttime condition compared to daytime condition. The mean values of average speed and maximum speed are higher in daytime condition. More aggressive driving can be observed during daytime condition, while risky driver behaviors like hard cornering and lane departures are higher in nighttime condition. The mean values of average headway and brake force are higher for the participant group that drove in rainy weather condition compared to the participant group that drove in clear weather condition. The mean values of other parameters such as hard braking, hard cornering, and lane departures are higher for participants that drove during in clear weather condition. More aggressive driving behavior was observed during clear weather condition while rain tended to make participants more careful.

Table 6. Driver Behavior Parameters - ADAS (Rural)

\begin{tabular}{|c|c|c|c|c|c|c|c|c|}
\hline \multirow{2}{*}{$\begin{array}{l}\text { Driver } \\
\text { Behavior }\end{array}$} & \multicolumn{2}{|c|}{ Minimum } & \multicolumn{2}{|l|}{ Mean } & \multicolumn{2}{|c|}{ Maximum } & \multicolumn{2}{|l|}{ Std. Dev. } \\
\hline & $\begin{array}{l}\text { Without } \\
\text { ADAS }\end{array}$ & \begin{tabular}{|l|} 
With \\
ADAS
\end{tabular} & $\begin{array}{l}\text { Without } \\
\text { ADAS }\end{array}$ & $\begin{array}{l}\text { With } \\
\text { ADAS }\end{array}$ & $\begin{array}{l}\text { Without } \\
\text { ADAS }\end{array}$ & $\begin{array}{l}\text { With } \\
\text { ADAS }\end{array}$ & $\begin{array}{l}\text { Without } \\
\text { ADAS }\end{array}$ & $\begin{array}{l}\text { With } \\
\text { ADAS }\end{array}$ \\
\hline \multicolumn{9}{|c|}{ Lane Departure Warning (LDW) } \\
\hline Hard Braking & 0.00 & 0.00 & 1.46 & 0.88 & 4.00 & 3.00 & 1.07 & 0.93 \\
\hline $\begin{array}{l}\text { Hard } \\
\text { Cornering }\end{array}$ & 0.00 & 0.00 & 3.92 & 2.24 & 12.00 & 6.00 & 3.40 & 1.60 \\
\hline $\begin{array}{l}\text { Lane } \\
\text { Departures }\end{array}$ & 1.00 & 0.00 & 10.12 & 5.65 & 30.00 & 16.00 & 7.90 & 4.18 \\
\hline $\begin{array}{l}\text { Avg. Speed } \\
(\mathrm{mph})\end{array}$ & 29.90 & 14.60 & 41.12 & 41.14 & 62.10 & 60.30 & 8.98 & 9.89 \\
\hline $\begin{array}{l}\text { Avg. } \\
\text { Headway (ft) }\end{array}$ & 65.50 & 49.50 & 400.24 & 478.71 & 631.30 & 853.70 & 196.56 & 240.40 \\
\hline $\begin{array}{l}\text { Maximum } \\
\text { Speed (mph) }\end{array}$ & 47.70 & 42.80 & 64.94 & 59.05 & 95.40 & 107.50 & 15.27 & 18.10 \\
\hline $\begin{array}{l}\text { Brake Force } \\
\text { (lbs) }\end{array}$ & 0.33 & 3.20 & 23.50 & 26.01 & 60.00 & 48.50 & 13.89 & 9.37 \\
\hline \multicolumn{9}{|c|}{ Blind Spot Warning (BSW) } \\
\hline Hard Braking & 0.00 & 0.00 & 1.33 & 1.06 & 4.00 & 3.00 & 1.14 & 0.85 \\
\hline $\begin{array}{l}\text { Hard } \\
\text { Cornering }\end{array}$ & 0.00 & 0.00 & 3.19 & 3.38 & 12.00 & 10.00 & 2.77 & 3.26 \\
\hline $\begin{array}{l}\text { Lane } \\
\text { Departures }\end{array}$ & 0.00 & 1.00 & 8.70 & 7.75 & 30.00 & 27.00 & 6.99 & 7.15 \\
\hline $\begin{array}{l}\text { Avg. Speed } \\
(\mathrm{mph})\end{array}$ & 14.60 & 33.40 & 41.45 & 40.59 & 62.10 & 55.6 & 10.57 & 6.67 \\
\hline $\begin{array}{l}\text { Avg. } \\
\text { Headway (ft) }\end{array}$ & 49.50 & 65.50 & 467.24 & 370.56 & 853.70 & 664.80 & 210.24 & 217.67 \\
\hline $\begin{array}{l}\text { Maximum } \\
\text { Speed (mph) }\end{array}$ & 42.80 & 48.30 & 61.44 & 64.59 & 107.50 & 95.40 & 16.65 & 16.56 \\
\hline $\begin{array}{l}\text { Brake Force } \\
\text { (lbs) }\end{array}$ & 1.26 & 0.33 & 27.41 & 19.58 & 60.00 & 36.40 & 11.67 & 11.94 \\
\hline
\end{tabular}




\begin{tabular}{|l|l|l|l|l|l|l|l|l|}
\hline \multirow{2}{*}{$\begin{array}{l}\text { Driver } \\
\text { Behavior }\end{array}$} & \multicolumn{3}{|l|}{ Minimum } & \multicolumn{2}{l}{ Mean } & \multicolumn{2}{l|}{ Maximum } \\
\cline { 2 - 9 } & $\begin{array}{l}\text { Without } \\
\text { ADAS }\end{array}$ & $\begin{array}{l}\text { With } \\
\text { ADAS }\end{array}$ & $\begin{array}{l}\text { Without } \\
\text { ADAS }\end{array}$ & $\begin{array}{l}\text { With } \\
\text { ADAS }\end{array}$ & $\begin{array}{l}\text { Without } \\
\text { ADAS }\end{array}$ & $\begin{array}{l}\text { With } \\
\text { ADAS }\end{array}$ & $\begin{array}{l}\text { Without } \\
\text { ADAS }\end{array}$ & $\begin{array}{l}\text { With } \\
\text { ADAS }\end{array}$ \\
\hline Hard Braking & 0.00 & 0.00 & 1.45 & 1.00 & 3.00 & 4.00 & 0.91 & 1.14 \\
\hline $\begin{array}{l}\text { Hard } \\
\text { Cornering }\end{array}$ & 0.00 & 0.00 & 2.36 & 4.19 & 10.00 & 12.00 & 1.97 & 3.49 \\
\hline $\begin{array}{l}\text { Lane } \\
\text { Departures }\end{array}$ & 1.00 & 0.00 & 6.41 & 10.38 & 23.00 & 30.00 & 5.34 & 7.99 \\
\hline $\begin{array}{l}\text { Avg. Speed } \\
\text { (mph) }\end{array}$ & 29.9 & 14.6 & 45.05 & 37.02 & 62.10 & 47.60 & 9.46 & 7.10 \\
\hline $\begin{array}{l}\text { Avg. } \\
\text { Headway (ft) }\end{array}$ & 65.50 & 49.50 & 449.41 & 412.25 & 757.6 & 853.70 & 186.15 & 246.10 \\
\hline $\begin{array}{l}\text { Maximum } \\
\text { Speed (mph) }\end{array}$ & 49.10 & 42.80 & 71.33 & 53.48 & 107.50 & 56.90 & 19.11 & 4.08 \\
\hline $\begin{array}{l}\text { Brake Force } \\
\text { (lbs) }\end{array}$ & 1.26 & 0.33 & 22.37 & 26.72 & 38.00 & 60.00 & 9.82 & 14.26 \\
\hline
\end{tabular}

Note: Braking, cornering and lane departures are numbers without units. They are the number of times the corresponding action was performed per participant per simulation.

Table 7. Driver Behavior Parameters - Age, Gender, Lighting Condition, and Weather Condition (Rural)

\begin{tabular}{|l|l|l|l|l|l|l|l|l|}
\hline Driver Behavior & \multicolumn{2}{l}{ Minimum } & \multicolumn{2}{l|}{ Mean } & \multicolumn{2}{l|}{ Maximum } \\
\hline Age & $\leq 25$ & $\begin{array}{l}\text { Std. Dev. } \\
\text { Years }\end{array}$ & $\begin{array}{l}\leq 25 \\
\text { Years }\end{array}$ & $\begin{array}{l}>25 \\
\text { Years }\end{array}$ & $\begin{array}{l}\leq 25 \\
\text { Years }\end{array}$ & $\begin{array}{l}> \\
\text { Years }\end{array}$ & $\begin{array}{l}\text { Years } \\
\text { Years }\end{array}$ \\
\hline Hard Braking & 0.00 & 0.00 & 0.90 & 1.50 & 4.00 & 3.00 & 1.00 & 1.00 \\
\hline Hard Cornering & 0.00 & 0.00 & 3.10 & 3.40 & 12.00 & 10.00 & 2.90 & 3.00 \\
\hline Lane Departures & 0.00 & 1.00 & 8.00 & 8.70 & 30.00 & 27.00 & 6.80 & 7.30 \\
\hline Avg. Speed (mph) & 14.60 & 29.90 & 38.60 & 43.30 & 55.60 & 62.10 & 7.70 & 10.00 \\
\hline $\begin{array}{l}\text { Avg. Headway } \\
\text { (ft) }\end{array}$ & 49.50 & 72.30 & 431.70 & 430.80 & 853.70 & 664.80 & 250.70 & 185.70 \\
\hline $\begin{array}{l}\text { Maximum Speed } \\
\text { (mph) }\end{array}$ & 42.80 & 47.70 & 58.10 & 66.50 & 92.50 & 107.50 & 14.00 & 17.70 \\
\hline Brake Force (lbs) & 1.30 & 0.30 & 24.20 & 24.80 & 48.50 & 60.00 & 12.10 & 12.60 \\
\hline Gender & Male & Female & Male & Female & Male & Female & Male & Female \\
\hline Hard Braking & 0.00 & 0.00 & 1.30 & 1.10 & 4.00 & 3.00 & 1.00 & 1.10 \\
\hline Hard Cornering & 0.00 & 0.00 & 3.40 & 3.10 & 10.00 & 12.00 & 2.80 & 3.20 \\
\hline Lane Departures & 3.00 & 0.00 & 8.70 & 7.70 & 27.00 & 30.00 & 6.60 & 7.80 \\
\hline Avg. Speed (mph) & 29.90 & 14.60 & 41.90 & 39.80 & 62.10 & 55.60 & 8.60 & 10.40 \\
\hline $\begin{array}{l}\text { Avg. Headway } \\
\text { (ft) }\end{array}$ & 49.50 & 49.50 & 423.50 & 444.30 & 853.70 & 757.60 & 212.60 & 227.20 \\
\hline $\begin{array}{l}\text { Maximum Speed } \\
\text { (mph) }\end{array}$ & 46.10 & 42.80 & 61.90 & 63.80 & 95.40 & 107.50 & 14.40 & 20.00 \\
\hline Brake Force (lbs) & 1.30 & 0.30 & 21.90 & 28.90 & 37.10 & 60.00 & 10.50 & 13.90 \\
\hline
\end{tabular}




\begin{tabular}{|l|l|l|l|l|l|l|l|l|}
\hline Driver Behavior & \multicolumn{2}{|l|}{ Minimum } & \multicolumn{2}{l|}{ Mean } & \multicolumn{2}{l|}{ Maximum } \\
\hline Age & $\begin{array}{l}\leq 25 \\
\text { Years }\end{array}$ & $\begin{array}{l}>25 \\
\text { Years }\end{array}$ & $\begin{array}{l}\leq 25 \\
\text { Years }\end{array}$ & $\begin{array}{l}>25 \\
\text { Years }\end{array}$ & $\begin{array}{l}\leq 25 \\
\text { Years }\end{array}$ & $\begin{array}{l}>25 \\
\text { Years }\end{array}$ & $\begin{array}{l}\text { Std. Dev. } \\
\text { Years }\end{array}$ & $\begin{array}{l}\text { Years } \\
\text { Lighting } \\
\text { Condition }\end{array}$ \\
\hline Hard Braking & 0.00 & 0.00 & 1.20 & 1.30 & 3.00 & 4.00 & 1.00 & 1.20 \\
\hline Hard Cornering & 0.00 & 0.00 & 2.90 & 3.80 & 10.00 & 12.00 & 2.80 & 3.10 \\
\hline Lane Departures & 0.00 & 2.00 & 5.30 & 13.10 & 16.00 & 30.00 & 3.70 & 8.20 \\
\hline Avg. Speed (mph) & 14.60 & 29.90 & 42.30 & 39.40 & 62.10 & 51.60 & 10.40 & 6.90 \\
\hline $\begin{array}{l}\text { Avg. Headway } \\
\text { (ft) }\end{array}$ & 49.50 & 81.50 & 355.70 & 546.90 & 625.90 & 853.70 & 200.00 & 190.10 \\
\hline $\begin{array}{l}\text { Maximum Speed } \\
\text { (mph) }\end{array}$ & 42.80 & 46.10 & 66.10 & 57.30 & 107.50 & 101.10 & 17.60 & 13.50 \\
\hline Brake Force (lbs) & 0.30 & 1.30 & 24.00 & 25.30 & 60.00 & 42.00 & 13.40 & 10.60 \\
\hline $\begin{array}{l}\text { Weather } \\
\text { Condition }\end{array}$ & Clear & Rain & Clear & Rain & Clear & Rain & Clear & Rain \\
\hline Hard Braking & 0.00 & 0.00 & 1.30 & 0.90 & 4.00 & 2.00 & 1.10 & 0.80 \\
\hline Hard Cornering & 0.00 & 0.00 & 2.60 & 1.90 & 6.00 & 5.00 & 1.50 & 1.70 \\
\hline Lane Departures & 1.00 & 0.00 & 8.00 & 4.60 & 23.00 & 14.00 & 5.70 & 3.80 \\
\hline Avg. Speed (mph) & 29.90 & 14.60 & 41.50 & 40.10 & 62.10 & 60.30 & 8.70 & 11.80 \\
\hline $\begin{array}{l}\text { Avg. Headway } \\
\text { (ft) }\end{array}$ & 49.50 & 417.80 & 418.90 & 567.30 & 757.60 & 853.70 & 207.80 & 115.50 \\
\hline $\begin{array}{l}\text { Maximum Speed } \\
\text { (mph) }\end{array}$ & 48.30 & 42.80 & 63.90 & 62.10 & 107.50 & 101.10 & 17.70 & 17.50 \\
\hline Brake Force (lbs) & 1.30 & 1.30 & 24.20 & 26.60 & 38.00 & 60.00 & 9.50 & 15.70 \\
\hline
\end{tabular}

Note: Braking, cornering and lane departures are numbers without units. They are the number of times the corresponding action was performed per participant per simulation.

\subsubsection{Urban Driving Scenario}

Table 8 shows descriptive statistics comparing the participant groups with one of the warning systems (LDW, BSW, and OSW) and without any advanced features in the urban scenario. Hard cornering and lane departures have lower mean values for the non-LDW participant group while the average headway is higher when compared to the LDW participant group. On the other hand, hard braking, average speed, maximum speed, and brake force are similar in values for both participant groups. The difference in the mean values indicate non-aggressive driving behaviors among participants provided with LDW, but these participants also tended to speed more compared to participants who did not have LDW features.

The mean values for hard braking, hard cornering, lane departures, average speed, and maximum speed for participants without BSW are lower compared to participants with BSW. Further lane departures, average headway, and brake pedal force for participants without BSW are higher compared to participants provided with BSW. Overall, BSW seems to make participants' carfollowing and speeding behavior more aggressive as they also exhibited fewer safe driving 
maneuvers such as speeding, braking, and handling the vehicle. Similar to the rural scenario, the mean values of the number of lane departure events and brake force are higher for the participant group provided with OSW but, the mean of average headway is lower for the participant group provided with OSW.

Whereas other driving behaviors, like handling the vehicle, speeding, turning, and sudden braking seem to be more frequent among drivers for the participant group that drove a vehicle without OSW.

Table 9 depicts descriptive statistics of driver behavior parameters comparing participant groups containing young and adult participants, male and female participants, daytime and nighttime conditions, and clear and rainy weather conditions in the urban scenario. The mean values of hard braking are higher for the adult participant group compared to the young participant group. On the other hand, the mean values of lane departures, average headway, and brake force are higher for the young participant group compared to the adult participant group. Higher braking force was applied by younger participants along with a greater frequency of lane departures. The mean values of hard braking, average headway, maximum speed, and brake force are higher for the male participant group compared to the female participant group. The other driver behavior parameters are similar for both the participant groups. The male participants seem to apply hard brakes and more pressure while braking. They also drove at higher speeds compared to female participants. The higher speeds may also lead to maintaining a higher average headway in urban conditions.

Table 8. Driver Behavior Parameters - ADAS (Urban)

\begin{tabular}{|c|c|c|c|c|c|c|c|c|}
\hline \multirow{2}{*}{$\begin{array}{l}\text { Driver } \\
\text { Behavior }\end{array}$} & \multicolumn{2}{|c|}{ Minimum } & \multicolumn{2}{|l|}{ Mean } & \multicolumn{2}{|c|}{ Maximum } & \multicolumn{2}{|l|}{ Std. Dev. } \\
\hline & $\begin{array}{l}\text { Without } \\
\text { ADAS }\end{array}$ & $\begin{array}{l}\text { With } \\
\text { ADAS }\end{array}$ & $\begin{array}{l}\text { Without } \\
\text { ADAS }\end{array}$ & $\begin{array}{l}\text { With } \\
\text { ADAS }\end{array}$ & $\begin{array}{l}\text { Without } \\
\text { ADAS }\end{array}$ & $\begin{array}{l}\text { With } \\
\text { ADAS }\end{array}$ & $\begin{array}{l}\text { Without } \\
\text { ADAS }\end{array}$ & $\begin{array}{l}\text { With } \\
\text { ADAS }\end{array}$ \\
\hline \multicolumn{9}{|c|}{ Lane Departure Warning (LDW) } \\
\hline Hard Braking & 0.00 & 0.00 & 1.57 & 1.45 & 4.00 & 4.00 & 1.16 & 1.36 \\
\hline $\begin{array}{l}\text { Hard } \\
\text { Cornering }\end{array}$ & 0.00 & 0.00 & 2.09 & 0.90 & 5.00 & 2.00 & 1.35 & 0.79 \\
\hline $\begin{array}{l}\text { Lane } \\
\text { Departures }\end{array}$ & 0.00 & 0.00 & 7.04 & 3.50 & 21.00 & 11.00 & 6.30 & 3.09 \\
\hline $\begin{array}{l}\text { Avg. Speed } \\
(\mathrm{mph})\end{array}$ & 30.50 & 31.50 & 43.36 & 40.35 & 55.30 & 53.90 & 6.14 & 6.27 \\
\hline $\begin{array}{l}\text { Avg. } \\
\text { Headway (ft) }\end{array}$ & 282.60 & 157.70 & 806.49 & 904.86 & 1660.20 & $\begin{array}{l}1432.2 \\
0\end{array}$ & 387.18 & 345.18 \\
\hline $\begin{array}{l}\text { Maximum } \\
\text { Speed (mph) }\end{array}$ & 50.80 & 49.40 & 60.98 & 62.87 & 78.70 & 102.20 & 6.68 & 12.40 \\
\hline $\begin{array}{l}\text { Brake Force } \\
\text { (lbs) }\end{array}$ & 3.90 & 6.10 & 23.61 & 26.82 & 61.20 & 49.30 & 18.17 & 12.73 \\
\hline \multicolumn{9}{|c|}{ Blind Spot Warning (BSW) } \\
\hline Hard Braking & 0.00 & 0.00 & 1.37 & 1.75 & 4.00 & 4.00 & 1.24 & 1.24 \\
\hline $\begin{array}{l}\text { Hard } \\
\text { Cornering }\end{array}$ & 0.00 & 0.00 & 1.30 & 1.94 & 4.00 & 5.00 & 1.03 & 1.53 \\
\hline
\end{tabular}




\begin{tabular}{|c|c|c|c|c|c|c|c|c|}
\hline \multirow{2}{*}{$\begin{array}{l}\text { Driver } \\
\text { Behavior }\end{array}$} & \multicolumn{2}{|c|}{ Minimum } & \multicolumn{2}{|l|}{ Mean } & \multicolumn{2}{|c|}{ Maximum } & \multicolumn{2}{|l|}{ Std. Dev. } \\
\hline & $\begin{array}{l}\text { Without } \\
\text { ADAS }\end{array}$ & $\begin{array}{l}\text { With } \\
\text { ADAS }\end{array}$ & $\begin{array}{l}\text { Without } \\
\text { ADAS }\end{array}$ & $\begin{array}{l}\text { With } \\
\text { ADAS }\end{array}$ & $\begin{array}{l}\text { Without } \\
\text { ADAS }\end{array}$ & $\begin{array}{l}\text { With } \\
\text { ADAS }\end{array}$ & $\begin{array}{l}\text { Without } \\
\text { ADAS }\end{array}$ & $\begin{array}{l}\text { With } \\
\text { ADAS }\end{array}$ \\
\hline $\begin{array}{l}\text { Lane } \\
\text { Departures }\end{array}$ & 0.00 & 1.00 & 5.93 & 4.50 & 21.00 & 10.00 & 6.31 & 2.99 \\
\hline $\begin{array}{l}\text { Avg. Speed } \\
(\mathrm{mph})\end{array}$ & 30.50 & 35.50 & 40.56 & 44.33 & 55.30 & 53.90 & 6.13 & 6.06 \\
\hline $\begin{array}{l}\text { Avg. } \\
\text { Headway (ft) }\end{array}$ & 157.70 & 282.60 & 912.74 & 750.15 & 1660.20 & $\begin{array}{l}1460.8 \\
0\end{array}$ & 331.82 & 411.27 \\
\hline $\begin{array}{l}\text { Maximum } \\
\text { Speed (mph) }\end{array}$ & 50.80 & 49.40 & 60.81 & 63.63 & 102.20 & 89.70 & 9.75 & 9.61 \\
\hline $\begin{array}{l}\text { Brake Force } \\
\text { (lbs) }\end{array}$ & 6.90 & 3.90 & 28.75 & 19.63 & 61.20 & 49.30 & 15.52 & 15.37 \\
\hline \multicolumn{9}{|c|}{ Over Speed Warning (OSW) } \\
\hline Hard Braking & 0.00 & 0.00 & 1.77 & 1.24 & 4.00 & 4.00 & 1.07 & 1.37 \\
\hline $\begin{array}{l}\text { Hard } \\
\text { Cornering }\end{array}$ & 0.00 & 0.00 & 1.73 & 1.33 & 4.00 & 5.00 & 1.24 & 1.28 \\
\hline $\begin{array}{l}\text { Lane } \\
\text { Departures }\end{array}$ & 0.00 & 0.00 & 4.00 & 6.86 & 20.00 & 21.00 & 4.86 & 5.50 \\
\hline $\begin{array}{l}\text { Avg. Speed } \\
(\mathrm{mph})\end{array}$ & 33.80 & 30.50 & 44.45 & 39.35 & 55.30 & 50.30 & 6.28 & 5.32 \\
\hline $\begin{array}{l}\text { Avg. } \\
\text { Headway (ft) }\end{array}$ & 157.7 & 356.00 & 730.99 & 979.27 & 1236.9 & $\begin{array}{l}1660.2 \\
0 \\
\end{array}$ & 360.55 & 337.14 \\
\hline $\begin{array}{l}\text { Maximum } \\
\text { Speed (mph) }\end{array}$ & 51.90 & 49.40 & 65.16 & 58.40 & 102.20 & 61.8 & 12.31 & 3.66 \\
\hline $\begin{array}{l}\text { Brake Force } \\
\text { (lbs) }\end{array}$ & 6.70 & 3.90 & 24.51 & 25.58 & 61.20 & 60.30 & 14.60 & 17.75 \\
\hline
\end{tabular}

Note: Braking, cornering, and lane departures are numbers without units. They are the number of times the corresponding action was performed per participant per simulation. 
Table 9. Driver Behavior Parameters by Age, Gender, Lighting Condition, and Weather Condition (Urban)

\begin{tabular}{|c|c|c|c|c|c|c|c|c|}
\hline Driver Behavior & Minimı & & Mean & & Maxim & & Std. De & \\
\hline Age & $\begin{array}{l}\leq 25 \\
\text { Years }\end{array}$ & $\begin{array}{l}>25 \\
\text { Years }\end{array}$ & $\begin{array}{l}\leq 25 \\
\text { Years }\end{array}$ & $\begin{array}{l}>25 \\
\text { Years }\end{array}$ & $\begin{array}{l}\leq 25 \\
\text { Years }\end{array}$ & $\begin{array}{l}>25 \\
\text { Years }\end{array}$ & $\begin{array}{l}\leq 25 \\
\text { Years }\end{array}$ & $\begin{array}{l}>25 \\
\text { Years }\end{array}$ \\
\hline Hard Braking & 0.00 & 0.00 & 1.20 & 1.80 & 4.00 & 4.00 & 1.30 & 1.10 \\
\hline Hard Cornering & 0.00 & 0.00 & 1.40 & 1.60 & 4.00 & 5.00 & 1.10 & 1.40 \\
\hline Lane Departures & 0.00 & 0.00 & 5.70 & 5.10 & 21.00 & 19.00 & 6.50 & 4.20 \\
\hline Avg. Speed (mph) & 31.60 & 30.50 & 41.70 & 42.20 & 55.30 & 53.60 & 6.70 & 6.10 \\
\hline $\begin{array}{l}\text { Avg. Headway } \\
(\mathrm{ft})\end{array}$ & 157.70 & 282.60 & 880.90 & 827.40 & $\begin{array}{l}1460.8 \\
0\end{array}$ & $\begin{array}{l}1660.2 \\
0\end{array}$ & 326.20 & 405.20 \\
\hline $\begin{array}{l}\text { Maximum Speed } \\
(\mathrm{mph})\end{array}$ & 50.80 & 49.40 & 61.00 & 62.60 & 89.70 & 102.20 & 8.40 & 10.80 \\
\hline Brake Force (lbs) & 6.20 & 3.90 & 28.50 & 22.00 & 61.20 & 50.30 & 17.60 & 14.10 \\
\hline Gender & Male & Female & Male & Female & Male & Female & Male & Female \\
\hline Hard Braking & 0.00 & 0.00 & 1.80 & 0.90 & 4.00 & 4.00 & 1.10 & 1.20 \\
\hline Hard Cornering & 0.00 & 0.00 & 1.40 & 1.70 & 5.00 & 4.00 & 1.20 & 1.40 \\
\hline Lane Departures & 0.00 & 0.00 & 5.50 & 5.20 & 20.00 & 21.00 & 5.30 & 5.50 \\
\hline Avg. Speed (mph) & 31.50 & 30.50 & 42.00 & 41.90 & 55.30 & 53.60 & 5.80 & 7.30 \\
\hline $\begin{array}{l}\text { Avg. Headway } \\
(\mathrm{ft})\end{array}$ & 282.60 & 157.70 & 924.70 & 729.90 & $\begin{array}{l}1460.8 \\
0\end{array}$ & $\begin{array}{l}1660.2 \\
0\end{array}$ & 348.80 & 376.00 \\
\hline $\begin{array}{l}\text { Maximum Speed } \\
(\mathrm{mph})\end{array}$ & 51.90 & 49.40 & 63.30 & 59.40 & 102.20 & 78.70 & 10.70 & 7.40 \\
\hline Brake Force (lbs) & 3.90 & 6.10 & 27.40 & 20.10 & 61.20 & 60.30 & 15.00 & 17.10 \\
\hline $\begin{array}{l}\text { Lighting } \\
\text { Condition }\end{array}$ & Day & Night & Day & Night & Day & Night & Day & Night \\
\hline Hard Braking & 0.00 & 0.00 & 1.30 & 1.90 & 4.00 & 4.00 & 1.20 & 1.40 \\
\hline Hard Cornering & 0.00 & 1.00 & 1.40 & 1.80 & 5.00 & 4.00 & 1.40 & 0.90 \\
\hline Lane Departures & 0.00 & 2.00 & 2.90 & 10.00 & 9.00 & 21.00 & 2.60 & 6.10 \\
\hline Avg. Speed (mph) & 31.60 & 30.50 & 42.40 & 41.20 & 53.90 & 55.30 & 6.30 & 6.50 \\
\hline $\begin{array}{l}\text { Avg. Headway } \\
(\mathrm{ft})\end{array}$ & 157.70 & 600.80 & 731.70 & $\begin{array}{l}1077.3 \\
0\end{array}$ & $\begin{array}{l}1432.2 \\
0\end{array}$ & $\begin{array}{l}1660.2 \\
0\end{array}$ & 347.40 & 297.60 \\
\hline $\begin{array}{l}\text { Maximum Speed } \\
(\mathrm{mph})\end{array}$ & 49.40 & 55.40 & 60.60 & 64.20 & 89.70 & 102.20 & 8.40 & 11.70 \\
\hline Brake Force (lbs) & 3.90 & 6.20 & 20.00 & 34.00 & 48.80 & 61.20 & 12.00 & 18.40 \\
\hline $\begin{array}{l}\text { Weather } \\
\text { Condition }\end{array}$ & Clear & Rain & Clear & Rain & Clear & Rain & Clear & Rain \\
\hline Hard Braking & 0.00 & 0.00 & 1.50 & 1.50 & 4.00 & 3.00 & 1.40 & 1.20 \\
\hline Hard Cornering & 0.00 & 0.00 & 1.50 & 0.80 & 4.00 & 2.00 & 1.00 & 0.80 \\
\hline Lane Departures & 0.00 & 0.00 & 5.50 & 4.30 & 21.00 & 12.00 & 5.30 & 4.30 \\
\hline Avg. Speed (mph) & 30.50 & 36.30 & 42.30 & 40.40 & 53.90 & 49.80 & 6.30 & 4.20 \\
\hline
\end{tabular}




\begin{tabular}{|c|c|c|c|c|c|c|c|c|}
\hline Driver Behavior & \multicolumn{2}{|c|}{ Minimum } & \multicolumn{2}{|l|}{ Mean } & \multicolumn{2}{|c|}{ Maximum } & \multicolumn{2}{|c|}{ Std. Dev. } \\
\hline Age & $\begin{array}{l}\leq 25 \\
\text { Years }\end{array}$ & $\begin{array}{l}>25 \\
\text { Years }\end{array}$ & $\begin{array}{l}\leq 25 \\
\text { Years }\end{array}$ & $\begin{array}{l}>25 \\
\text { Years }\end{array}$ & $\begin{array}{l}\leq 25 \\
\text { Years }\end{array}$ & $\begin{array}{l}>25 \\
\text { Years }\end{array}$ & $\begin{array}{l}\leq 25 \\
\text { Years }\end{array}$ & $\begin{array}{l}>25 \\
\text { Years }\end{array}$ \\
\hline $\begin{array}{l}\text { Avg. Headway } \\
(\mathrm{ft})\end{array}$ & 157.70 & 404.50 & 766.70 & $\begin{array}{l}1099.4 \\
0\end{array}$ & $\begin{array}{l}1660.2 \\
0\end{array}$ & $\begin{array}{l}1432.2 \\
0\end{array}$ & 368.00 & 293.00 \\
\hline $\begin{array}{l}\text { Maximum Speed } \\
(\mathrm{mph})\end{array}$ & 49.40 & 51.90 & 62.50 & 58.60 & 102.20 & 69.50 & 11.00 & 5.10 \\
\hline Brake Force (lbs) & 6.10 & 14.10 & 21.20 & 32.80 & 60.30 & 50.30 & 14.90 & 13.00 \\
\hline
\end{tabular}

Note: Braking, cornering and lane departures are numbers without units. They are the number of times the corresponding action was performed per participant per simulation.

The mean values of hard braking, hard cornering, lane departures, average headway, and brake force are higher for the participant group that drove in nighttime condition. The mean values of other driver behavior parameters are similar. Typically, more aggressive driving behaviors were observed in nighttime condition though participants tried to maintain larger headways. The mean values of hard cornering, lane departures, average speed, and maximum speed are higher for the participant group that drove during clear weather condition. The mean values of average headway and brake force are higher in rainy weather condition. Though the participants exhibited more aggressive driving during clear weather, higher brake force was applied in rainy weather condition which could be due to slippery roads.

\subsubsection{Freeway Driving Scenario}

Table 10 shows descriptive statistics comparing the participant groups where one group was provided with one of the warning systems and the other group was not in the freeway scenario. It can be observed that lane departures and hard cornering events have distinct mean values among the two participant groups, while other driver behavior parameters have similar values. The mean values of these driver behaviors are higher for the participant group without warning systems. Participants that drove a vehicle without warning systems seem to be more aggressive in lanefollowing and turning. Participants that drove a vehicle with LDW seem to demonstrate safer driving behavior.

The mean values for hard braking events and brake pedal force are higher for the participant group that drove a vehicle without BSW compared to the participant group that drove a vehicle with BSW. The hard cornering events, lane departure events, maximum speed, and average headway were lower for the participant group that drove a vehicle without BSW. The participant group that drove a vehicle with BSW seemed to exhibit more aggressive lane-following and speeding but displayed safer car-following and braking behaviors. The mean brake force is higher for the participant group that drove a vehicle with OSW across all driving conditions. This could be because of the speed warning that may have triggered participants to brake immediately. Similarly, the speeding behavior of the participant group that drove a vehicle without OSW is also similar across driving conditions.

Table 11 shows the comparison of descriptive statistics between young and adult participants, male and female participants, daytime and nighttime conditions, and clear and rainy weather conditions in the freeway scenario. The mean values of average headway, maximum speed, and brake force are higher for adult participants compared to young participants. The adult participants were 
observed to maintain longer headways and also speed more than young participants in the freeway scenario. The mean value of average headway is higher for female participants in the freeway scenario. The mean values of lane departures and brake force are higher for male participants indicating more aggressive driving behavior.

Table 10. Driver Behavior Parameters - ADAS (Freeway)

\begin{tabular}{|c|c|c|c|c|c|c|c|c|}
\hline \multirow{2}{*}{$\begin{array}{l}\text { Driver } \\
\text { Behavior }\end{array}$} & \multicolumn{2}{|c|}{ Minimum } & \multicolumn{2}{|l|}{ Mean } & \multicolumn{2}{|c|}{ Maximum } & \multicolumn{2}{|l|}{ Std. Dev. } \\
\hline & $\begin{array}{l}\text { Without } \\
\text { ADAS }\end{array}$ & $\begin{array}{l}\text { With } \\
\text { ADAS }\end{array}$ & $\begin{array}{l}\text { Without } \\
\text { ADAS }\end{array}$ & $\begin{array}{l}\text { With } \\
\text { ADAS }\end{array}$ & $\begin{array}{l}\text { Without } \\
\text { ADAS }\end{array}$ & $\begin{array}{l}\text { With } \\
\text { ADAS }\end{array}$ & $\begin{array}{l}\text { Without } \\
\text { ADAS }\end{array}$ & $\begin{array}{l}\text { With } \\
\text { ADAS }\end{array}$ \\
\hline \multicolumn{9}{|c|}{ Lane Departure Warning (LDW) } \\
\hline Hard Braking & 0.00 & 0.00 & 0.41 & 0.43 & 1.00 & 2.00 & 0.50 & 0.68 \\
\hline $\begin{array}{l}\text { Hard } \\
\text { Cornering }\end{array}$ & 1.00 & 0.00 & 3.91 & 2.81 & 10.00 & 7.00 & 2.22 & 1.44 \\
\hline $\begin{array}{l}\text { Lane } \\
\text { Departures }\end{array}$ & 4.00 & 0.00 & 22.32 & 11.67 & 39.00 & 26.00 & 7.97 & 6.58 \\
\hline $\begin{array}{l}\text { Avg. Speed } \\
(\mathrm{mph})\end{array}$ & 49.50 & 40.40 & 57.65 & 57.31 & 67.80 & 66.60 & 4.25 & 6.10 \\
\hline $\begin{array}{l}\text { Avg. } \\
\text { Headway (ft) }\end{array}$ & 114.50 & 77.30 & 355.39 & 374.80 & 814.90 & 823.70 & 191.48 & 240.06 \\
\hline $\begin{array}{l}\text { Maximum } \\
\text { Speed (mph) }\end{array}$ & 72.20 & 64.50 & 79.52 & 78.87 & 92.70 & 95.50 & 5.66 & 7.24 \\
\hline $\begin{array}{l}\text { Brake Force } \\
\text { (lbs) }\end{array}$ & 0.70 & 1.60 & 10.57 & 10.99 & 31.30 & 41.00 & 9.76 & 9.98 \\
\hline \multicolumn{9}{|c|}{ Blind Spot Warning (BSW) } \\
\hline Hard Braking & 0.00 & 0.00 & 0.45 & 0.38 & 2.00 & 2.00 & 0.60 & 0.59 \\
\hline $\begin{array}{l}\text { Hard } \\
\text { Cornering }\end{array}$ & 0.00 & 1.00 & 3.32 & 3.43 & 10.00 & 9.00 & 2.03 & 1.89 \\
\hline $\begin{array}{l}\text { Lane } \\
\text { Departures }\end{array}$ & 0.00 & 0.00 & 16.68 & 17.57 & 39.00 & 36.00 & 9.63 & 8.55 \\
\hline $\begin{array}{l}\text { Avg. Speed } \\
(\mathrm{mph})\end{array}$ & 47.40 & 40.4 & 57.49 & 57.49 & 67.80 & 65.10 & 5.08 & 5.40 \\
\hline $\begin{array}{l}\text { Avg. } \\
\text { Headway (ft) }\end{array}$ & 77.30 & 118.40 & 303.84 & 428.80 & 666.80 & 823.70 & 155.70 & 249.98 \\
\hline $\begin{array}{l}\text { Maximum } \\
\text { Speed (mph) }\end{array}$ & 64.5 & 71.90 & 77.94 & 80.52 & 87.50 & 95.50 & 5.44 & 7.19 \\
\hline $\begin{array}{l}\text { Brake Force } \\
\text { (lbs) }\end{array}$ & 1.60 & 0.70 & 12.53 & 8.48 & 41.00 & 28.80 & 10.72 & 8.01 \\
\hline \multicolumn{9}{|c|}{ Over Speed Warning (OSW) } \\
\hline Hard Braking & 0.00 & 0.00 & 0.36 & 0.50 & 2.00 & 2.00 & 0.57 & 0.62 \\
\hline $\begin{array}{l}\text { Hard } \\
\text { Cornering }\end{array}$ & 1.00 & 0.00 & 3.40 & 3.33 & 10.00 & 9.00 & 2.06 & 1.81 \\
\hline $\begin{array}{l}\text { Lane } \\
\text { Departures }\end{array}$ & 1.00 & 0.00 & 17.80 & 16.17 & 39.00 & 27.00 & 9.36 & 8.70 \\
\hline
\end{tabular}




\begin{tabular}{|c|c|c|c|c|c|c|c|c|}
\hline \multirow{2}{*}{$\begin{array}{l}\text { Driver } \\
\text { Behavior }\end{array}$} & \multicolumn{2}{|c|}{ Minimum } & \multicolumn{2}{|l|}{ Mean } & \multicolumn{2}{|c|}{ Maximum } & \multicolumn{2}{|l|}{ Std. Dev. } \\
\hline & $\begin{array}{l}\text { Without } \\
\text { ADAS }\end{array}$ & $\begin{array}{l}\text { With } \\
\text { ADAS }\end{array}$ & $\begin{array}{l}\text { Without } \\
\text { ADAS }\end{array}$ & $\begin{array}{l}\text { With } \\
\text { ADAS }\end{array}$ & $\begin{array}{l}\text { Without } \\
\text { ADAS }\end{array}$ & $\begin{array}{l}\text { With } \\
\text { ADAS }\end{array}$ & $\begin{array}{l}\text { Without } \\
\text { ADAS }\end{array}$ & $\begin{array}{l}\text { With } \\
\text { ADAS }\end{array}$ \\
\hline $\begin{array}{l}\text { Avg. Speed } \\
(\mathrm{mph})\end{array}$ & 40.40 & 47.40 & 58.19 & 56.51 & 67.80 & 62.90 & 5.95 & 3.81 \\
\hline $\begin{array}{l}\text { Avg. } \\
\text { Headway (ft) }\end{array}$ & 77.30 & 123.50 & 344.36 & 393.35 & 775.9 & 823.70 & 205.32 & 228.77 \\
\hline $\begin{array}{l}\text { Maximum } \\
\text { Speed (mph) }\end{array}$ & 64.50 & 69.80 & 80.25 & 77.75 & 95.50 & 84.40 & 7.56 & 4.11 \\
\hline $\begin{array}{l}\text { Brake Force } \\
\text { (lbs) }\end{array}$ & 0.70 & 1.60 & 9.46 & 12.51 & 28.80 & 41.00 & 8.19 & 11.49 \\
\hline
\end{tabular}

Note: Braking, cornering and lane departures are numbers without units. They are the number of times the corresponding action was performed per participant per simulation.

Table 11. Driver Behavior Parameters - Age, Gender, Lighting Condition, and Weather Condition (Freeway)

\begin{tabular}{|l|l|l|l|l|l|l|l|l|}
\hline Driver Behavior & \multicolumn{2}{l}{ Minimum } & \multicolumn{2}{l}{ Mean } & \multicolumn{2}{l|}{ Maximum } \\
\hline Age & $\leq 25$ & $\begin{array}{l}\text { Years } \\
\text { Years }\end{array}$ & $\begin{array}{l}\leq 25 \\
\text { Years }\end{array}$ & $\begin{array}{l}>25 \\
\text { Years }\end{array}$ & $\begin{array}{l}\leq 25 \\
\text { Years }\end{array}$ & $\begin{array}{l}\text { Years } \\
\text { Ye Dev. }\end{array}$ & $\begin{array}{l}\text { Years } \\
\text { Years }\end{array}$ \\
\hline Hard Braking & 0.00 & 0.00 & 0.30 & 0.50 & 1.00 & 2.00 & 0.50 & 0.70 \\
\hline Hard Cornering & 1.00 & 0.00 & 3.40 & 3.30 & 9.00 & 10.00 & 1.80 & 2.10 \\
\hline Lane Departures & 0.00 & 0.00 & 17.60 & 16.70 & 36.00 & 39.00 & 9.00 & 9.30 \\
\hline Avg. Speed (mph) & 53.00 & 40.40 & 56.80 & 58.10 & 62.90 & 67.80 & 2.90 & 6.60 \\
\hline $\begin{array}{l}\text { Avg. Headway } \\
\text { (ft) }\end{array}$ & 123.50 & 77.30 & 323.70 & 400.70 & 814.90 & 823.70 & 168.80 & 245.10 \\
\hline $\begin{array}{l}\text { Maximum Speed } \\
\text { (mph) }\end{array}$ & 64.50 & 69.80 & 78.20 & 80.00 & 92.70 & 95.50 & 6.50 & 6.30 \\
\hline Brake Force (lbs) & 0.70 & 1.60 & 9.30 & 11.90 & 41.00 & 31.30 & 10.20 & 9.40 \\
\hline Gender & Male & Female & Male & Female & Male & Female & Male & Female \\
\hline Hard Braking & 0.00 & 0.00 & 0.40 & 0.50 & 2.00 & 1.00 & 0.60 & 0.50 \\
\hline Hard Cornering & 0.00 & 1.00 & 3.30 & 3.50 & 10.00 & 6.00 & 2.20 & 1.50 \\
\hline Lane Departures & 0.00 & 1.00 & 17.90 & 15.80 & 39.00 & 27.00 & 9.70 & 7.90 \\
\hline Avg. Speed (mph) & 47.40 & 40.40 & 57.60 & 57.20 & 65.3 .00 & 67.80 & 4.60 & 6.10 \\
\hline $\begin{array}{l}\text { Avg. Headway } \\
\text { (ft) }\end{array}$ & 77.30 & 114.50 & 361.30 & 370.80 & 775.90 & 823.70 & 210.70 & 226.80 \\
\hline $\begin{array}{l}\text { Maximum Speed } \\
\text { (mph) }\end{array}$ & 69.80 & 64.50 & 79.20 & 79.10 & 95.50 & 92.70 & 6.40 & 6.60 \\
\hline Brake Force (lbs) & 1.50 & 0.70 & 12.30 & 8.30 & 41.00 & 24.70 & 11.00 & 6.90 \\
\hline $\begin{array}{l}\text { Lighting } \\
\text { Condition }\end{array}$ & Day & Night & Day & Night & Day & Night & Day & Night \\
\hline Hard Braking & 0.00 & 0.00 & 0.50 & 0.40 & 2.00 & 1.00 & 0.60 & 0.50 \\
\hline Hard Cornering & 0.00 & 1.00 & 3.10 & 3.80 & 9.00 & 10.00 & 1.80 & 2.10 \\
\hline Lane Departures & 0.00 & 9.00 & 13.60 & 22.50 & 27.00 & 39.00 & 7.70 & 8.40 \\
\hline
\end{tabular}




\begin{tabular}{|c|c|c|c|c|c|c|c|c|}
\hline Driver Behavior & \multicolumn{2}{|c|}{ Minimum } & \multicolumn{2}{|l|}{ Mean } & \multicolumn{2}{|c|}{ Maximum } & \multicolumn{2}{|c|}{ Std. Dev. } \\
\hline Age & $\begin{array}{l}\leq 25 \\
\text { Years }\end{array}$ & $\begin{array}{l}>25 \\
\text { Years }\end{array}$ & $\begin{array}{l}\leq 25 \\
\text { Years }\end{array}$ & $\begin{array}{l}>25 \\
\text { Years }\end{array}$ & $\begin{array}{l}\leq 25 \\
\text { Years }\end{array}$ & $\begin{array}{l}>25 \\
\text { Years }\end{array}$ & $\begin{array}{l}\leq 25 \\
\text { Years }\end{array}$ & $\begin{array}{l}>25 \\
\text { Years }\end{array}$ \\
\hline Avg. Speed (mph) & 40.40 & 49.50 & 57.70 & 57.20 & 67.80 & 65.30 & 5.70 & 4.40 \\
\hline $\begin{array}{l}\text { Avg. Headway } \\
(\mathrm{ft})\end{array}$ & 77.30 & 141.70 & 280.90 & 493.30 & 823.70 & 814.90 & 185.70 & 193.80 \\
\hline $\begin{array}{l}\text { Maximum Speed } \\
(\mathrm{mph})\end{array}$ & 64.50 & 71.90 & 78.80 & 79.80 & 92.70 & 95.50 & 5.80 & 7.40 \\
\hline Brake Force (lbs) & 0.70 & 1.60 & 12.40 & 7.90 & 41.00 & 28.80 & 10.60 & 7.40 \\
\hline $\begin{array}{l}\text { Weather } \\
\text { Condition }\end{array}$ & Clear & Rain & Clear & Rain & Clear & Rain & Clear & Rain \\
\hline Hard Braking & 0.00 & 0.00 & 0.40 & 0.30 & 2.00 & 2.00 & 0.60 & 0.60 \\
\hline Hard Cornering & 2.00 & 0.00 & 3.00 & 3.20 & 5.00 & 10.00 & 0.90 & 2.80 \\
\hline Lane Departures & 0.00 & 0.00 & 17.00 & 15.30 & 36.00 & 39.00 & 8.70 & 10.60 \\
\hline Avg. Speed (mph) & 53.00 & 40.40 & 58.00 & 54.10 & 66.60 & 64.60 & 3.90 & 6.40 \\
\hline $\begin{array}{l}\text { Avg. Headway } \\
(\mathrm{ft})\end{array}$ & 77.30 & 206.50 & 305.90 & 561.30 & 714.60 & 823.70 & 172.00 & 206.90 \\
\hline $\begin{array}{l}\text { Maximum Speed } \\
(\mathrm{mph})\end{array}$ & 64.50 & 69.80 & 78.70 & 79.20 & 92.70 & 95.50 & 6.30 & 7.00 \\
\hline Brake Force (lbs) & 0.70 & 1.50 & 11.30 & 8.90 & 41.00 & 20.70 & 11.00 & 6.70 \\
\hline
\end{tabular}

Note: Braking, cornering and lane departures are numbers without units. They are the number of times the corresponding action was performed per participant per simulation.

The mean values of hard cornering, lane departures, and average headway are higher for the participant group that drove in nighttime driving conditions. The mean values of other driver behavior parameters are similar. Riskier driving behavior in lane-following and braking was observed at night, while greater headway values indicated safer car-following maneuvers. Except average headways, the mean values of all the driver behavior parameters are similar between the two participant groups. The mean value of average headway is higher for the participant group that drove in the rain which indicates safer car-following maneuvers.

\subsubsection{Automated System}

This section discusses the effects of automated systems (in particular, LKA and ACC) compared to warning systems and vehicles without ADAS. When a vehicle engages both LKA and ACC while driving, a level- 2 vehicle is simulated. Table 12 shows the comparison of descriptive statistics between participant groups that drove vehicles with automated systems compared to vehicles with warning systems and without any ADAS in the rural scenario. The mean values of lane departures, average headway, maximum speed, and brake force for automated systems are lower compared to both warning systems and vehicles without ADAS. Further, the standard deviation for all driver behavior parameters is low for vehicles equipped with automated systems compared to warning systems and vehicles without ADAS. This shows lower variation in participants' driving behavior.

Table 13 shows the comparison of descriptive statistics between the participant group that drove a vehicle with LKA compared to the participant group that drove a vehicle with LDW in the rural 
scenario. The mean values of lane departures, average speed, average headway, and brake force are lower for LKA compared to LDW. The standard deviation for these driver behaviors is also low, which shows lower variation in participants' driving behavior.

Table 14 shows the comparison of descriptive statistics between the participant group that drove a vehicle with ACC compared to the participant group that drove a vehicle with BSW and the participant group that drove a vehicle with OSW in the rural scenario. The mean values of average headway and brake force are lower for the participant group that drove a vehicle with ACC compared to BSW and OSW.

Table 12. Driver Behavior Parameters - No ADAS, Warning and Automated Systems (Rural)

\begin{tabular}{|c|c|c|c|c|}
\hline Driver Behavior & Statistic & No ADAS & Warning & Automated \\
\hline Hard Braking & \multirow[t]{7}{*}{ Minimum } & 1.00 & 0.00 & 1.00 \\
\hline Hard Cornering & & 1.00 & 0.00 & 1.00 \\
\hline Lane Departures & & 2.00 & 0.00 & 1.00 \\
\hline Avg. Speed (mph) & & 29.90 & 14.60 & 36.90 \\
\hline Avg. Headway (ft) & & 89.50 & 49.50 & 94.00 \\
\hline Maximum Speed (mph) & & 50.00 & 42.80 & 52.80 \\
\hline Brake Force (lbs.) & & 10.30 & 0.33 & 1.11 \\
\hline Hard Braking & \multirow[t]{7}{*}{ Mean } & 2.14 & 1.06 & 2.14 \\
\hline Hard Cornering & & 3.00 & 3.30 & 2.14 \\
\hline Lane Departures & & 8.57 & 8.31 & 1.43 \\
\hline Avg. Speed (mph) & & 45.20 & 40.33 & 39.46 \\
\hline Avg. Headway (ft) & & 421.71 & 433.12 & 112.00 \\
\hline Maximum Speed (mph) & & 69.20 & 61.33 & 57.56 \\
\hline Brake Force (lbs.) & & 22.64 & 24.85 & 1.67 \\
\hline Hard Braking & \multirow[t]{7}{*}{ Maximum } & 3.00 & 4.00 & 3.00 \\
\hline Hard Cornering & & 10.00 & 12.00 & 4.00 \\
\hline Lane Departures & & 23.00 & 30.00 & 3.00 \\
\hline Avg. Speed (mph) & & 62.10 & 60.30 & 41.60 \\
\hline Avg. Headway (ft) & & 631.30 & 853.70 & 175.40 \\
\hline Maximum Speed (mph) & & 89.00 & 107.50 & 61.20 \\
\hline Brake Force (lbs.) & & 38.00 & 60.00 & 2.72 \\
\hline Hard Braking & \multirow[t]{7}{*}{ Std. Dev. } & 0.69 & 1.01 & 0.69 \\
\hline Hard Cornering & & 3.11 & 2.94 & 1.07 \\
\hline Lane Departures & & 7.14 & 7.05 & 0.79 \\
\hline Avg. Speed (mph) & & 12.46 & 8.47 & 1.72 \\
\hline Avg. Headway (ft) & & 181.18 & 223.99 & 28.68 \\
\hline Maximum Speed (mph) & & 15.33 & 16.61 & 2.99 \\
\hline Brake Force (lbs.) & & 8.80 & 12.87 & 0.56 \\
\hline
\end{tabular}

Note: Braking, cornering and lane departures are numbers without units. They are the number of times the corresponding action was performed per participant per simulation. 
Table 13. Driver Behavior Parameters - LKA and LDW (Rural)

\begin{tabular}{|l|l|l|l|l|l|l|l|l|}
\hline Driver Behavior & \multicolumn{2}{|l|}{ Minimum } & \multicolumn{2}{l|}{ Mean } & \multicolumn{2}{l|}{ Maximum } & \multicolumn{2}{l|}{ Std. Dev. } \\
\hline & LKA & LDW & LKA & LDW & LKA & LDW & LKA & LDW \\
\hline Hard Braking & 0.00 & 0.00 & 1.50 & 1.50 & 3.00 & 3.00 & 1.29 & 1.05 \\
\hline Hard Cornering & 2.00 & 1.00 & 2.75 & 2.50 & 4.00 & 5.00 & 0.96 & 1.38 \\
\hline Lane Departures & 2.00 & 2.00 & 3.50 & 5.33 & 5.00 & 13.00 & 1.29 & 4.03 \\
\hline Avg. Speed (mph) & 39.80 & 41.30 & 41.43 & 49.96 & 43.40 & 60.30 & 1.64 & 6.93 \\
\hline Avg. Headway (ft) & 383.80 & 381.10 & 440.30 & 566.40 & 506.50 & 757.60 & 50.74 & 136.41 \\
\hline Maximum Speed (mph) & 61.60 & 49.10 & 68.20 & 72.70 & 73.40 & 107.50 & 5.08 & 25.7 \\
\hline Brake Force (lbs.) & 14.60 & 21.40 & 19.60 & 26.22 & 23.40 & 31.80 & 3.75 & 4.08 \\
\hline
\end{tabular}

Note: Braking, cornering and lane departures are numbers without units. They are the number of times the corresponding action was performed per participant per simulation.

Table 15 shows the comparison of descriptive statistics between the participant group that drove a vehicle with automated systems compared to the participant group that drove a vehicle with warning systems or without any ADAS in the urban scenario. The mean values of lane departures, average headway, and brake force are lower for automated systems. Lower standard deviation values for lane departures, average speed, average headway, maximum speed, and brake force indicated less variance in participants' driving behavior.

Table 16 shows the comparison of descriptive statistics between the participant group that drove a vehicle with LKA compared to the participant group that drove a vehicle with LDW in the urban scenario. The mean value of hard cornering events is higher for LKA which also yielded lower mean values for lane departures, average headway, and brake force.

Table 17 compares descriptive statistics between the participant group that drove a vehicle with ACC compared to the participant group that drove a vehicle with BSW or OSW in the urban scenario. The mean values of hard braking and hard cornering are higher for the participant group that drove a vehicle with ACC compared to BSW and OSW, whereas the mean values of average headway and brake force are lower.

Table 18 shows the comparison of descriptive statistics between the participant group that drove a vehicle with automated systems compared to the participant group that drove a vehicle with warning systems or without any ADAS in the freeway scenario. The mean values of hard braking, lane departures, average speed, average headway, maximum speed, and brake force are lower for automated systems. Lower standard deviation was also observed for these driver behaviors, indicating less variance in participant driving behavior. 
Table 14. Driver Behavior Parameters - ACC, BSW and OSW (Rural)

\begin{tabular}{|c|c|c|c|c|}
\hline Driver Behavior & Statistic & ACC & BSW & OSW \\
\hline Hard Braking & \multirow{7}{*}{ Minimum } & 1.00 & 0.00 & 0.00 \\
\hline Hard Cornering & & 2.00 & 0.00 & 0.00 \\
\hline Lane Departures & & 8.00 & 1.00 & 7.00 \\
\hline Avg. Speed (mph) & & 35.30 & 33.40 & 31.40 \\
\hline Avg. Headway (ft) & & 94.30 & 65.50 & 121.60 \\
\hline Maximum Speed (mph) & & 55.40 & 52.80 & 47.70 \\
\hline Brake Force (lbs.) & & 1.19 & 1.26 & 1.26 \\
\hline Hard Braking & \multirow[t]{7}{*}{ Mean } & 2.25 & 1.00 & 1.43 \\
\hline Hard Cornering & & 2.50 & 1.57 & 4.86 \\
\hline Lane Departures & & 10.25 & 3.71 & 15.29 \\
\hline Avg. Speed (mph) & & 36.53 & 41.81 & 36.94 \\
\hline Avg. Headway (ft) & & 97.15 & 388.11 & 489.56 \\
\hline Maximum Speed (mph) & & 57.35 & 78.11 & 53.96 \\
\hline Brake Force (lbs.) & & 1.29 & 19.52 & 32.09 \\
\hline Hard Braking & \multirow[t]{7}{*}{ Maximum } & 3.00 & 2.00 & 4.00 \\
\hline Hard Cornering & & 3.00 & 3.00 & 12.00 \\
\hline Lane Departures & & 13.00 & 7.00 & 30.00 \\
\hline Avg. Speed (mph) & & 38.20 & 55.60 & 46.50 \\
\hline Avg. Headway (ft) & & 102.80 & 588.40 & 600.10 \\
\hline Maximum Speed (mph) & & 59.10 & 95.40 & 56.40 \\
\hline Brake Force (lbs.) & & 1.46 & 32.70 & 60.00 \\
\hline Hard Braking & \multirow[t]{7}{*}{ Std. Dev. } & 0.96 & 0.58 & 1.40 \\
\hline Hard Cornering & & 0.58 & 0.98 & 3.58 \\
\hline Lane Departures & & 2.22 & 2.21 & 7.70 \\
\hline Avg. Speed (mph) & & 1.21 & 8.72 & 6.06 \\
\hline Avg. Headway (ft) & & 3.88 & 178.39 & 166.09 \\
\hline Maximum Speed (mph) & & 1.70 & 17.11 & 3.33 \\
\hline Brake Force (lbs.) & & 0.12 & 11.29 & 18.43 \\
\hline
\end{tabular}

Note: Braking, cornering and lane departures are numbers without units. They are the number of times the corresponding action was performed per participant per simulation. 
Table 15. Driver Behavior Parameters - No ADAS, Warning and Automated Systems (Urban)

\begin{tabular}{|c|c|c|c|c|}
\hline Driver Behavior & Statistic & No ADAS & Warning & Automated \\
\hline Hard Braking & \multirow[t]{7}{*}{ Minimum } & 0.00 & 0.00 & 0.00 \\
\hline Hard Cornering & & 0.00 & 0.00 & 0.00 \\
\hline Lane Departures & & 0.00 & 0.00 & 0.00 \\
\hline Avg. Speed (mph) & & 37.20 & 30.50 & 34.77 \\
\hline Avg. Headway (ft) & & 616.70 & 157.70 & 94.00 \\
\hline Maximum Speed (mph) & & 51.90 & 49.40 & 57.90 \\
\hline Brake Force (lbs.) & & 18.30 & 3.90 & 1.09 \\
\hline Hard Braking & \multirow[t]{7}{*}{ Mean } & 1.50 & 1.51 & 1.71 \\
\hline Hard Cornering & & 1.50 & 1.54 & 2.14 \\
\hline Lane Departures & & 6.83 & 5.16 & 1.43 \\
\hline Avg. Speed (mph) & & 41.72 & 42.00 & 43.66 \\
\hline Avg. Headway (ft) & & 937.93 & 838.35 & 126.44 \\
\hline Maximum Speed (mph) & & 59.22 & 62.29 & 61.23 \\
\hline Brake Force (lbs.) & & 38.48 & 23.03 & 1.65 \\
\hline Hard Braking & \multirow[t]{7}{*}{ Maximum } & 3.00 & 4.00 & 3.00 \\
\hline Hard Cornering & & 3.00 & 5.00 & 4.00 \\
\hline Lane Departures & & 20.00 & 21.00 & 4.00 \\
\hline Avg. Speed (mph) & & 55.30 & 53.90 & 45.80 \\
\hline Avg. Headway (ft) & & 1170.30 & 1660.20 & 230.90 \\
\hline Maximum Speed (mph) & & 75.40 & 102.20 & 64.40 \\
\hline Brake Force (lbs.) & & 61.20 & 60.30 & 2.69 \\
\hline Hard Braking & \multirow[t]{7}{*}{ Std. Dev. } & 1.05 & 1.28 & 0.95 \\
\hline Hard Cornering & & 1.22 & 1.28 & 1.21 \\
\hline Lane Departures & & 7.94 & 4.88 & 1.27 \\
\hline Avg. Speed (mph) & & 6.88 & 6.31 & 3.93 \\
\hline Avg. Headway (ft) & & 218.89 & 386.39 & 49.34 \\
\hline Maximum Speed (mph) & & 8.21 & 9.94 & 2.10 \\
\hline Brake Force (lbs.) & & 17.10 & 14.99 & 0.55 \\
\hline
\end{tabular}

Note: Braking, cornering and lane departures are numbers without units. They are the number of times the corresponding action was performed per participant per simulation. 
Table 16. Driver Behavior Parameters - LKA and LDW (Urban)

\begin{tabular}{|l|l|l|l|l|l|l|l|l|}
\hline Driver Behavior & \multicolumn{2}{l}{ Minimum } & \multicolumn{2}{l|}{ Mean } & \multicolumn{2}{l|}{ Maximum } & \multicolumn{2}{l|}{ Std. Dev. } \\
\hline & LKA & LDW & LKA & LDW & LKA & LDW & LKA & LDW \\
\hline Hard Braking & 1.00 & 1.00 & 2.00 & 2.14 & 3.00 & 4.00 & 0.82 & 1.21 \\
\hline Hard Cornering & 1.00 & 0.00 & 2.25 & 1.14 & 3.00 & 2.00 & 0.96 & 0.90 \\
\hline Lane Departures & 1.00 & 0.00 & 1.75 & 2.86 & 3.00 & 11.00 & 0.96 & 3.80 \\
\hline Avg. Speed (mph) & 36.90 & 33.80 & 40.53 & 42.37 & 44.70 & 51.80 & 3.29 & 5.81 \\
\hline Avg. Headway (ft) & 311.20 & 157.70 & 363.75 & 876.40 & 432.60 & 1236.90 & 51.42 & 396.16 \\
\hline Maximum Speed (mph) & 64.20 & 51.90 & 68.25 & 66.37 & 71.00 & 102.20 & 3.13 & 16.82 \\
\hline Brake Force (lbs.) & 15.60 & 8.00 & 19.00 & 27.86 & 22.20 & 41.10 & 3.03 & 11.39 \\
\hline
\end{tabular}

Note: Braking, cornering and lane departures are numbers without units. They are the number of times the corresponding action was performed per participant per simulation.

Table 17. Driver Behavior Parameters - ACC, BSW and OSW (Urban)

\begin{tabular}{|c|c|c|c|c|}
\hline Driver Behavior & Statistic & $\mathrm{ACC}$ & BSW & OSW \\
\hline Hard Braking & \multirow{7}{*}{ Minimum } & 1.00 & 0.00 & 0.00 \\
\hline Hard Cornering & & 1.00 & 1.00 & 1.00 \\
\hline Lane Departures & & 7.00 & 1.00 & 2.00 \\
\hline Avg. Speed (mph) & & 44.60 & 37.60 & 30.50 \\
\hline Avg. Headway (ft) & & 97.60 & 282.60 & 600.80 \\
\hline Maximum Speed (mph) & & 59.30 & 56.60 & 50.80 \\
\hline Brake Force (lbs.) & & 1.11 & 6.70 & 6.90 \\
\hline Hard Braking & \multirow[t]{7}{*}{ Mean } & 2.00 & 1.86 & 0.67 \\
\hline Hard Cornering & & 3.00 & 2.57 & 2.00 \\
\hline Lane Departures & & 10.50 & 3.14 & 11.00 \\
\hline Avg. Speed (mph) & & 45.77 & 47.71 & 40.68 \\
\hline Avg. Headway (ft) & & 102.55 & 422.59 & 889.15 \\
\hline Maximum Speed (mph) & & 61.10 & 65.50 & 59.12 \\
\hline Brake Force (lbs.) & & 1.44 & 12.11 & 23.47 \\
\hline Hard Braking & \multirow[t]{7}{*}{ Maximum } & 3.00 & 3.00 & 2.00 \\
\hline Hard Cornering & & 2.00 & 4.00 & 4.00 \\
\hline Lane Departures & & 14.00 & 6.00 & 21.00 \\
\hline Avg. Speed (mph) & & 47.10 & 53.60 & 50.30 \\
\hline Avg. Headway (ft) & & 108.10 & 900.00 & 1660.20 \\
\hline Maximum Speed (mph) & & 62.10 & 78.70 & 61.60 \\
\hline Brake Force (lbs.) & & 1.63 & 20.40 & 60.30 \\
\hline Hard Braking & \multirow[t]{5}{*}{ Std. Dev. } & 0.82 & 1.07 & 0.82 \\
\hline Hard Cornering & & 0.82 & 1.40 & 1.09 \\
\hline Lane Departures & & 3.11 & 2.12 & 7.87 \\
\hline Avg. Speed (mph) & & 1.10 & 4.95 & 6.68 \\
\hline Avg. Headway (ft) & & 4.93 & 217.38 & 389.93 \\
\hline
\end{tabular}




\begin{tabular}{|l|l|l|l|l|}
\hline Driver Behavior & Statistic & ACC & BSW & OSW \\
\hline Maximum Speed (mph) & & 1.26 & 7.31 & 4.11 \\
\cline { 1 - 1 } Brake Force (lbs.) & & 0.23 & 4.39 & 19.65 \\
\hline
\end{tabular}

Note: Braking, cornering and lane departures are numbers without units. They are the number of times the corresponding action was performed per participant per simulation.

Table 18. Driver Behavior Parameters - No ADAS, Warning and Automated Systems (Freeway)

\begin{tabular}{|c|c|c|c|c|}
\hline Driver Behavior & Statistic & No ADAS & Warning & Automated \\
\hline Hard Braking & \multirow[t]{7}{*}{ Minimum } & 0.00 & 0.00 & 0.00 \\
\hline Hard Cornering & & 3.00 & 0.00 & 2.00 \\
\hline Lane Departures & & 16.00 & 0.00 & 1.00 \\
\hline Avg. Speed (mph) & & 49.50 & 40.40 & 48.20 \\
\hline Avg. Headway (ft) & & 114.50 & 77.30 & 117.00 \\
\hline Maximum Speed (mph) & & 73.60 & 64.50 & 63.60 \\
\hline Brake Force (lbs.) & & 2.20 & 0.70 & 0.03 \\
\hline Hard Braking & \multirow[t]{7}{*}{ Mean } & 0.50 & 0.41 & 0.00 \\
\hline Hard Cornering & & 5.33 & 3.05 & 3.14 \\
\hline Lane Departures & & 25.83 & 15.70 & 3.29 \\
\hline Avg. Speed (mph) & & 58.73 & 57.29 & 50.69 \\
\hline Avg. Headway (ft) & & 356.62 & 366.21 & 206.57 \\
\hline Maximum Speed (mph) & & 79.40 & 79.17 & 66.36 \\
\hline Brake Force (lbs.) & & 6.65 & 11.58 & 0.12 \\
\hline Hard Braking & \multirow[t]{7}{*}{ Maximum } & 1.00 & 2.00 & 0.00 \\
\hline Hard Cornering & & 10.00 & 9.00 & 6.00 \\
\hline Lane Departures & & 39.00 & 36.00 & 6.00 \\
\hline Avg. Speed (mph) & & 67.80 & 66.60 & 54.70 \\
\hline Avg. Headway (ft) & & 588.90 & 823.70 & 269.30 \\
\hline Maximum Speed (mph) & & 87.50 & 95.50 & 69.90 \\
\hline Brake Force (lbs.) & & 12.60 & 41.00 & 0.27 \\
\hline Hard Braking & \multirow[t]{7}{*}{ Std. Dev. } & 0.55 & 0.60 & 0.00 \\
\hline Hard Cornering & & 2.66 & 1.63 & 1.46 \\
\hline Lane Departures & & 8.28 & 8.41 & 1.80 \\
\hline Avg. Speed (mph) & & 6.79 & 4.95 & 2.00 \\
\hline Avg. Headway (ft) & & 193.53 & 219.78 & 59.32 \\
\hline Maximum Speed (mph) & & 5.66 & 6.59 & 2.14 \\
\hline Brake Force (lbs.) & & 4.22 & 10.15 & 0.08 \\
\hline
\end{tabular}

Note: Braking, cornering and lane departures are numbers without units. They are the number of times the corresponding action was performed per participant per simulation. 
Table 19 shows the comparison of descriptive statistics between the participant group that drove a vehicle with LKA compared to the participant group that drove a vehicle with LDW in the freeway scenario. The mean value of the number of hard braking events is higher for LKA. The mean values of the number of hard braking events, lane departures, and brake force are lower for LKA.

Table 20 shows the comparison of descriptive statistics between the participant group that drove a vehicle with ACC compared to the participant group that drove a vehicle with BSW or OSW in the freeway scenario. The mean of the number of hard braking events is higher for the participant group that drove a vehicle with ACC compared to BSW and OSW, whereas the mean values of the number of hard cornering events, average headway, and brake force are lower.

The mean values of some of the variables vary based on the ADAS provided to the participant. The type of driving scenario also impacted driving behavior. LDW and OSW affected the mean values of the majority of the driver behaviors for all the scenarios, but BSW affected fewer driving behaviors. Additionally, age, gender, lighting and weather conditions also had an effect on participants' driving behaviors. They exhibited safer car-following maneuvers during rainy and nighttime driving conditions. The type of driving scenario also affected male and female participants' driving behavior. The differences in the mean values need to be further investigated to derive meaningful results. The sample sizes were not equal for different groups (for example, the number of participants provided with LDW, BSW or OSW are not the same). A one-way ANOVA test can accommodate comparison groups of unequal sample sizes. The next chapter presents and discusses the one-way ANOVA test results.

Table 19. Driver Behavior Parameters - LKA and LDW (Freeway)

\begin{tabular}{|l|l|l|l|l|l|l|l|l|}
\hline Driver Behavior & \multicolumn{2}{l}{ Minimum } & \multicolumn{2}{l|}{ Mean } & \multicolumn{2}{l|}{ Maximum } & \multicolumn{2}{l|}{ Std. Dev. } \\
\hline & LKA & LDW & LKA & LDW & LKA & LDW & LKA & LDW \\
\hline Hard Braking & 0.00 & 0.00 & 0.50 & 0.29 & 1.00 & 1.00 & 0.58 & 0.49 \\
\hline Hard Cornering & 1.00 & 2.00 & 1.75 & 2.29 & 3.00 & 3.00 & 0.96 & 0.49 \\
\hline Lane Departures & 1.00 & 1.00 & 2.00 & 10.86 & 3.00 & 15.00 & 0.82 & 5.61 \\
\hline Avg. Speed (mph) & 58.30 & 54.40 & 62.00 & 59.20 & 65.40 & 66.60 & 3.03 & 4.20 \\
\hline Avg. Headway (ft) & 188.20 & 77.30 & 209.45 & 201.39 & 256.20 & 367.30 & 32.03 & 89.52 \\
\hline Maximum Speed (mph) & 78.40 & 64.50 & 80.58 & 76.81 & 82.20 & 86.50 & 1.65 & 6.49 \\
\hline Brake Force (lbs.) & 7.40 & 4.20 & 8.70 & 13.49 & 11.30 & 24.70 & 1.76 & 7.68 \\
\hline
\end{tabular}

Note: Braking, cornering and lane departures are numbers without units. They are the number of times the corresponding action was performed per participant per simulation. 
Table 20. Driver Behavior Parameters - ACC, BSW and OSW (Freeway)

\begin{tabular}{|c|c|c|c|c|}
\hline Driver Behavior & Statistic & $\mathrm{ACC}$ & BSW & OSW \\
\hline Hard Braking & \multirow[t]{7}{*}{ Minimum } & 0.00 & 0.00 & 0.00 \\
\hline Hard Cornering & & 1.00 & 1.00 & 2.00 \\
\hline Lane Departures & & 19.00 & 4.00 & 11.00 \\
\hline Avg. Speed (mph) & & 55.10 & 53.90 & 54.00 \\
\hline Avg. Headway (ft) & & 169.40 & 198.90 & 204.80 \\
\hline Maximum Speed (mph) & & 71.40 & 73.80 & 76.90 \\
\hline Brake Force (lbs.) & & 0.11 & 0.70 & 4.90 \\
\hline Hard Braking & \multirow[t]{7}{*}{ Mean } & 0.50 & 0.29 & 0.20 \\
\hline Hard Cornering & & 2.00 & 2.71 & 3.20 \\
\hline Lane Departures & & 20.75 & 20.71 & 21.20 \\
\hline Avg. Speed (mph) & & 57.80 & 56.53 & 56.26 \\
\hline Avg. Headway (ft) & & 185.38 & 403.40 & 294.12 \\
\hline Maximum Speed (mph) & & 77.40 & 80.41 & 80.10 \\
\hline Brake Force (lbs.) & & 0.19 & 11.28 & 17.07 \\
\hline Hard Braking & \multirow[t]{7}{*}{ Maximum } & 1.00 & 1.00 & 1.00 \\
\hline Hard Cornering & & 3.00 & 5.00 & 5.00 \\
\hline Lane Departures & & 24.00 & 36.00 & 27.00 \\
\hline Avg. Speed (mph) & & 60.10 & 62.60 & 59.40 \\
\hline Avg. Headway (ft) & & 211.20 & 705.60 & 430.60 \\
\hline Maximum Speed (mph) & & 80.90 & 92.70 & 84.40 \\
\hline Brake Force (lbs.) & & 0.31 & 28.80 & 31.30 \\
\hline Hard Braking & \multirow[t]{7}{*}{ Std. Dev. } & 0.58 & 0.49 & 0.45 \\
\hline Hard Cornering & & 0.82 & 1.38 & 1.10 \\
\hline Lane Departures & & 2.36 & 10.34 & 6.34 \\
\hline Avg. Speed (mph) & & 2.08 & 3.21 & 2.66 \\
\hline Avg. Headway (ft) & & 18.84 & 188.08 & 90.91 \\
\hline Maximum Speed (mph) & & 4.49 & 8.29 & 2.82 \\
\hline Brake Force (lbs.) & & 0.09 & 12.05 & 14.16 \\
\hline
\end{tabular}

Note: Braking, cornering and lane departures are numbers without units. They are the number of times the corresponding action was performed per participant per simulation. 


\section{Results}

This chapter presents the results from the ANOVA test on the significant differences in participant group mean values for hard braking, hard cornering, lane departures, average speed, average headway, maximum speed, and brake pedal force. While many variables can be extracted from miniSim ${ }^{\mathrm{TM}}$, the variables that convey the most information were chosen for the analysis. Since the focus of this study is to capture the effect of advanced features on driving behavior, the factors that can best explain these differences were selected. The hard braking and hard cornering events help differentiate safe and aggressive driving behavior. The lane departure event was selected to verify the effectiveness of LDW on driving behavior. Similarly, the maximum speed parameter was chosen to evaluate the effectiveness of OSW. OSW was set up to activate when the participant crosses the designated speed limit (5 mph higher than the posted speed limit) in the simulations. The maximum speed represents the event when a participant would have crossed the set speed limit for OSW. This helps to compare the two participant groups.

The LKA was tested using both the lane departure events and percentage parameter. The ACC was tested using the average headway parameter, or distance from the leading vehicle. Also, a level 2 connected and automated vehicle was tested on some randomly selected participants with LKA and ACC engaged simultaneously. The behavior of these participants was compared to the participant groups that was provided with warning systems and vehicles without any ADAS.

\subsection{Rural Driving Scenario}

In order to evaluate the effectiveness of LDW, the number of lane departure events from the simulations were extracted. The lane departure data was combined with the ADAS provision data. A one-way ANOVA test was performed on the dataset as the sample sets were unequal. The inequality in the data samples is due to the random assignment of the ADAS to the participants. The ANOVA test results are presented by the scenario type. The ANOVA results of only the driver behaviors that were significant at a p-value of 0.05 in the rural scenario are presented in Table 21. The results from Table 21 include the effects of ADAS, lighting, and weather conditions.

BSW was set up to show a warning light on the mirror when the participants were driving only at certain periods of time. This system was simulated by setting up a car-following session and activating BSW at the same time to capture the participants reaction. BSW was found to affect the brake pedal force variable in the rural scenario. Table 21 summarizes the ANOVA test results of brake pedal force for BSW in the rural scenario.

OSW was set up using the "expression" trigger which was set to go off when the participant was exceeding speeds of more than 5 or $10 \mathrm{mph}$ than the posted speed limit. Similar to LDW, OSW system was also tested for effectiveness using the maximum speed variable. The maximum speed is a direct measure of the effects of OSW. Table 21 also shows the ANOVA test results for the maximum speed in rural scenario. All the null and alternate hypotheses from Table 21 are discussed next in the same sequential order. 
Table 21. ANOVA Results - ADAS, Lighting, and Weather Conditions (Rural)

\begin{tabular}{|c|c|c|c|c|c|c|c|}
\hline Source of Variation & $\begin{array}{l}\text { Driving } \\
\text { Behavior \& } \\
\text { ADAS }\end{array}$ & SS & $\mathrm{df}$ & MS & $\mathrm{F}$ & P-value & F-critical \\
\hline Between Groups & \multirow{3}{*}{$\begin{array}{l}\text { Lane } \\
\text { Departures - } \\
\text { LDW }\end{array}$} & 205.23 & 1 & 205.23 & 4.57 & 0.04 & 4.08 \\
\hline Within Groups & & $1,840.54$ & 41 & 44.89 & & & \\
\hline Total & & $2,045.77$ & 42 & & & & \\
\hline Between Groups & \multirow{3}{*}{$\begin{array}{l}\text { Brake Pedal } \\
\text { Force - BSW }\end{array}$} & 615.20 & 1 & 615.20 & 4.44 & 0.04 & 4.08 \\
\hline Within Groups & & $5,678.58$ & 41 & 138.50 & & & \\
\hline Total & & $6,293.78$ & 42 & & & & \\
\hline Between Groups & \multirow{3}{*}{$\begin{array}{l}\text { Maximum } \\
\text { Speed - OSW }\end{array}$} & 692.88 & 1 & 692.88 & 9.83 & $<0.01$ & 4.08 \\
\hline Within Groups & & 2888.48 & 41 & 70.45 & & & \\
\hline Total & & $3,581.37$ & 42 & & & & \\
\hline Between Groups & \multirow{3}{*}{$\begin{array}{l}\text { Average Speed - } \\
\text { OSW }\end{array}$} & $3,423.67$ & 1 & $3,423.67$ & 17.54 & $<0.01$ & 4.08 \\
\hline Within Groups & & $8,003.22$ & 41 & 195.20 & & & \\
\hline Total & & $11,426.89$ & 42 & & & & \\
\hline Between Groups & \multirow{3}{*}{$\begin{array}{l}\text { Brake Pedal } \\
\text { Force - Two } \\
\text { ADAS }\end{array}$} & 7.07 & 1 & 7.07 & 7.27 & 0.01 & 4.09 \\
\hline Within Groups & & 37.96 & 39 & 0.97 & & & \\
\hline Total & & 45.02 & 40 & & & & \\
\hline Between Groups & \multirow{3}{*}{$\begin{array}{l}\text { Average } \\
\text { Headway - } \\
\text { Light } \\
\text { Condition }\end{array}$} & 375828.10 & 1 & 375828.10 & 9.76 & $<0.01$ & 4.09 \\
\hline Within Groups & & 1578003.00 & 41 & 38487.90 & & & \\
\hline Total & & 1953831.00 & 42 & & & & \\
\hline Between Groups & \multirow{3}{*}{$\begin{array}{l}\text { Lane } \\
\text { Departures - } \\
\text { Light } \\
\text { Condition }\end{array}$} & 623.70 & 1 & 623.70 & 17.98 & $<0.01$ & 4.09 \\
\hline Within Groups & & 1422.10 & 41 & 34.70 & & & \\
\hline Total & & 2045.80 & 42 & & & & \\
\hline Between Groups & \multirow{3}{*}{$\begin{array}{l}\text { Average } \\
\text { Headway - } \\
\text { Weather } \\
\text { Condition }\end{array}$} & 180865.2 & 1 & 180865.20 & 5.31 & 0.03 & 4.09 \\
\hline Within Groups & & 1226487 & 36 & 340691 & & & \\
\hline Total & & 1407352 & 37 & & & & \\
\hline
\end{tabular}

The null hypothesis is defined as there is no significant difference between the mean values of lane departure events between the participant group provided with LDW and the participant group who did not have LDW in the rural scenario. The alternate hypothesis states that there is a significance difference in the mean values of lane departure events between the participant group provided with LDW and participant group who did not have LDW in the rural scenario. Based on the F-statistic and p-value, the null hypothesis can be rejected at a $95 \%$ confidence level. The effectiveness of LDW on lane departure events is significant at a $95 \%$ confidence level.

The null hypothesis states that there is no significant difference between the mean values of brake pedal force between the participant group provided with BSW and the participant group who did not have BSW in the rural scenario. The alternate hypothesis states that there is a significant 
difference between the mean values of brake pedal force between the participant group provided with BSW and participant group without BSW in the rural scenario. Based on the F-statistic and p-value, the null hypothesis can be rejected confirming the effect of BSW on brake force pedal. Similar results were observed when the participant group provided with any two ADAS types was compared with the participant group provided with one or without ADAS. Two advanced features affected the brake pedal force.

The null hypothesis states that there is no significant difference between the mean values of maximum speed between the participant group provided with OSW and the participant group who did not have OSW in the rural scenario. The alternate hypothesis states that there is a significant difference between the mean values of maximum speed between the participant group provided with OSW and participant group without OSW in the rural scenario. Based on the Fstatistic and $\mathrm{p}$-value, the null hypothesis can be rejected implying a significant difference in the maximum speeds reached by participants with and without OSW. Similarly, the effect of OSW on the average speed was significant at a 95\% confidence level (Table 21).

The null hypothesis states that there is no significant difference between the mean values of average speed between the participant group provided with OSW and the participant group who did not have OSW in the rural scenario. The alternate hypothesis states that there is a significant difference between the mean values of average speed between the participant group provided with OSW and the participant group who did not have OSW in the rural scenario. Based on the Fstatistic and p-value, the null hypothesis can be rejected as the mean values of average speed between the two participant groups are not the same. However, the effect of OSW was not found to be significant on any of the other variables in the rural scenario.

The null hypothesis states that there is no significant difference between the mean values of brake pedal force between the participant group provided with any two advanced features and the participant group who did not have ADAS in the rural scenario. The alternate hypothesis states that there is a significant difference between the mean values of brake pedal force between the participant group provided with any two advanced features and the participant group who did not have any ADAS in the rural scenario. Based on the F-statistic and p-value, the null hypothesis can be rejected as the mean values are significantly different. Therefore, providing two ADAS significantly affects the braking behavior. However, providing two ADAS did not have a significant influence on other driving behaviors.

The null hypothesis states that there is no significant difference between the mean values of average headway between the participant group driving in daytime condition and the participant group driving in nighttime condition in the rural scenario. The alternate hypothesis states that there is a significant difference between the mean values of average headway between the participant group driving in daytime condition and the participant group driving in nighttime condition in the rural scenario. Based on the F-statistic and $\mathrm{p}$-value, the null hypothesis can be rejected implying a significant difference between the mean values. Therefore, the effect of the time of driving on the driving behavior is evident.

The null hypothesis states that there is no significant difference between the mean values of lane departures between the participant group driving in daytime condition and the participant group driving in nighttime condition in the rural scenario. The alternate hypothesis states that there is a significant difference between the mean values of lane departures between the participant group 
driving in daytime condition and the participant group driving in nighttime condition in the rural scenario. Based on the F-statistic and p-value, the null hypothesis can be rejected implying a significant difference between the mean values. The time of driving also impacts lane departures.

The null hypothesis states that there is no significant difference between the mean values of average headway between the participant group driving in clear weather condition and the participant group driving in rainy weather condition in the rural scenario. The alternate hypothesis states that there is a significant difference between the mean values of average headway between the participant group driving in clear weather condition and the participant group driving in rainy weather condition in the rural scenario. Based on the F-statistic and $\mathrm{p}$-value, the null hypothesis can be rejected, implying a significant difference between the mean values. Thus, the weather conditions impact the average headway maintained by the participants.

\subsection{Urban Driving Scenario}

The ANOVA test results of only the driver behaviors that were significant at a p-value of 0.05 in the urban scenario are presented in Table 22. The results from Table 22 include the effects of ADAS, lighting, and weather conditions. The null and alternate hypotheses of all the results from Table 22 are discussed next.

The null hypothesis states that there is no significant difference between the mean values of lane departure events between the participant group provided with LDW and the participant group without LDW in the urban scenario. The alternate hypothesis states that there is a significant difference between the mean values of lane departure events between the participant group provided with LDW and participant group without LDW in the urban scenario. Based on the Fstatistic and p-value, the null hypothesis can be rejected. The effectiveness of LDW on lane departure events in an urban scenario is also significant at a $95 \%$ confidence level.

The null hypothesis states that there is no significant difference between the mean values of total hard cornering events between the participant group provided with LDW and the participant group without LDW in the urban scenario. The alternate hypothesis states that there is a significant difference between the mean values of total hard cornering events between the participant group provided with LDW and the participant group without LDW in the urban scenario. The presence of LDW in a vehicle seems to result in a greater number of hard cornering events. 
Table 22. ANOVA Results - ADAS, Lighting, and Weather Conditions (Urban)

\begin{tabular}{|c|c|c|c|c|c|c|c|}
\hline Source of Variation & \begin{tabular}{|l} 
Driving \\
Behavior \& \\
ADAS
\end{tabular} & SS & $\mathrm{df}$ & MS & $\mathrm{F}$ & $\mathrm{P}$-value & F-critical \\
\hline Between Groups & \multirow{3}{*}{$\begin{array}{l}\text { Lane } \\
\text { Departures - } \\
\text { LDW }\end{array}$} & 134.32 & 1 & 134.32 & 5.23 & 0.03 & 4.08 \\
\hline Within Groups & & $1,053.96$ & 41 & 25.71 & & & \\
\hline Total & & $1,188.28$ & 42 & & & & \\
\hline Between Groups & \multirow{3}{*}{$\begin{array}{l}\text { Hard Cornering } \\
\text { - LDW }\end{array}$} & 15.07 & 1 & 15.07 & 11.97 & $<0.01$ & 4.08 \\
\hline Within Groups & & 51.63 & 41 & 1.26 & & & \\
\hline Total & & 66.70 & 42 & & & & \\
\hline Between Groups & \multirow{3}{*}{$\begin{array}{l}\text { Maximum } \\
\text { Speed - OSW }\end{array}$} & $4,876,652$ & 1 & $4,876,652$ & 74.94 & $<0.01$ & 4.07 \\
\hline Within Groups & & $2,733,042$ & 42 & $65,072.42$ & & & \\
\hline Total & & $7,609,694$ & 43 & & & & \\
\hline Between Groups & \multirow{3}{*}{$\begin{array}{l}\text { Average } \\
\text { Headway - } \\
\text { Light } \\
\text { Condition }\end{array}$} & 1166855.00 & 1 & 1166855.0 & 10.63 & $<0.01$ & 4.09 \\
\hline Within Groups & & 4498522.00 & 41 & 109720.00 & & & \\
\hline Total & & 5665377.00 & 42 & & & & \\
\hline Between Groups & \multirow{3}{*}{$\begin{array}{l}\text { Brake Pedal } \\
\text { Force - Light } \\
\text { Condition }\end{array}$} & 1774.44 & 1 & 1774.44 & 8.36 & $<0.01$ & 4.09 \\
\hline Within Groups & & 7852.38 & 37 & 212.22 & & & \\
\hline Total & & 9626.82 & 38 & & & & \\
\hline Between Groups & \multirow{3}{*}{$\begin{array}{l}\text { Lane } \\
\text { Departures - } \\
\text { Light } \\
\text { Condition }\end{array}$} & 488.42 & 1 & 488.42 & 28.61 & $<0.01$ & 4.09 \\
\hline Within Groups & & 699.85 & 41 & 17.06 & & & \\
\hline Total & & 1188.27 & 42 & & & & \\
\hline Between Groups & \multirow{3}{*}{$\begin{array}{l}\text { Average } \\
\text { Headway - } \\
\text { Weather } \\
\text { Condition }\end{array}$} & 909143.10 & 1 & 909143.10 & 7.56 & $<0.01$ & 4.09 \\
\hline Within Groups & & 4330524.00 & 36 & 120292.30 & & & \\
\hline Total & & 5239667.00 & 37 & & & & \\
\hline Between Groups & \multirow{3}{*}{$\begin{array}{l}\text { Brake Pedal } \\
\text { Force - } \\
\text { Weather } \\
\text { Condition }\end{array}$} & 1016.15 & 1 & 1016.15 & 4.95 & 0.03 & 4.09 \\
\hline Within Groups & & 6569.83 & 32 & 205.31 & & & \\
\hline Total & & 7585.97 & 33 & & & & \\
\hline
\end{tabular}

The null hypothesis states that there is no significant difference between the mean values of maximum speed between the participant group provided with OSW and the participant group without OSW in the urban scenario. The alternate hypothesis states that there is a significant difference between the mean values of maximum speed between the participant group provided with OSW and the participant group without OSW in the urban scenario. The null hypothesis can be rejected based on the F-statistic and p-value, implying a significant difference in the mean values of maximum speed between the two participant groups. However, OSW was not found to have a significant effect on any of the other driver behaviors.

No variables were affected by BSW in the urban scenario. 
The null hypothesis states that there is no significant difference between the mean values of average headway between the participant group driving in daytime condition and the participant group driving in nighttime condition in the urban scenario. The alternate hypothesis states that there is a significant difference between the mean values of average headway between the participant group driving in daytime condition and the participant group driving in nighttime condition in the urban scenario. The null hypothesis can be rejected based on the F-statistic and p-value, implying a significant difference in the mean values of average headway between the two participant groups. The headways maintained by the participants based on the lighting conditions are different.

The null hypothesis states that there is no significant difference between the mean values of brake force between the participant group driving in daytime condition and the participant group driving in nighttime condition in the urban scenario. The alternate hypothesis states that there is a significant difference between the mean values of brake force between the participant group driving in daytime condition and the participant group driving in nighttime condition in the urban scenario. Based on the F-statistic and $\mathrm{p}$-value, the null hypothesis can be rejected, demonstrating a significant difference between the mean values. The lighting conditions impact the brake force applied by the participants.

The null hypothesis states that there is no significant difference between the mean values of lane departures between the participant group driving in daytime condition and the participant group driving in nighttime condition in the urban scenario. The alternate hypothesis states that there is a significant difference between the mean values of lane departures between the participant group driving in daytime condition and the participant group driving in nighttime condition in the urban scenario. Based on the F-statistic and p-value, the null hypothesis can be rejected, as there is a significant difference between the mean values. The lighting conditions impact the brake force applied by the participants.

The null hypothesis states that there is no significant difference between the mean values of average headway between the participant group driving in clear weather condition and the participant group driving in rainy weather condition in the urban scenario. The alternate hypothesis states that there is a significant difference between the mean values of average headway between the participant group driving in clear weather condition and the participant group driving in rainy weather condition in the urban scenario. The null hypothesis can be rejected based on the Fstatistic and $\mathrm{p}$-value, implying a significant difference in the mean values of average headway between the two participant groups. The headways maintained by participants based on the weather conditions are different.

The null hypothesis states that there is no significant difference between the mean values of brake force between the participant group driving in clear weather condition and the participant group driving in rainy weather condition in the urban scenario. The alternate hypothesis states that there is a significant difference between the mean values of brake force between the participant group driving in clear weather condition and the participant group driving in rainy weather condition in the urban scenario. Based on the F-statistic and p-value, the null hypothesis can be rejected as there is a significant difference between the mean values. The weather conditions also impact the brake force applied by participants. 


\subsection{Freeway Driving Scenario}

The ANOVA test results of the driver behaviors that were significant at a p-value of 0.05 in the freeway scenario are presented in Table 23. The results from Table 23 include the effects of ADAS, lighting, and weather conditions. The null and alternate hypotheses of all the results from the Table 23 are discussed next.

Table 23. ANOVA Results - ADAS, Lighting, and Weather Conditions (Freeway)

\begin{tabular}{|c|c|c|c|c|c|c|c|}
\hline Source of Variation & $\begin{array}{l}\text { Driving } \\
\text { Behavior \& } \\
\text { ADAS }\end{array}$ & SS & $\mathrm{df}$ & MS & $\mathrm{F}$ & P-value & F-critical \\
\hline Between Groups & \multirow{3}{*}{$\begin{array}{l}\text { Lane } \\
\text { Departures - } \\
\text { LDW }\end{array}$} & $1,218.98$ & 1 & $1,218.98$ & 22.72 & $<0.01$ & 4.08 \\
\hline Within Groups & & $2,199.44$ & 41 & 53.65 & & & \\
\hline Total & & $3,418.42$ & 42 & & & & \\
\hline Between Groups & \multirow{4}{*}{$\begin{array}{l}\text { Average } \\
\text { Headway - } \\
\text { Light } \\
\text { Condition }\end{array}$} & 463506.20 & 1 & 463506.20 & 12.98 & $<0.01$ & 4.09 \\
\hline Within Groups & & 1463141.00 & 41 & 35686.37 & & & \\
\hline Total & & 1926647.00 & 42 & & & & \\
\hline Between Groups & & 806.03 & 1 & 806.03 & 12.65 & $<0.01$ & 4.09 \\
\hline Within Groups & & 2612.39 & 41 & 63.72 & & & \\
\hline Total & & 3418.42 & 42 & & & & \\
\hline Between Groups & \multirow{3}{*}{$\begin{array}{l}\text { Average Speed } \\
\text { - Weather } \\
\text { Condition }\end{array}$} & 121.54 & 1 & 121.54 & 5.39 & 0.02 & 4.09 \\
\hline Within Groups & & 835.09 & 37 & 22.57 & & & \\
\hline Total & & 956.63 & 38 & & & & \\
\hline Between Groups & \multirow{3}{*}{$\begin{array}{l}\text { Average } \\
\text { Headway - } \\
\text { Weather } \\
\text { Condition }\end{array}$} & 515154.90 & 1 & 515154.90 & 15.54 & $<0.01$ & 4.09 \\
\hline Within Groups & & 1226503.00 & 37 & 33148.72 & & & \\
\hline Total & & 1741658.00 & 38 & & & & \\
\hline
\end{tabular}

The null hypothesis states that there is no significant difference between the mean values of lane departure events between the participant group provided with LDW and the participant group without LDW in the freeway scenario. The alternate hypothesis states that there is a significant difference between the mean values of lane departure events between the participant group provided with LDW and the participant group without LDW in the freeway scenario. Based on the F-statistic and p-value, the null hypothesis can be rejected. The effectiveness of LDW on lane departure events in the freeway scenario is significant at a $99 \%$ confidence level.

No driving behavior variables were affected by BSW in the freeway scenario. Also, the effect of OSW was not found to be significant on the maximum or the average speed in the freeway scenario. Further, OSW was not found to affect any of the other driver behaviors in the freeway scenario.

Based on the results, it can be inferred that the LDW system has a significant effect on the lane departure behavior in all three driving scenarios. While the null hypothesis was rejected at a $99 \%$ confidence level in the freeway scenario, the null hypothesis in the rural and urban scenarios were 
rejected at a 95\% confidence level. Hence, the effect of LDW for the targeted purpose is quite evident.

The null hypothesis states that there is no significant difference between the mean values of average headway between the participant group driving in daytime condition and the participant group driving in nighttime condition in the freeway scenario. The alternate hypothesis states that there is a significant difference between the mean values of average headway between the participant group driving in daytime condition and the participant group driving in nighttime condition in the freeway scenario. Based on the F-statistic and p-value, the null hypothesis can be rejected with a significant difference between the mean values. The lighting conditions impact the average headway maintained by the participants.

The null hypothesis states that there is no significant difference between the mean values of lane departures between the participant group driving in daytime condition and the participant group driving in nighttime condition in the freeway scenario. The alternate hypothesis states that there is a significant difference between the mean values of lane departures between the participant group driving in daytime condition and the participant group driving in nighttime condition in the freeway scenario. Based on the F-statistic and $\mathrm{p}$-value, the null hypothesis can be rejected as there is a significant difference between the mean values. The lighting conditions impact the lane departure events while driving on a freeway.

The null hypothesis states that there is no significant difference between the mean values of average speed between the participant group driving in clear weather condition and the participant group driving in rainy weather condition in the freeway scenario. The alternate hypothesis states that there is a significant difference between the mean values of average speed between the participant group driving in clear weather condition and the participant group driving in rainy weather condition in the freeway scenario. Based on the F-statistic and $\mathrm{p}$-value, the null hypothesis can be rejected showing a significant difference between the mean values. The weather conditions impact the average speed maintained by the participants while driving on a freeway.

The null hypothesis states that there is no significant difference between the mean values of average headway between the participant group driving in clear weather condition and the participant group driving in rainy weather condition in the freeway scenario. The alternate hypothesis states that there is a significant difference between the mean values of average headway between the participant group driving in clear weather condition and the participant group driving in rainy weather condition in the freeway scenario. Based on the F-statistic and p-value, the null hypothesis can be rejected as there is a significant difference between the mean values. The weather conditions impact the average headway maintained by participants while driving on a freeway.

\subsection{Automated Systems}

This section presents the ANOVA test results of the effects of automated systems on driver behavior compared to warning systems and vehicles without ADAS. The automated systems were simulated where both LKA and ACC were engaged. The vehicle maintained a constant headway and the lane in this condition simulating a level 2 connected and automated vehicle. The warning systems include the simulation of any one of LDW, BSW, or OSW or in combination. 


\subsubsection{Rural Scenario}

The ANOVA test results of only the driver behaviors that were significant at a p-value of 0.05 in the rural scenario are presented in Table 24 . The null and alternate hypotheses of the results from the Table 24 are discussed.

Table 24. ANOVA Results - Automated, Warning, and No ADAS (Rural)

\begin{tabular}{|c|c|c|c|c|c|c|c|}
\hline Source of Variation & $\begin{array}{l}\text { Driving Behavior \& } \\
\text { ADAS }\end{array}$ & $\mathrm{SS}$ & $\mathrm{df}$ & MS & $\mathrm{F}$ & $\mathrm{P}$-value & F-critical \\
\hline Between Groups & \multirow{3}{*}{$\begin{array}{l}\text { Hard Braking - } \\
\text { Automated vs } \\
\text { Warning }\end{array}$} & 6.93 & 1 & 6.93 & 7.33 & $<0.01$ & 4.08 \\
\hline Within Groups & & 38.75 & 41 & 0.95 & & & \\
\hline Total & & 45.67 & 42 & & & & \\
\hline Between Groups & \multirow{3}{*}{$\begin{array}{l}\text { Lane Departure - } \\
\text { Automated vs No } \\
\text { ADAS }\end{array}$} & 178.57 & 1 & 178.57 & 6.93 & $<0.05$ & 4.75 \\
\hline Within Groups & & 309.43 & 12 & 25.79 & & & \\
\hline Total & & 488 & 13 & & & & \\
\hline Between Groups & \multirow{3}{*}{$\begin{array}{l}\text { Lane Departure - } \\
\text { Automated vs } \\
\text { Warning }\end{array}$} & 277.16 & 1 & 277.16 & 6.52 & $<0.05$ & 4.08 \\
\hline Within Groups & & 1743.35 & 12 & 42.52 & & & \\
\hline Total & & 2020.51 & 13 & & & & \\
\hline Between Groups & \multirow{3}{*}{$\begin{array}{l}\text { Average Headway - } \\
\text { Automated vs } \\
\text { Warning }\end{array}$} & 604328.1 & 1 & 604328.1 & 14.07 & $<0.01$ & 4.08 \\
\hline Within Groups & & 1761054 & 41 & 42952.54 & & & \\
\hline Total & & 2365382 & 42 & & & & \\
\hline Between Groups & \multirow{3}{*}{$\begin{array}{l}\text { Average Headway - } \\
\text { Automated vs No } \\
\text { ADAS }\end{array}$} & 335730.3 & 1 & 335730.3 & 19.96 & $<0.01$ & 4.75 \\
\hline Within Groups & & 201886.5 & 12 & 16823.88 & & & \\
\hline Total & & 537616.8 & 13 & & & & \\
\hline Between Groups & \multirow{4}{*}{$\begin{array}{l}\text { Brake Force - } \\
\text { Automated vs } \\
\text { Warning }\end{array}$} & 3149.26 & 1 & 3149.26 & 22.25 & $<0.01$ & 4.08 \\
\hline Within Groups & & 5802.19 & 41 & 141.52 & & & \\
\hline Total & & 8951.45 & 42 & & & & \\
\hline Between Groups & & 1539.09 & 1 & 1539.09 & 39.57 & $<0.01$ & 4.75 \\
\hline Within Groups & & 466.74 & 12 & 38.89 & & & \\
\hline Total & & 2005.84 & 13 & & & & \\
\hline
\end{tabular}

The null hypothesis states that there is no significant difference between the mean values of the number of hard braking events between the participant group provided with automated systems and the participant group provided with warning systems in the rural scenario. The alternate hypothesis states that there is a significant difference between the mean values of the number of hard braking events between the participant group provided with automated systems and the participant group provided with warning systems in the freeway scenario. Based on the F-statistic and $\mathrm{p}$-value, the null hypothesis can be rejected implying a significant difference between the mean values. Automated systems influence the braking behavior of participants when driving in the rural scenario. 
The null hypothesis states that there is no significant difference between the mean values of the number of lane departure events between the participant group provided with automated systems and the participant group without any ADAS in the rural scenario. The alternate hypothesis states that there is a significant difference between the mean values of the number of lane departure events between the participant group provided with automated systems and the participant group without ADAS in the rural scenario. Based on the F-statistic and p-value, the null hypothesis can be rejected implying a significant difference between the mean values. Automated systems influence the lane-following behavior of participants while driving in the rural scenario.

The null hypothesis states that there is no significant difference between the mean values of the number of lane departure events between the participant group provided with automated systems and the participant group provided with warning systems in the rural scenario. The alternate hypothesis states that there is a significant difference between the mean values of the number of lane departure events between the participant group provided with automated systems and the participant group provided with warning systems in the rural scenario. Based on the F-statistic and p-value, the null hypothesis can be rejected implying a significant difference between the mean values. Automated systems influence the lane-following behavior of participants while driving in the rural scenario.

The null hypothesis states that there is no significant difference between the mean values of the average headway between the participant group provided with automated systems and the participant group provided with warning systems in the rural scenario. The alternate hypothesis states that there is a significant difference between the mean values of the average headway between the participant group provided with automated systems and the participant group provided with warning systems in the rural scenario. Based on the F-statistic and p-value, the null hypothesis can be rejected implying a significant difference between the mean values. Automated systems influence the car-following behavior of participants compared to warning systems while driving in the rural scenario.

The null hypothesis states that there is no significant difference between the mean values of the average headway between the participant group provided with automated systems and the participant group without ADAS in the rural scenario. The alternate hypothesis states that there is a significant difference between the mean values of the average headway between the participant group provided with automated systems and the participant group without ADAS in the rural scenario. Based on the F-statistic and p-value, the null hypothesis can be rejected implying a significant difference between the mean values. Automated systems influence the car-following behavior of participants compared to vehicles without ADAS while driving in rural scenario.

The null hypothesis states that there is no significant difference between the mean values of the brake force between the participant group provided with automated systems and the participant group provided with warning systems in the rural scenario. The alternate hypothesis states that there is a significant difference between the mean values of the brake force between the participant group provided with automated systems and the participant group provided with warning systems in the rural scenario. Based on the F-statistic and p-value, the null hypothesis can be rejected implying a significant difference between the mean values. Automated systems influence the braking behavior of participants compared to vehicles with warning systems while driving in the rural scenario. 
The null hypothesis states that there is no significant difference between the mean values of the brake force between the participant group provided with automated systems and the participant group without ADAS in the rural scenario. The alternate hypothesis states that there is a significant difference between the mean values of the brake force between the participant group provided with automated systems and the participant group without ADAS in the rural scenario. Based on the F-statistic and p-value, the null hypothesis can be rejected implying a significant difference between the mean values. Automated systems influence the braking behavior of participants compared to vehicles without ADAS when driving in the rural scenario.

\subsubsection{Urban Scenario}

The ANOVA test results of the driver behaviors that were significant at a p-value of 0.05 in the urban scenario are presented in Table 25. The null and alternate hypotheses of all the results from the Table 25 are discussed next.

Table 25. ANOVA Results - Automated, Warning, and No ADAS (Urban)

\begin{tabular}{|c|c|c|c|c|c|c|c|}
\hline Source of Variation & $\begin{array}{l}\text { Driving Behavior } \\
\text { Parameter \& } \\
\text { ADAS }\end{array}$ & SS & $\mathrm{df}$ & MS & $\mathrm{F}$ & $\mathrm{P}$-value & F-critical \\
\hline Between Groups & \multirow{3}{*}{$\begin{array}{l}\text { Average Headway - } \\
\text { Automated vs } \\
\text { Warning }\end{array}$} & 2983244 & 1 & 2983244 & 23.25 & $<0.01$ & 4.07 \\
\hline Within Groups & & 5389220 & 42 & 128314.8 & & & \\
\hline Total & & 8372465 & 43 & & & & \\
\hline Between Groups & \multirow{3}{*}{$\begin{array}{l}\text { Average Headway - } \\
\text { Automated vs No } \\
\text { ADAS }\end{array}$} & 2127516 & 1 & 2127516 & 92.08 & $<0.01$ & 4.84 \\
\hline Within Groups & & 254168.9 & 11 & 23106.26 & & & \\
\hline Total & & 2381685 & 12 & & & & \\
\hline Between Groups & \multirow{3}{*}{$\begin{array}{l}\text { Brake Force - } \\
\text { Automated vs } \\
\text { Warning }\end{array}$} & 2652.91 & 1 & 2652.91 & 13.94 & $<0.01$ & 4.09 \\
\hline Within Groups & & 7421.13 & 39 & 190.29 & & & \\
\hline Total & & 10074.04 & 40 & & & & \\
\hline Between Groups & \multirow{3}{*}{$\begin{array}{l}\text { Brake Force - } \\
\text { Automated vs No } \\
\text { ADAS }\end{array}$} & 3956.62 & 1 & 3956.62 & 33.86 & $<0.01$ & 4.96 \\
\hline Within Groups & & 1168.41 & 10 & 116.84 & & & \\
\hline Total & & 5125.03 & 11 & & & & \\
\hline
\end{tabular}

The null hypothesis states that there is no significant difference between the mean values of the average headway between the participant group provided with automated systems and the participant group provided with warning systems in the urban scenario. The alternate hypothesis states that there is a significant difference between the mean values of the average headway between the participant group provided with automated systems and the participant group provided with warning systems in the urban scenario. Based on the F-statistic and p-value, the null hypothesis can be rejected, implying a significant difference between the mean values. Automated systems influence the car-following behavior of participants compared to vehicles with warning systems while driving in the urban scenario.

The null hypothesis states that there is no significant difference between the mean values of the average headway between the participant group provided with automated systems and the 
participant group without ADAS in the urban scenario. The alternate hypothesis states that there is a significant difference between the mean values of the average headway between the participant group provided with automated systems and the participant group without ADAS in the urban scenario. Based on the F-statistic and p-value, the null hypothesis can be rejected implying a significant difference between the mean values. Automated systems influence the car-following behavior of participants compared to vehicles without any ADAS when driving in the urban scenario.

The null hypothesis states that there is no significant difference between the mean values of the brake force between the participant group provided with automated systems and the participant group provided with warning systems in the urban scenario. The alternate hypothesis states that there is a significant difference between the mean values of the brake force between the participant group provided with automated systems and the participant group provided with warning systems in the urban scenario. Based on the F-statistic and p-value, the null hypothesis can be rejected implying a significant difference between the mean values. Automated systems influence the braking behavior of participants compared to vehicles with warning systems while driving in the urban scenario.

The null hypothesis states that there is no significant difference between the mean values of the brake force between the participant group provided with automated systems and the participant group without ADAS in the urban scenario. The alternate hypothesis states that there is a significant difference between the mean values of the brake force between the participant group provided with automated systems and the participant group without ADAS in the urban scenario. Based on the F-statistic and $\mathrm{p}$-value, the null hypothesis can be rejected, implying a significant difference between the mean values. Automated systems influence the braking behavior of participants compared to vehicles without any ADAS when driving in the urban scenario.

\subsubsection{Freeway Scenario}

The ANOVA test results of only the driver behaviors that were significant at a p-value of 0.05 in the freeway scenario are presented in Table 26. The null and alternate hypotheses of all the results from the Table 26 are discussed next. 
Table 26. ANOVA Results - Automated, Warning, and No ADAS (Freeway)

\begin{tabular}{|c|c|c|c|c|c|c|c|}
\hline Source of Variation & $\begin{array}{l}\text { Driving Behavior } \\
\text { Parameter \& ADAS }\end{array}$ & $\mathrm{SS}$ & $\mathrm{df}$ & MS & $\mathrm{F}$ & $\mathrm{P}$-value & F-critical \\
\hline Between Groups & \multirow{3}{*}{$\begin{array}{l}\text { Hard Braking - } \\
\text { Automated vs No } \\
\text { ADAS }\end{array}$} & 0.81 & 1 & 0.81 & 5.92 & $<0.05$ & 4.84 \\
\hline Within Groups & & 1.5 & 11 & 0.14 & & & \\
\hline Total & & 2.31 & 12 & & & & \\
\hline Between Groups & \multirow{3}{*}{$\begin{array}{l}\text { Lane Departure - } \\
\text { Automated vs } \\
\text { Warning }\end{array}$} & 907.57 & 1 & 907.57 & 14.86 & $<0.01$ & 4.07 \\
\hline Within Groups & & 2565.16 & 42 & 61.08 & & & \\
\hline Total & & 3472.73 & 43 & & & & \\
\hline Between Groups & \multirow{3}{*}{$\begin{array}{l}\text { Lane Departure - } \\
\text { Automated vs No } \\
\text { ADAS }\end{array}$} & 1642.51 & 1 & 1642.51 & 49.87 & $<0.01$ & 4.84 \\
\hline Within Groups & & 362.26 & 11 & 32.93 & & & \\
\hline Total & & 2004.77 & 12 & & & & \\
\hline Between Groups & \multirow{3}{*}{$\begin{array}{l}\text { Average Speed - } \\
\text { Automated vs } \\
\text { Warning }\end{array}$} & 256.47 & 1 & 256.47 & 11.87 & $<0.01$ & 4.07 \\
\hline Within Groups & & 907.79 & 42 & 21.61 & & & \\
\hline Total & & 1164.26 & 43 & & & & \\
\hline Between Groups & \multirow{3}{*}{$\begin{array}{l}\text { Average Speed - } \\
\text { Automated vs No } \\
\text { ADAS }\end{array}$} & 209.24 & 1 & 209.24 & 9.04 & $<0.05$ & 4.84 \\
\hline Within Groups & & 254.48 & 11 & 23.13 & & & \\
\hline Total & & 463.72 & 12 & & & & \\
\hline Between Groups & \multirow{3}{*}{$\begin{array}{l}\text { Maximum Speed - } \\
\text { Automated vs } \\
\text { Warning }\end{array}$} & 966.40 & 1 & 966.40 & 25.49 & $<0.01$ & 4.07 \\
\hline Within Groups & & 1592.27 & 42 & 37.91 & & & \\
\hline Total & & 2558.68 & 43 & & & & \\
\hline Between Groups & \multirow{3}{*}{$\begin{array}{l}\text { Maximum Speed - } \\
\text { Automated vs No } \\
\text { ADAS }\end{array}$} & 549.61 & 1 & 549.61 & 32.22 & $<0.01$ & 4.84 \\
\hline Within Groups & & 187.66 & 11 & 17.06 & & & \\
\hline Total & & 737.26 & 12 & & & & \\
\hline Between Groups & \multirow{3}{*}{$\begin{array}{l}\text { Brake Force - } \\
\text { Automated vs } \\
\text { Warning }\end{array}$} & 754.51 & 1 & 754.51 & 8.73 & $<0.01$ & 4.11 \\
\hline Within Groups & & 3196.56 & 37 & 86.39 & & & \\
\hline Total & & 3951.07 & 38 & & & & \\
\hline Between Groups & \multirow{3}{*}{$\begin{array}{l}\text { Brake Force - } \\
\text { Automated vs No } \\
\text { ADAS }\end{array}$} & 137.64 & 1 & 137.64 & 17.03 & $<0.01$ & 4.84 \\
\hline Within Groups & & 88.89 & 11 & 8.08 & & & \\
\hline Total & & 226.53 & 12 & & & & \\
\hline
\end{tabular}

The null hypothesis states that there is no significant difference between the mean values of the number of hard braking events between the participant group provided with automated systems and the participant group without ADAS in the freeway scenario. The alternate hypothesis states that there is a significant difference between the mean values of the number of hard braking events between the participant group provided with automated systems and the participant group without ADAS in the freeway scenario. Based on the F-statistic and p-value, the null hypothesis can be rejected implying a significant difference between the mean values. Automated systems influence the braking behavior of participants compared to vehicles without ADAS while driving in freeway scenario. 
The null hypothesis states that there is no significant difference between the mean values of the number of lane departure events between the participant group provided with automated systems and the participant group provided with warning systems in the freeway scenario. The alternate hypothesis states that there is a significant difference between the mean values of the number of lane departure events between the participant group provided with automated systems and the participant group provided with warning systems in the freeway scenario. Based on the F-statistic and $\mathrm{p}$-value, the null hypothesis can be rejected implying a significant difference between the mean values. Automated systems influence the lane-following behavior of participants compared to vehicles with warning systems while driving in the freeway scenario.

The null hypothesis states that there is no significant difference between the mean values of the number of lane departure events between the participant group provided with automated systems and the participant group without ADAS in the freeway scenario. The alternate hypothesis states that there is a significant difference between the mean values of the number of lane departure events between the participant group provided with automated systems and the participant group without ADAS in the freeway scenario. Based on the F-statistic and p-value, the null hypothesis can be rejected implying a significant difference between the mean values. Automated systems influence the lane-following behavior of participants compared to vehicles without ADAS when driving in the freeway scenario.

The null hypothesis states that there is no significant difference between the mean values of the average speed between the participant group provided with automated systems and the participant group provided with warning systems in the freeway scenario. The alternate hypothesis states that there is a significant difference between the mean values of the average speed between the participant group provided with automated systems and the participant group provided with warning systems in the freeway scenario. Based on the F-statistic and p-value, the null hypothesis can be rejected, implying a significant difference between the mean values. Automated systems influence the speeding behavior of participants compared to vehicles with warning systems while driving in the freeway scenario.

The null hypothesis states that there is no significant difference between the mean values of the average speed between the participant group provided with automated systems and the participant group without ADAS in the freeway scenario. The alternate hypothesis states that there is a significant difference between the mean values of the average speed between the participant group provided with automated systems and the participant group without ADAS in the freeway scenario. Based on the F-statistic and p-value, the null hypothesis can be rejected implying a significant difference between the mean values. Automated systems influence the speeding behavior of participants compared to vehicles without ADAS while driving in the freeway scenario.

The null hypothesis states that there is no significant difference between the mean values of the maximum speed between the participant group provided with automated systems and the participant group provided with warning systems in the freeway scenario. The alternate hypothesis states that there is a significant difference between the mean values of the maximum speed between the participant group provided with automated systems and the participant group provided with warning systems in the freeway scenario. Based on the F-statistic and p-value, the null hypothesis can be rejected implying a significant difference between the mean values. Automated systems influence the speeding behavior of participants compared to vehicles with warning systems while driving in freeway scenario. 
The null hypothesis states that there is no significant difference between the mean values of the maximum speed between the participant group provided with automated systems and the participant group without ADAS in the freeway scenario. The alternate hypothesis states that there is a significant difference between the mean values of the maximum speed between the participant group provided with automated systems and the participant group without ADAS in the freeway scenario. Based on the F-statistic and p-value, the null hypothesis can be rejected, implying a significant difference between the mean values. Automated systems influence the speeding behavior of participants compared to vehicles without ADAS while driving in the freeway scenario.

The null hypothesis states that there is no significant difference between the mean values of the brake force between the participant group provided with automated systems and the participant group provided with warning systems in the freeway scenario. The alternate hypothesis states that there is a significant difference between the mean values of the brake force between the participant group provided with automated systems and the participant group provided with warning systems in the freeway scenario. Based on the F-statistic and p-value, the null hypothesis can be rejected implying a significant difference between the mean values. Automated systems influence the braking behavior of participants compared to vehicles with warning systems while driving in the freeway scenario.

The null hypothesis states that there is no significant difference between the mean values of the brake force between the participant group provided with automated systems and the participant group without any ADAS in the freeway scenario. The alternate hypothesis states that there is a significant difference between the mean values of the brake force between the participant group provided with automated systems and the participant group without ADAS in the freeway scenario. Based on the F-statistic and p-value, the null hypothesis can be rejected, implying a significant difference between the mean values. Automated systems influence the braking behavior of participants compared to vehicles without any ADAS while driving in the freeway scenario. 


\section{Conclusions}

This study tested the effects of three different warning systems and two automated systems on driver behavior. The warning systems were shown to influence the participants' behaviors as per their intended purpose. For example, LDW was effective in influencing the lane departure behavior of the participants. Also, OSW was effective in influencing the maximum speed and average speed in some cases. BSW did not have a significant effect on any of the driver behavior variables.

The hard cornering, lane departures, and average headway had distinct mean values for the participant group with LDW compared to the participant group without LDW. The mean values of LDW and non-LDW group for different variables varied based on the driving scenario. For example, while the mean values of lane departure varied in the urban scenario, the mean values of brake pedal force varied in the freeway scenario. Similarly, the mean values of some of the driver behaviors were different for the OSW and non-OSW group, as well as the BSW and non-BSW group.

The effect of different warning systems on participants varied with the driving scenario. LDW had a significant effect on lane departure events, which indicates the number of times a participant went out of their lane. LDW was effective in all the three driving scenarios. However, OSW was only able to influence the speeding behavior of participants in rural and urban settings. As participants tend to drive at higher speeds on freeways, there is a lower chance to draw significantly different results when the two participant groups are compared.

BSW did not significantly affect the driver behavior in any of the three driving scenarios. However, the brake pedal force was significantly affected in the rural scenario. The activation of BSW when a vehicle is in the adjoining lane could trigger a participant to adopt safe maneuvering, possibly accounting for the observed change in the brake pedal force. Similarly, providing two ADAS increased the interaction when both the features are engaged, invoking a natural response to drive cautiously or slow-down, which might have segregated the brake pedal force application. Overall, the effect of warning systems on driving behaviors such as lane departures, speeding, and braking by driving scenario are evident.

Lighting and weather conditions also had a significant effect on some driving behaviors. Nighttime driving condition was observed to affect car-following and lane-changing behavior in all three driving scenarios. Additionally, lighting condition also affected the brake force applied by the participants in the urban scenarios. The participants maintained larger headway distance and had more lane departures at night compared to during the day.

The age of the participant also influenced the driving behavior. The braking behavior and average speed was higher for participants over twenty-five years in age. The young or teen participants below the age of twenty-five could be better accustomed to such driving simulators as they are more used to technology and video games, resulting in safer driving profiles. Smaller headways were observed for participants under the age of twenty-five in urban settings but had larger headways in rural and freeway scenarios. Additionally, the driving behavior differed with the gender of the participant. Male participants displayed more aggressive driving maneuvers, while female participants demonstrated higher brake force. Further, the type of driving scenario also 
affected the driving behaviors. Female participants had smaller headways in the urban scenario but had larger headways in rural and freeway scenarios.

Similarly, rainy weather condition also affected the participants' car-following behavior. They were observed to maintain longer headways in rainy weather condition in all three scenarios. However, the lane-changing, braking, and turning behaviors of the participants were observed to be less aggressive in rainy weather condition. Also, participants applied higher brake force in rainy weather condition, especially in urban driving settings which could be due to slippery roads. The change in average speed was also significantly different in the freeway scenario, with higher speeds in clear weather condition.

Automated systems like LKA and ACC were also explored in this study. The results from the participant group that drove a vehicle with LKA and ACC were compared to the participant group provided with the warning systems (LDW, BSW and OSW) as well as with the participant group without advanced features. Participants who drove a vehicle with LKA and ACC displayed less aggressive lane-following and braking behavior but maintained smaller headways. These results were observed in all three driving scenarios. Better braking behavior was additionally observed in the freeway scenario. Further, LKA and ACC reduced the variation in lane-following, handling, speeding, and car-following behaviors among the participants compared to both warning systems and no ADAS in all three driving scenarios.

Participants with LKA displayed less aggressive lane-following and braking behavior compared to participants with LDW. The driving scenario was also observed to affect the type of effects LKA had on a participant compared to LDW. Participants that a drove a vehicle with only LKA demonstrated more aggressive car-following behavior in rural and urban scenarios. The effects of ACC on improved braking behavior compared to both BSW and OSW is very evident. Additionally, both LKA and ACC drastically reduced the variation in vehicle handling, lanefollowing, car-following, and braking behavior in all three driving scenarios.

The effects of automated systems on braking, lane-following, and car-following behaviors in the rural scenario were found to be significant. Likewise, the effects of ACC on car-following and lane-following in the urban scenario were also found to be significant. In addition to braking, lanefollowing, and car-following behaviors, speed behavior was also significantly affected by automated systems in the freeway scenario. Though the considered automated systems led to aggressive carfollowing behavior, other driver behaviors were found to be less aggressive, leading to safer driving overall. Vehicles equipped with automated systems either in combination or individually led to safer driving compared to warning systems alone and vehicles without any ADAS. The change in driver behavior of the participants provided with automated systems was more harmonized as well.

These findings can be used to define vehicle parameters within microscopic simulation software and mimic the effect of vehicles with and without advanced features on transportation system performance. Additional samples can be collected and other advanced features may also be tested and compared using the driver simulator. 


\section{Endnotes}

${ }^{1}$ Association for Safe International Road Travel (ASIRT). (2019). Road safety facts. https://www.asirt.org/safe-travel/road-safety-facts/, Accessed 02/03/2020.

${ }^{2}$ Garcia A. (2017). CNN business, car sales set another US record. https://money.cnn.com/2017/01/04/news/companies/car-sales-2016/index.html, Accessed 02/03/2020.

${ }^{3}$ Alternative Fuels Data Center (AFDC), United States Department of Energy. (2019). Maps and data - annual vehicle miles traveled in the United States. https://afdc.energy.gov/data/10315, Accessed 02/03/2020.

${ }^{4}$ National Safety Council (NSC), Advanced Driver Assistance Systems. (2020). Injury facts. https://injuryfacts.nsc.org/motor-vehicle/occupant-protection/advanced-driver-assistancesystems/, Accessed 03/07/2020.

${ }^{5}$ Bellis, E., \& Page, J. (2008). National motor vehicle crash causation survey (NMVCCS) SAS analytical user's manual. Report No. HS-811 053, Buffalo, New York.

${ }^{6}$ Safelite Auto Glass. (2020). The features of ADAS: your driver assist system. https:/www.safelite.com/windshield-auto-glass-technology/adas, Accessed 02/03/2020.

${ }^{7}$ Naughton K. (2017). The globe and mail: will driver-assist technology turn you into a bad driver? https://www.theglobeandmail.com/globe-drive/culture/commuting/will-driverassist-technology-turn-you-into-a-bad-driver/article35967419/, Accessed 02/03/2020.

${ }^{8}$ McDonald A., Carney C., \& McGehee D. V. (2018). American Automobile Association: Vehicle owner's experiences with and reactions to advanced driver assistance systems. Washington, DC, https://publicaffairsresources.aaa.biz/wpcontent/uploads/dlm_uploads/2018/09/18-0621_AAAFTS-ADAS-Fact-Sheet_v1BTjc.pdf, Accessed 03/07/2020.

${ }^{9}$ Fleet Manager. (2019). The importance of educating drivers about the limits of ADAS. Wex Inc., Portland, OR, https://www.wexinc.com/insights/blog/fleet/the-importance-ofeducating-drivers-about-the-limits-of-adas/, Accessed 03/07/2020.

${ }^{10}$ Highway Loss Data Institute, Insurance Institute for Highway Safety (IIHS). (2018). IIHS examines driver assistance features in road, track tests. https://www.iihs.org/news/detail/iihs-examines-driver-assistance-features-in-road-tracktests, Accessed 05/11/2021.

${ }^{11}$ Consumer Reports (2017a). Consumer clarity and safety for today's advanced driver systems. https://data.consumerreports.org/wp-content/uploads/2020/05/auto-safety-report.pdf, Accessed 05/18/2021 
${ }^{12}$ Consumer Reports (2019). Guide to lane departure warning and lane keeping assist. https://www.consumerreports.org/car-safety/lane-departure-warning-lane-keeping-assistguide/, Accessed 05/11/2021.

${ }^{13}$ Dunn, N., Dingus, T., \& Soccolich, S. (2019). Understanding the impact of technology: do advanced driver assistance and semi-automated vehicle systems lead to improper driving behavior? Virginia Tech Transportation Institute, American Automobile Association, Washington, DC.

${ }^{14}$ Kim, W., Kelley-Baker, T., Sener, I. N., Zmud, J., Graham, M., \& Kolek, S. (2019). Users' understanding of automated vehicles and perception to improve traffic safety-results from a national survey. AAA Foundation for Traffic Safety, Washington, DC.

${ }^{15}$ Highway Loss Data Institute, Insurance Institute for Highway Safety (IIHS). (2021). Advanced driver assistance. https://www.iihs.org/topics/advanced-driver-assistance, Accessed 06/18/2021.

${ }^{16}$ National Highway Traffic Safety Administration (NHTSA), United States Department of Transportation (2021). NHSTA launches influencer campaign to educate drivers on safety features. https://www.nhtsa.gov/press-releases/nhtsa-launches-influencer-campaigneducate-drivers-safety-features, Accessed 06/18/2021.

${ }^{17}$ Abdul, W., Wen, T. G., \& Kamaruddin, N. (2007, December). Understanding driver behavior using multi-dimensional CMAC. In 2007 th International Conference on Information, Communications E' Signal Processing, 1-5.

${ }^{18}$ Wang, W., Xi, J., \& Chen, H. (2014). Modeling and recognizing driver behavior based on driving data: A survey. Mathematical Problems in Engineering, https://www.hindawi.com/journals/mpe/2014/245641/, Accessed 05/18/2021.

${ }^{19}$ Kamaruddin, N., \& Wahab, A. (2010, June). Driver behavior analysis through speech emotion understanding. In 2010 IEEE Intelligent Vehicles Symposium, 238-243.

${ }^{20}$ Kuge, N., Yamamura, T., Shimoyama, O., \& Liu, A. (2000). A driver behavior recognition method based on a driver model framework. SAE Transactions, 469-476.

${ }^{21}$ Sathyanarayana, A., Boyraz, P., \& Hansen, J. H. (2008, September). Driver behavior analysis and route recognition by hidden Markov models. In 2008 IEEE International Conference on Vehicular Electronics and Safety, 276-281.

${ }^{22}$ Tran, C., Doshi, A., \& Trivedi, M. M. (2012). Modeling and prediction of driver behavior by foot gesture analysis. Computer Vision and Image Understanding, 116(3), 435-445.

${ }^{23}$ Yannis, G., Antoniou, C., Vardaki, S., \& Kanellaidis, G. (2010). Older drivers' perception and acceptance of in-vehicle devices for traffic safety and traffic efficiency. Journal of Transportation Engineering, 136(5), 472-479. 
${ }^{24}$ Morignot, P., Rastelli, J. P., \& Nashashibi, F. (2014, June). Arbitration for balancing control between the driver and ADAS systems in an automated vehicle: Survey and approach. In 2014 IEEE Intelligent Vehicles Symposium Proceedings, 575-580.

${ }^{25}$ Alkim, T. P., Bootsma, G., \& Hoogendoorn, S. P. (2007, June). Field operational test "the assisted driver". In 2007 IEEE Intelligent Vehicles Symposium, 1198-1203.

${ }^{26}$ McCall, J. C., \& Trivedi, M. M. (2007). Driver behavior and situation aware brake assistance for intelligent vehicles. Proceedings of the IEEE, 95(2), 374-387.

${ }^{27}$ Ziefle, M., Pappachan, P., Jakobs, E. M., \&Wallentowitz, H. (2008, July). Visual and auditory interfaces of advanced driver assistant systems for older drivers. In International Conference on Computers for Handicapped Persons, 62-69, Springer, Berlin, Heidelberg.

${ }^{28}$ Inata, K., Raksincharoensak, P., \& Nagai, M. (2008, October). Driver behavior modeling based on database of personal mobility driving in urban area. In 2008 International Conference on Control, Automation and Systems, IEEE, 2902-2907.

${ }^{29}$ Angkititrakul, P., Ryuta, T., Wakita, T., Takeda, K., Miyajima, C., \& Suzuki, T. (2009). Evaluation of driver-behavior models in real-world car-following task. In 2009 IEEE International Conference on Vehicular Electronics and Safety (ICVES), 113-118.

${ }^{30}$ Kondyli, A., \& Elefteriadou, L. (2009). Driver behavior at freeway-ramp merging areas: focus group findings. Transportation Research Record, 2124(1), 157-166.

${ }^{31}$ Pauwelussen, J., \& Feenstra, P. J. (2010). Driver behavior analysis during ACC activation and deactivation in a real traffic environment. IEEE Transactions on Intelligent Transportation Systems, 11(2), 329-338.

${ }^{32}$ Farah, H., \& Koutsopoulos, H. N. (2014). Do cooperative systems make drivers' car-following behavior safer? Transportation Research Part C: Emerging Technologies, 41, 61-72.

${ }^{33}$ Olaverri-Monreal, C., Hasan, A. E., Bulut, J., Körber, M., \& Bengler, K. (2014). Impact of in-vehicle displays location preferences on drivers' performance and gaze. IEEE Transactions on Intelligent Transportation Systems, 15(4), 1770-1780.

${ }^{34}$ Son, J., Park, M., \& Park, B. B. (2015). The effect of age, gender and roadway environment on the acceptance and effectiveness of advanced driver assistance systems. Transportation Research Part F: Traffic Psychology and Behaviour, 31, 12-24.

${ }^{35}$ Miyajima, C., \& Takeda, K. (2016). Driver-behavior modeling using on-road driving data: A new application for behavior signal processing. IEEE Signal Processing Magazine, 33(6), 1421.

${ }^{36}$ Sieber, M., \& Färber, B. (2016). Driver perception and reaction in collision avoidance: implications for ADAS development and testing. In 2016 IEEE Intelligent Vebicles Symposium (IV), 239-245. 
${ }^{37}$ Cades, D. M., Crump, C., Lester, B. D., \& Young, D. (2017). Driver distraction and advanced vehicle assistive systems (ADAS): investigating effects on driver behavior. In Advances in Human Aspects of Transportation, Springer, Cham, 1015-1022.

${ }^{38}$ Lyu, N., Deng, C., Xie, L., Wu, C., \& Duan, Z. (2019). A field operational test in China: Exploring the effect of an advanced driver assistance system on driving performance and braking behavior. Transportation Research Part F: Traffic Psychology and Behavior, 65, 730747.

${ }^{39}$ Kikuchi, S., Uno, N., \& Tanaka, M. (2003). Impacts of shorter perception-reaction time of adapted cruise-controlled vehicles on traffic flow and safety. Journal of Transportation Engineering, 129(2), 146-154.

${ }^{40}$ Derbel, O., Mourllion, B., \& Basset, M. (2012). Safety assessment of mixed traffic based on accident scenario. IFAC Proceedings Volumes, 45(24), 126-131.

${ }^{41}$ Jeong, E., Oh, C., Lee, G., \& Cho, H. (2014). Safety impacts of intervehicle warning information systems for moving hazards in connected vehicle environments. Transportation Research Record, 2424(1), 11-19.

${ }^{42}$ Li, Y., Wang, H., Wang, W., Liu, S., \& Xiang, Y. (2016). Reducing the risk of rear-end collisions with infrastructure-to-vehicle (I2V) integration of variable speed limit control and adaptive cruise control system. Traffic Injury Prevention, 17(6), 597-603.

${ }^{43}$ Li, Y., Li, Z., Wang, H., Wang, W., \& Xing, L. (2017a). Evaluating the safety impact of adaptive cruise control in traffic oscillations on freeways. Accident Analysis E Prevention, 104, 137-145.

${ }^{44}$ Li, Y., Wang, H., Wang, W., Xing, L., Liu, S., \&Wei, X. (2017b). Evaluation of the impacts of cooperative adaptive cruise control on reducing rear-end collision risks on freeways. Accident Analysis \& Prevention, 98, 87-95.

${ }^{45}$ Cicchino, J. B. (2017). Effectiveness of forward collision warning and autonomous emergency braking systems in reducing front-to-rear crash rates. Accident Analysis E Prevention, 99, 142-152.

${ }^{46}$ Yue, L., Abdel-Aty, M., Wu, Y., \& Wang, L. (2018). Assessment of the safety benefits of vehicles' advanced driver assistance, connectivity and low-level automation systems. Accident Analysis \& Prevention, 117, 55-64.

${ }^{47}$ Kaptein, N. A., Theeuwes, J., \& van Der Horst, R. (1996). Driving simulator validity: Some considerations. Transportation Research Record, 1550(1), 30-36.

${ }^{48}$ Strayer, D. L., \& Johnston, W. A. (2001). Driven to distraction: Dual-task studies of simulated driving and conversing on a cellular telephone. Psychological Science, 12(6), 462466.

${ }^{49}$ Strayer, D. L., Drews, F. A., \& Johnston, W. A. (2003). Cell phone-induced failures of visual attention during simulated driving. Journal of Experimental Psychology: Applied, 9(1), 23. 
${ }^{50}$ Choudhary, P., \& Velaga, N. R. (2017). Mobile phone use during driving: Effects on speed and effectiveness of driver compensatory behaviour. Accident Analysis \& Prevention, 106, 370-378.

${ }^{51}$ Strayer, D. L., \& Drews, F. A. (2004). Profiles in driver distraction: Effects of cell phone conversations on younger and older drivers. Human Factors, 46(4), 640-649.

${ }^{52}$ Strayer, D. L., Drews, F. A., \& Crouch, D. J. (2006). A comparison of the cell phone driver and the drunk driver. Human Factors, 48(2), 381-391.

${ }^{53}$ Drews, F. A., Yazdani, H., Godfrey, C. N., Cooper, J. M., \& Strayer, D. L. (2009). Text messaging during simulated driving. Human Factors, 51(5), 762-770.

${ }^{54}$ Lundgren, J., \& Tapani, A. (2006). Evaluation of safety effects of driver assistance systems through traffic simulation. Transportation Research Record, 1953(1), 81-88.

${ }^{55}$ van Driel, C. J., Hoedemaeker, M., \& van Arem, B. (2007). Impacts of a congestion assistant on driving behaviour and acceptance using a driving simulator. Transportation Research Part F: Traffic Psychology and Behaviour, 10(2), 139-152.

${ }^{56}$ Lee, C., \& Abdel-Aty, M. (2008). Testing effects of warning messages and variable speed limits on driver behavior using driving simulator. Transportation Research Record, 2069(1), 55-64.

${ }^{57}$ Hoogendoorn, S. P., \& Minderhoud, M. M. (2002). Motorway flow quality impacts of advanced driver assistance systems. Transportation Research Record, 1800(1), 69-77.

${ }^{58}$ Martin, B. B., \& Elefteriadou, L. (2010). Driver behavior and advanced driver assistance systems: an exploratory driving simulator study. Advances in Transportation Studies, Dec 2010 Special, 79-88.

${ }^{59}$ Calvi, A., \& De Blasiis, M. R. (2011). Driver behavior on acceleration lanes: driving simulator study. Transportation Research Record, 2248(1), 96-103.

${ }^{60}$ Son, J., Lee, Y., \& Kim, M. H. (2011). Impact of traffic environment and cognitive workload on older drivers' behavior in simulated driving. International Journal of Precision Engineering and Manufacturing, 12(1), 135-141.

${ }^{61}$ Maag, C., Muhlbacher, D., Mark, C., \& Kruger, H. P. (2012). Studying effects of advanced driver assistance systems (ADAS) on individual and group level using multi-driver simulation. IEEE Intelligent Transportation Systems Magazine, 4(3), 45-54.

${ }^{62}$ Saleh, L., Chevrel, P., Claveau, F., Lafay, J. F., \& Mars, F. (2013). Shared steering control between a driver and an automation: stability in the presence of driver behavior uncertainty. IEEE Transactions on Intelligent Transportation Systems, 14(2), 974-983.

${ }^{63}$ Aziz, T., Horiguchi, Y., \& Sawaragi, T. (2013). An empirical investigation of the development of driver's mental model of a lane departure warning system while driving. IFAC Proceedings Volumes, 46(15), 461-468. 
${ }^{64}$ Rommerskirchen, C. P., Helmbrecht, M., \& Bengler, K. J. (2014). The impact of an anticipatory eco-driver assistant system in different complex driving situations on the driver behavior. IEEE Intelligent Transportation Systems Magazine, 6(2), 45-56.

${ }^{65}$ Biondi, F., Rossi, R., Gastaldi, M., \& Mulatti, C. (2014). Beeping ADAS: Reflexive effect on drivers' behavior. Transportation Research Part F: Traffic Psychology and Behaviour, 25, 27-33.

${ }^{66}$ Spivey, H., \& Pulugurtha, S. S. (2016). Visibility of two-wheelers approaching left-turning vehicles compared with other hazards under nighttime conditions at urban signalized intersections. Transportation Research Record, 2587(1), 133-140.

${ }^{67}$ Gaspar, J., Brown, T., Schwarz, C., Chrysler, S., \& Gunaratne, P. (2016). Driver behavior in forward collision and lane departure scenarios. No. 2016-01-1455, SAE Technical Paper.

${ }^{68}$ Mas, A., Merienne, F., \& Kemeny, A. (2011, September). Lateral control assistance and driver behavior in emergency situations. 3rd International Conference on Road Safety and Simulation, Indianapolis, United States, 1-12.

${ }^{69}$ Witt, M., Wang, L., Fahrenkrog, F., Kompaß, K., \& Prokop, G. (2018, July). Cognitive driver behavior modeling: Influence of personality and driver characteristics on driver behavior. In International Conference on Applied Human Factors and Ergonomics, Springer, Cham, 751-763.

${ }^{70}$ Choudhary, P., \& Velaga, N. R. (2019). Effects of phone use on driving performance: A comparative analysis of young and professional drivers. Safety Science, 111, 179-187.

${ }^{71}$ Consumer Reports (2017b). Guide to lane departure warning and lane keeping assist. https://www.consumerreports.org/car-safety/lane-departure-warning-lane-keeping-assistguide/, Accessed 05/11/2021.

${ }^{72}$ Consumer Reports (2017c). Guide to adaptive cruise control. https://www.consumerreports.org/car-safety/adaptive-cruise-control-guide/, Accessed 05/11/2021.

${ }^{73}$ Green Car Congress (2021). IIHS study finds drivers significantly more likely to speed while using adaptive cruise control. https://www.greencarcongress.com/2021/03/20210314iihs.html, Accessed 05/18/2021.

${ }^{74}$ Benson, A. J., Tefft, B. C., Svancara, A. M., \& Horrey, W. J. (2018). Potential reductions in crashes, injuries, and deaths from large-scale deployment of advanced driver assistance systems. Research Brief, Washington, DC: AAA Foundation for Traffic Safety.

${ }^{75}$ German Association of the Automotive Industry (VDA). (2020). Lane keeping assist systems. https://www.vda.de/en/topics/safety-and-standards/lkas/lane-keeping-assist-systems.html, Accessed 05/18/2021.

${ }^{76}$ Tan, H., Zhao, F., Hao, H., \& Liu, Z. (2020). Estimate of safety impact of lane keeping assistant system on fatalities and injuries reduction for China: scenarios through 2030. Traffic Injury Prevention, 21(2), 156-162. 
${ }_{77}$ Transport Accident Commission (TAC). (2020). How safe is your car?: lane keep assist. https://howsafeisyourcar.com.au/safety-features/lane-keep-assist, Accessed 05/18/2021.

${ }^{78}$ Penmetsa, P., Hudnall, M., \& Nambisan, S. (2019). Potential safety benefits of lane departure prevention technology. IATSS research, 43(1), 21-26.

${ }^{79}$ The National Advanced Driver Simulator, The University of Iowa, Endor AG (2016). Fanatec Universal Hub Grant Wheel and Horn Installation Guide. Iowa City, IA, https://fanatec.com/media/pdf/0d/99/51/CSUH_Manual_webKzzoH6lofDdpy.pdf, Accessed 05/18/2021.

${ }^{80}$ van den Berg R. G. (2020). SPSS Tutorials: one-way ANOVA tutorial. https://www.spsstutorials.com/spss-one-way-anova/, Accessed 12/7/2020.

${ }^{81}$ World Health Organization (WHO). (2021). Adolescent health in the South-East Asia region. https://www.who.int/southeastasia/health-topics/adolescenthealth\#: :text=WHO\%20defines\%20'Adolescents'\%20as\%20individuals,age\%20range\%201 0\%2D24\%20years., Accessed 06/18/2021. 


\section{Bibliography}

Abdul, W., Wen, T. G., \& Kamaruddin, N. (2007, December). Understanding driver behavior using multi-dimensional CMAC. In 2007 6th International Conference on Information, Communications E Signal Processing, 1-5.

Alkim, T. P., Bootsma, G., \& Hoogendoorn, S. P. (2007, June). Field operational test "the assisted driver". In 2007 IEEE Intelligent Vehicles Symposium, 1198-1203.

Alternative Fuels Data Center (AFDC), United States Department of Energy. (2019). Maps and data - annual vehicle miles traveled in the United States. https://afdc.energy.gov/data/10315, Accessed 02/03/2020.

Angkititrakul, P., Ryuta, T., Wakita, T., Takeda, K., Miyajima, C., \& Suzuki, T. (2009). Evaluation of driver-behavior models in real-world car-following task. In 2009 IEEE International Conference on Vehicular Electronics and Safety (ICVES), 113-118.

Association for Safe International Road Travel (ASIRT). (2019). Road safety facts. https://www.asirt.org/safe-travel/road-safety-facts/, Accessed 02/03/2020.

Aziz, T., Horiguchi, Y., \& Sawaragi, T. (2013). An empirical investigation of the development of driver's mental model of a lane departure warning system while driving. IFAC Proceedings Volumes, 46(15), 461-468.

Bellis, E., \& Page, J. (2008). National motor vehicle crash causation survey (NMVCCS) SAS analytical user's manual. Report No. HS-811 053, Buffalo, New York.

Benson, A. J., Tefft, B. C., Svancara, A. M., \& Horrey, W. J. (2018). Potential reductions in crashes, injuries, and deaths from large-scale deployment of advanced driver assistance systems. Research Brief, Washington, DC: AAA Foundation for Traffic Safety.

Biondi, F., Rossi, R., Gastaldi, M., \& Mulatti, C. (2014). Beeping ADAS: Reflexive effect on drivers' behavior. Transportation Research Part F: Traffic Psychology and Behaviour, 25, 2733.

Cades, D. M., Crump, C., Lester, B. D., \& Young, D. (2017). Driver distraction and advanced vehicle assistive systems (ADAS): investigating effects on driver behavior. In Advances in Human Aspects of Transportation, Springer, Cham, 1015-1022.

Calvi, A., \& De Blasiis, M. R. (2011). Driver behavior on acceleration lanes: driving simulator study. Transportation Research Record, 2248(1), 96-103.

Choudhary, P., \& Velaga, N. R. (2017). Mobile phone use during driving: Effects on speed and effectiveness of driver compensatory behaviour. Accident Analysis \& Prevention, 106, 370378. 
Choudhary, P., \& Velaga, N. R. (2019). Effects of phone use on driving performance: A comparative analysis of young and professional drivers. Safety Science, 111, 179-187.

Cicchino, J. B. (2017). Effectiveness of forward collision warning and autonomous emergency braking systems in reducing front-to-rear crash rates. Accident Analysis \& Prevention, 99, $142-152$.

Consumer Reports (2017a). Consumer clarity and safety for today's advanced driver systems. https://data.consumerreports.org/wp-content/uploads/2020/05/auto-safety-report.pdf, Accessed 05/18/2021.

Consumer Reports (2019). Guide to lane departure warning and lane keeping assist. https://www.consumerreports.org/car-safety/lane-departure-warning-lane-keepingassist-guide/, Accessed 05/11/2021.

Consumer Reports (2017b). Guide to lane departure warning and lane keeping assist. https://www.consumerreports.org/car-safety/lane-departure-warning-lane-keepingassist-guide/, Accessed 05/11/2021.

Consumer Reports (2017c). Guide to adaptive cruise control. https://www.consumerreports.org/car-safety/adaptive-cruise-control-guide/, Accessed 05/11/2021.

Derbel, O., Mourllion, B., \& Basset, M. (2012). Safety assessment of mixed traffic based on accident scenario. IFAC Proceedings Volumes, 45(24), 126-131.

Drews, F. A., Yazdani, H., Godfrey, C. N., Cooper, J. M., \& Strayer, D. L. (2009). Text messaging during simulated driving. Human Factors, 51(5), 762-770.

Dunn, N., Dingus, T., \& Soccolich, S. (2019). Understanding the impact of technology: do advanced driver assistance and semi-automated vehicle systems lead to improper driving behavior? Virginia Tech Transportation Institute, American Automobile Association, Washington, DC.

Farah, H., \& Koutsopoulos, H. N. (2014). Do cooperative systems make drivers' car-following behavior safer? Transportation Research Part C: Emerging Technologies, 41, 61-72.

Fleet Manager. (2019). The importance of educating drivers about the limits of ADAS. Wex Inc., Portland, OR, https://www.wexinc.com/insights/blog/fleet/the-importance-ofeducating-drivers-about-the-limits-of-adas/, Accessed 03/07/2020.

Garcia A. (2017). CNN business, car sales set another US record. https://money.cnn.com/2017/01/04/news/companies/car-sales-2016/index.html, Accessed 02/03/2020.

Gaspar, J., Brown, T., Schwarz, C., Chrysler, S., \& Gunaratne, P. (2016). Driver behavior in forward collision and lane departure scenarios. No. 2016-01-1455, SAE Technical Paper. 
German Association of the Automotive Industry (VDA). (2020). Lane keeping assist systems. https://www.vda.de/en/topics/safety-and-standards/lkas/lane-keeping-assistsystems.html, Accessed 05/18/2021.

Green Car Congress (2021). IIHS study finds drivers significantly more likely to speed while using adaptive cruise control. https://www.greencarcongress.com/2021/03/20210314-iihs.html, Accessed 05/18/2021.

Highway Loss Data Institute, Insurance Institute for Highway Safety (IIHS). (2018). IIHS examines driver assistance features in road, track tests. https://www.iihs.org/news/detail/iihs-examines-driver-assistance-features-in-road-tracktests, Accessed 05/11/2021.

Highway Loss Data Institute, Insurance Institute for Highway Safety (IIHS). (2021). Advanced driver assistance. https://www.iihs.org/topics/advanced-driver-assistance, Accessed $06 / 18 / 2021$.

Hoogendoorn, S. P., \& Minderhoud, M. M. (2002). Motorway flow quality impacts of advanced driver assistance systems. Transportation Research Record, 1800(1), 69-77.

Inata, K., Raksincharoensak, P., \& Nagai, M. (2008, October). Driver behavior modeling based on database of personal mobility driving in urban area. In 2008 International Conference on Control, Automation and Systems, IEEE, 2902-2907.

Jeong, E., Oh, C., Lee, G., \& Cho, H. (2014). Safety impacts of intervehicle warning information systems for moving hazards in connected vehicle environments. Transportation Research Record, 2424(1), 11-19.

Kamaruddin, N., \& Wahab, A. (2010, June). Driver behavior analysis through speech emotion understanding. In 2010 IEEE Intelligent Vebicles Symposium, 238-243.

Kaptein, N. A., Theeuwes, J., \& van Der Horst, R. (1996). Driving simulator validity: Some considerations. Transportation Research Record, 1550(1), 30-36.

Kikuchi, S., Uno, N., \& Tanaka, M. (2003). Impacts of shorter perception-reaction time of adapted cruise-controlled vehicles on traffic flow and safety. Journal of Transportation Engineering, 129(2), 146-154.

Kim, W., Kelley-Baker, T., Sener, I. N., Zmud, J., Graham, M., \& Kolek, S. (2019). Users' understanding of automated vehicles and perception to improve traffic safety—results from a national survey. AAA Foundation for Traffic Safety, Washington DC.

Kondyli, A., \& Elefteriadou, L. (2009). Driver behavior at freeway-ramp merging areas: focus group findings. Transportation Research Record, 2124(1), 157-166.

Kuge, N., Yamamura, T., Shimoyama, O., \& Liu, A. (2000). A driver behavior recognition method based on a driver model framework. SAE Transactions, 469-476. 
Lee, C., \& Abdel-Aty, M. (2008). Testing effects of warning messages and variable speed limits on driver behavior using driving simulator. Transportation Research Record, 2069(1), 55-64.

Li, Y., Li, Z., Wang, H., Wang, W., \& Xing, L. (2017a). Evaluating the safety impact of adaptive cruise control in traffic oscillations on freeways. Accident Analysis \& Prevention, 104, 137145 .

Li, Y., Wang, H., Wang, W., Liu, S., \& Xiang, Y. (2016). Reducing the risk of rear-end collisions with infrastructure-to-vehicle (I2V) integration of variable speed limit control and adaptive cruise control system. Traffic Injury Prevention, 17(6), 597-603.

Li, Y., Wang, H., Wang, W., Xing, L., Liu, S., \& Wei, X. (2017b). Evaluation of the impacts of cooperative adaptive cruise control on reducing rear-end collision risks on freeways. Accident Analysis \& Prevention, 98, 87-95.

Lundgren, J., \& Tapani, A. (2006). Evaluation of safety effects of driver assistance systems through traffic simulation. Transportation Research Record, 1953(1), 81-88.

Lyu, N., Deng, C., Xie, L., Wu, C., \& Duan, Z. (2019). A field operational test in China: Exploring the effect of an advanced driver assistance system on driving performance and braking behavior. Transportation Research Part F: Traffic Psychology and Behavior, 65, 730747.

Maag, C., Muhlbacher, D., Mark, C., \&Kruger, H. P. (2012). Studying effects of advanced driver assistance systems (ADAS) on individual and group level using multi-driver simulation. IEEE Intelligent Transportation Systems Magazine, 4(3), 45-54.

Martin, B. B., \& Elefteriadou, L. (2010). Driver behavior and advanced driver assistance systems: an exploratory driving simulator study. Advances in Transportation Studies, Dec 2010 Special, 79-88.

Mas, A., Merienne, F., \& Kemeny, A. (2011, September). Lateral control assistance and driver behavior in emergency situations. 3rd International Conference on Road Safety and Simulation, Indianapolis, United States, 1-12.

McCall, J. C., \& Trivedi, M. M. (2007). Driver behavior and situation aware brake assistance for intelligent vehicles. Proceedings of the IEEE, 95(2), 374-387.

McDonald A., Carney C., \& McGehee D. V. (2018). American Automobile Association: Vehicle owner's experiences with and reactions to advanced driver assistance systems. Washington, DC, https://publicaffairsresources.aaa.biz/wp-content/uploads/dlm_uploads/2018/09/180621_AAAFTS-ADAS-Fact-Sheet_v1-BTjc.pdf, Accessed 03/07/2020.

Miksic M. Y. (2020). Institute for Education Policy - glossary. Baltimore, MD, https://edpolicy.education.jhu.edu/glossary/\#: :text=Comparison\%20groups\%20are\%20o ften\%20used,is\%20called\%20the\%20control\%20group, Accessed 12/7/2020. 
Miyajima, C., \& Takeda, K. (2016). Driver-behavior modeling using on-road driving data: A new application for behavior signal processing. IEEE Signal Processing Magazine, 33(6), 14-21.

Morignot, P., Rastelli, J. P., \& Nashashibi, F. (2014, June). Arbitration for balancing control between the driver and ADAS systems in an automated vehicle: Survey and approach. In 2014 IEEE Intelligent Vehicles Symposium Proceedings, 575-580.

National Highway Traffic Safety Administration (NHTSA), United States Department of Transportation (2021). NHSTA launches influencer campaign to educate drivers on safety features. https://www.nhtsa.gov/press-releases/nhtsa-launches-influencer-campaigneducate-drivers-safety-features, Accessed 06/18/2021.

National Safety Council (NSC), Advanced Driver Assistance Systems. (2020). Injury facts. https://injuryfacts.nsc.org/motor-vehicle/occupant-protection/advanced-driverassistance-systems/, Accessed 03/07/2020.

Naughton K. (2017). The globe and mail: will driver-assist technology turn you into a bad driver? https://www.theglobeandmail.com/globe-drive/culture/commuting/will-driver-assisttechnology-turn-you-into-a-bad-driver/article35967419/, Accessed 02/03/2020.

Olaverri-Monreal, C., Hasan, A. E., Bulut, J., Körber, M., \& Bengler, K. (2014). Impact of invehicle displays location preferences on drivers' performance and gaze. IEEE Transactions on Intelligent Transportation Systems, 15(4), 1770-1780.

Pauwelussen, J., \& Feenstra, P. J. (2010). Driver behavior analysis during ACC activation and deactivation in a real traffic environment. IEEE Transactions on Intelligent Transportation Systems, 11(2), 329-338.

Penmetsa, P., Hudnall, M., \& Nambisan, S. (2019). Potential safety benefits of lane departure prevention technology. IATSS research, 43(1), 21-26.

Rommerskirchen, C. P., Helmbrecht, M., \& Bengler, K. J. (2014). The impact of an anticipatory eco-driver assistant system in different complex driving situations on the driver behavior. IEEE Intelligent Transportation Systems Magazine, 6(2), 45-56.

Safelite Auto Glass. (2020). The features of ADAS: your driver assist system. https://www.safelite.com/windshield-auto-glass-technology/adas, Accessed 02/03/2020.

Saleh, L., Chevrel, P., Claveau, F., Lafay, J. F., \& Mars, F. (2013). Shared steering control between a driver and an automation: stability in the presence of driver behavior uncertainty. IEEE Transactions on Intelligent Transportation Systems, 14(2), 974-983.

Sathyanarayana, A., Boyraz, P., \& Hansen, J. H. (2008, September). Driver behavior analysis and route recognition by hidden Markov models. In 2008 IEEE International Conference on Vehicular Electronics and Safety, 276-281. 
Sieber, M., \& Färber, B. (2016). Driver perception and reaction in collision avoidance: implications for ADAS development and testing. In 2016 IEEE Intelligent Vebicles Symposium (IV), 239-245.

Son, J., Lee, Y., \& Kim, M. H. (2011). Impact of traffic environment and cognitive workload on older drivers' behavior in simulated driving. International Journal of Precision Engineering and Manufacturing, 12(1), 135-141.

Son, J., Park, M., \& Park, B. B. (2015). The effect of age, gender and roadway environment on the acceptance and effectiveness of advanced driver assistance systems. Transportation Research Part F: Traffic Psychology and Behaviour, 31, 12-24.

Spivey, H., \& Pulugurtha, S. S. (2016). Visibility of two-wheelers approaching left-turning vehicles compared with other hazards under nighttime conditions at urban signalized intersections. Transportation Research Record, 2587(1), 133-140.

Strayer, D. L., \& Drew, F. A. (2004). Profiles in driver distraction: Effects of cell phone conversations on younger and older drivers. Human Factors, 46(4), 640-649.

Strayer, D. L., \& Johnston, W. A. (2001). Driven to distraction: Dual-task studies of simulated driving and conversing on a cellular telephone. Psychological Science, 12(6), 462-466.

Strayer, D. L., Drews, F. A., \& Crouch, D. J. (2006). A comparison of the cell phone driver and the drunk driver. Human Factors, 48(2), 381-391.

Strayer, D. L., Drews, F. A., \& Johnston, W. A. (2003). Cell phone-induced failures of visual attention during simulated driving. Journal of Experimental Psychology: Applied, 9(1), 23.

Tan, H., Zhao, F., Hao, H., \& Liu, Z. (2020). Estimate of safety impact of lane keeping assistant system on fatalities and injuries reduction for China: scenarios through 2030. Traffic Injury Prevention, 21(2), 156-162.

The National Advanced Driver Simulator, The University of Iowa, Endor AG (2016). Fanatec Universal Hub Grant Wheel and Horn Installation Guide. Iowa City, IA. https://fanatec.com/media/pdf/0d/99/51/CSUH_Manual_webKzzoH6lofDdpy.pdf, Accessed 05/18/2021.

Tran, C., Doshi, A., \& Trivedi, M. M. (2012). Modeling and prediction of driver behavior by foot gesture analysis. Computer Vision and Image Understanding, 116(3), 435-445.

Transport Accident Commission (TAC). (2020). How safe is your car?: lane keep assist. https://howsafeisyourcar.com.au/safety-features/lane-keep-assist, Accessed 05/18/2021.

van den Berg R. G. (2020). SPSS Tutorials: one-way ANOVA tutorial. https://www.spsstutorials.com/spss-one-way-anova/, Accessed 12/7/2020. 
van Driel, C. J., Hoedemaeker, M., \& van Arem, B. (2007). Impacts of a congestion assistant on driving behaviour and acceptance using a driving simulator. Transportation Research Part F: Traffic Psychology and Behaviour, 10(2), 139-152.

Wang, W., Xi, J., \& Chen, H. (2014). Modeling and recognizing driver behavior based on driving data: A survey. Mathematical Problems in Engineering. https://www.hindawi.com/journals/mpe/2014/245641/, _ Accessed 05/18/2021.

Witt, M., Wang, L., Fahrenkrog, F., Kompaß, K., \& Prokop, G. (2018, July). Cognitive driver behavior modeling: Influence of personality and driver characteristics on driver behavior. In International Conference on Applied Human Factors and Ergonomics, Springer, Cham, 751-763.

World Health Organization (WHO). (2021). Adolescent health in the South-East Asia region. https://www.who.int/southeastasia/health-topics/adolescenthealth\#: :text=WHO\%20defines\%20'Adolescents'\%20as\%20individuals,age\%20range\%2 010\%2D24\%20years., Accessed 06/18/2021.

Yannis, G., Antoniou, C., Vardaki, S., \& Kanellaidis, G. (2010). Older drivers' perception and acceptance of in-vehicle devices for traffic safety and traffic efficiency. Journal of Transportation Engineering, 136(5), 472-479.

Yue, L., Abdel-Aty, M., Wu, Y., \&Wang, L. (2018). Assessment of the safety benefits of vehicles' advanced driver assistance, connectivity and low-level automation systems. Accident Analysis E Prevention, 117, 55-64.

Ziefle, M., Pappachan, P., Jakobs, E. M., \& Wallentowitz, H. (2008, July). Visual and auditory interfaces of advanced driver assistant systems for older drivers. In International Conference on Computers for Handicapped Persons, Springer, Berlin, Heidelberg, 62-69. 


\section{About the Authors}

Mr. Raghuveer Gouribhatla is pursuing his $\mathrm{PhD}$ in the Infrastructure and Environmental Systems (INES) program at the University of North Carolina at Charlotte, where he earned his Master's degree in Transportation Engineering. His areas of interest are traffic safety, connected and automated vehicles, transit systems, and traffic operations.

Dr. Srinivas S. Pulugurtha, PE, F.ASCE is currently working as a Professor \& Research Director of the Department of Civil and Environmental Engineering at the University of North Carolina at Charlotte. He is also the Director of the Infrastructure, Design, Environment, and Sustainability (IDEAS) Center at the University of North Carolina at Charlotte. 
Founder, Honorable

Norman Mineta*

Secretary (ret.),

US Department of Transportation

Chair,

Will Kempton

Retired Transportation Executive

Vice Chair,

Jeff Morales

Managing Principal

InfraStrategies, LLC

Executive Director,

Karen Philbrick, PhD*

Mineta Transportation Institute

San José State University

Winsome Bowen

Vice President, Project Development

Strategy

WSP

David Castagnetti

Co-Founder

Mehlman Castagnetti Rosen \&

Thomas

Maria Cino

Vice President, America \& U.S.

Government Relations

Hewlett-Packard Enterprise

Grace Crunican**

Owner

Crunican LLC

Donna DeMartino

Managing Director

Los Angeles-San Diego-San Luis

Obispo Rail Corridor Agency
John Flaherty

Senior Fellow

Silicon Valley American Leadership

Forum

William Flynn *

President \& CEO

Amtrak

Rose Guilbault

Board Member

Peninsula Corridor Joint Power

Board

Ian Jefferies*

President \& CEO

Association of American Railroads

Diane Woodend Jones

Principal \& Chair of Board

Lea \& Elliott, Inc.

David S. Kim*

Secretary

California State Transportation

Agency (CALSTA)

Therese McMillan

Executive Director

Metropolitan Transportation

Commission (MTC)

Abbas Mohaddes

President \& COO

Econolite Group Inc.

Stephen Morrissey

Vice President - Regulatory and

Policy

United Airlines
Dan Moshavi, $\mathrm{PhD}^{*}$

Dean

Lucas College and GraduateSchool

of Business, San José State

University

Toks Omishakin*

Director

California Department of

Transportation (Caltrans)

Takayoshi Oshima

Chairman \& CEO

Allied Telesis, Inc.

Greg Regan

President

Transportation Trades Department, AFL-CIO

Paul Skoutelas*

President \& CEO

American Public Transportation

Association (APTA)

Kimberly Slaughter

CEO

Systra USA

Beverley Swaim-Staley

President

Union Station Redevelopment

Corporation

Jim Tymon*

Executive Director

American Association of State

Highway and Transportation

Officials (AASHTO)

$*$ Ex-Officio

** = Past Chair, Board of Trustees

\section{Directors}

Karen Philbrick, PhD

Executive Director

Hilary Nixon, PhD

Deputy Executive Director

Asha Weinstein Agrawal, PhD

Education Director

National Transportation Finance Center Director

Brian Michael Jenkins National Transportation Security Center Director

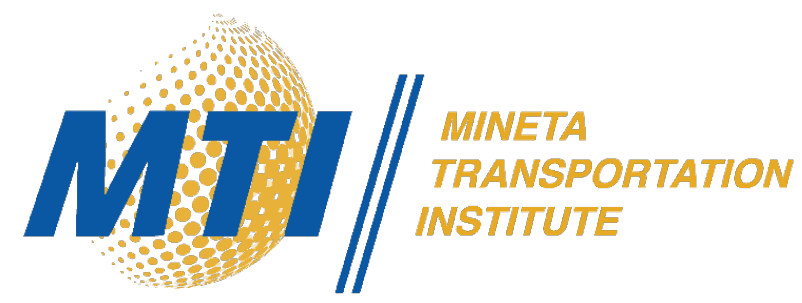

